\title{
Two-Phase Flow
}

\author{
M.M. Awad
}

Additional information is available at the end of the chapter

http://dx.doi.org/10.5772/76201

\section{Introduction}

A phase is defined as one of the states of the matter. It can be a solid, a liquid, or a gas. Multiphase flow is the simultaneous flow of several phases. The study of multiphase flow is very important in energy-related industries and applications. The simplest case of multiphase flow is two-phase flow. Two-phase flow can be solid-liquid flow, liquid-liquid flow, gas-solid flow, and gas-liquid flow. Examples of solid-liquid flow include flow of corpuscles in the plasma, flow of mud, flow of liquid with suspended solids such as slurries, motion of liquid in aquifers. The flow of two immiscible liquids like oil and water, which is very important in oil recovery processes, is an example of liquid-liquid flow. The injection of water into the oil flowing in the pipeline reduces the resistance to flow and the pressure gradient. Thus, there is no need for large pumping units. Immiscible liquid-liquid flow has other industrial applications such as dispersive flows, liquid extraction processes, and coextrusion flows. In dispersive flows, liquids can be dispersed into droplets by injecting a liquid through an orifice or a nozzle into another continuous liquid. The injected liquid may drip or may form a long jet at the nozzle depending upon the flow rate ratio of the injected liquid and the continuous liquid. If the flow rate ratio is small, the injected liquid may drip continuously at the nozzle outlet. For higher flow rate ratio, the injected liquid forms a continuous jet at the end of the nozzle. In other applications, the injected liquid could be dispersed as tiny droplets into another liquid to form an emulsion. In liquid extraction processes, solutes dissolved in a liquid solution are separated by contact with another immiscible liquid. Polymer processing industry is an instance of co-extrusion flow where the products are required to manifest a steady interface to obtain superior mechanical properties. Examples of gas-solid flow include fluidized bed, and transport of powdered cement, grains, metal powders, ores, coal, and so on using pneumatic conveying. The main advantages in pneumatic conveying over other systems like conveyor belt are the continuous operation, the relative flexibility of the pipeline location to avoid obstructions or to save space, and the capability to tap the pipeline at any location to remove some or all powder. 
Sometimes, the term two-component is used to describe flows in which the phases do not consist of the same chemical substance. Steam-water flow found in nuclear power plants and other power systems is an example of two-phase single-component flow. Argon-water is an instance of two-phase two-component flow. Air-water is an example of two-phase multi component flow. Actually, the terms two-component flow and two-phase flow are often used rather loosely in the literature to mean liquid-gas flow and liquid-vapor flow respectively. The engineers developed the terminology rather than the chemists. However, there is little danger of ambiguity.

\section{Basic definitions and terminology}

The total mass flow rate ( $\dot{m}$ ) (in kg per second) is the sum of the mass flow rate of liquid phase $\left(\dot{m}_{l}\right)$ and the mass flow rate of gas phase $\left(\dot{m}_{g}\right)$.

$$
\dot{m}=\dot{m}_{l}+\dot{m}_{g}
$$

The total volumetric flow rate ( $\dot{Q}$ ) (in cubic meter per second) is the sum of the volumetric flow rate of liquid phase $\left(\dot{Q}_{l}\right)$ and the volumetric flow rate of gas phase $\left(\dot{Q}_{g}\right)$.

$$
\dot{Q}=\dot{Q}_{l}+\dot{Q}_{g}
$$

The volumetric flow rate of liquid phase $\left(\dot{Q}_{l}\right)$ is related to the mass flow rate of liquid phase $\left(\dot{m}_{l}\right)$ as follows:

$$
\dot{Q}_{l}=\frac{\dot{m}_{l}}{\rho_{l}}
$$

The volumetric flow rate of gas phase $\left(\dot{Q}_{g}\right)$ is related to the mass flow rate of gas phase $\left(\dot{m}_{g}\right)$ as follows:

$$
\dot{Q}_{g}=\frac{\dot{m}_{g}}{\rho_{g}}
$$

The total mass flux of the flow $(G)$ is defined the total mass flow rate $(\dot{m})$ divided by the pipe cross-sectional area $(A)$.

$$
G=\frac{\dot{m}}{A}
$$

The quality (dryness fraction) $(x)$ is defined as the ratio of the mass flow rate of gas phase $\left(\dot{m}_{g}\right)$ to the total mass flow rate $(\dot{m})$.

$$
x=\frac{\dot{m}_{g}}{\dot{m}}=\frac{\dot{m}_{g}}{\dot{m}_{l}+\dot{m}_{g}}
$$


The volumetric quality $(\beta)$ is defined as the ratio of the volumetric flow rate of gas phase $\left(\dot{Q}_{g}\right)$ to the total volumetric flow rate $(\dot{Q})$.

$$
\beta=\frac{\dot{Q}_{g}}{\dot{Q}}=\frac{\dot{Q}_{g}}{\dot{Q}_{l}+\dot{Q}_{g}}
$$

The volumetric quality $(\beta)$ can be related to the mass quality $(x)$ as follows:

$$
\beta=\frac{x v_{g}}{x v_{g}+(1-x) v_{l}}=\frac{1}{1+\left(\frac{1-x}{x}\right)\left(\frac{\rho_{g}}{\rho_{l}}\right)}
$$

The void fraction $(\alpha)$ is defined as the ratio of the pipe cross-sectional area (or volume) occupied by the gas phase to the pipe cross-sectional area (or volume).

$$
\alpha=\frac{\dot{A}_{g}}{\dot{A}}=\frac{\dot{A}_{g}}{\dot{A}_{l}+\dot{A}_{g}}
$$

The superficial velocity of liquid phase flow $\left(U_{l}\right)$ is the velocity if the liquid is flowing alone in the pipe. It is defined as the volumetric flow rate of liquid phase $\left(\dot{Q}_{l}\right)$ divided by the pipe cross-sectional area $(A)$.

$$
U_{l}=\frac{\dot{Q}_{l}}{A}
$$

The superficial velocity of gas phase flow $\left(U_{g}\right)$ is the velocity if the gas is flowing alone in the pipe. It is defined as the volumetric flow rate of gas phase $\left(\dot{Q}_{g}\right)$ divided by the pipe crosssectional area $(A)$.

$$
U_{g}=\frac{\dot{Q}_{g}}{A}
$$

The mixture velocity of flow $\left(U_{m}\right)$ is defined as the total volumetric flow rate ( $\dot{Q}$ ) divided by the pipe cross-sectional area $(A)$.

$$
U_{m}=\frac{\dot{Q}}{A}
$$

The mixture velocity of flow $\left(U_{m}\right)$ (in meter per second) can also be expressed in terms of the superficial velocity of liquid phase flow $\left(U_{l}\right)$ and the superficial velocity of gas phase flow $\left(U_{g}\right)$ as follows:

$$
U_{m}=U_{l}+U_{g}
$$

The average velocity of liquid phase flow $(u l)$ is defined as the volumetric flow rate of liquid phase $\left(\dot{Q}_{l}\right)$ divided by the pipe cross-sectional area occupied by the liquid phase flow $\left(A_{l}\right)$. 


$$
u_{l}=\frac{\dot{Q}_{l}}{A_{l}}=\frac{\dot{Q}_{l}}{(1-\alpha) A}=\frac{U_{l}}{(1-\alpha)}
$$

The average velocity of gas phase flow $\left(u_{g}\right)$ is defined as the volumetric flow rate of gas phase $\left(\dot{Q}_{g}\right)$ divided by the pipe cross-sectional area occupied by the gas phase flow $\left(A_{g}\right)$.

$$
u_{g}=\frac{\dot{Q}_{g}}{A_{g}}=\frac{\dot{Q}_{g}}{\alpha A}=\frac{U_{g}}{\alpha}
$$

In order to characterize a two-phase flow, the slip ratio $(S)$ is frequently used instead of void fraction. The slip ratio is defined as the ratio of the average velocity of gas phase flow $\left(u_{g}\right)$ to the average velocity of liquid phase flow $\left(u_{l}\right)$. The void fraction $(\alpha)$ can be related to the slip ratio (S) as follows:

$$
\begin{gathered}
S=\frac{u_{g}}{u_{l}}=\frac{\dot{Q}_{g} / A \alpha}{\dot{Q}_{l} / A(1-\alpha)}=\frac{\dot{Q}_{g}(1-\alpha)}{\dot{Q}_{l} \alpha} \\
S=\frac{u_{g}}{u_{l}}=\frac{G x / A \alpha \rho_{g}}{G(1-x) / A(1-\alpha) \rho_{l}}=\frac{\rho_{l} x(1-\alpha)}{\rho_{g}(1-x) \alpha}
\end{gathered}
$$

Equations (16) and (17) can be rewritten in the form:

$$
\begin{gathered}
\alpha=\frac{\dot{Q}_{g}}{S \dot{Q}_{l}+\dot{Q}_{g}} \\
\alpha=\frac{1}{1+S\left(\frac{1-x}{x}\right)\left(\frac{\rho_{g}}{\rho_{l}}\right)}
\end{gathered}
$$

It is obvious from Eqs. (7), and (18) or from Eqs. (8), and (19) that the volumetric quality ( $\beta$ ) is equivalent to the void fraction $(\alpha)$ when the slip ratio $(S)$ is 1 . The void fraction $(\alpha)$ is called the homogeneous void fraction $\left(\alpha_{m}\right)$ when the slip ratio $(S)$ is 1 . This means that $\beta=$ $\alpha_{m}$. When $\left(\rho_{l} / \rho_{g}\right)$ is large, the void fraction based on the homogeneous model $\left(\alpha_{m}\right)$ increases very rapidly once the mass quality $(x)$ increases even slightly above zero. The prediction of the void fraction using the homogeneous model is reasonably accurate only for bubble and mist flows since the entrained phase travels at nearly the same velocity as the continuous phase. Also, when $\left(\rho / \rho_{8}\right)$ approaches 1 (i.e. near the critical state), the void fraction based on the homogeneous model $\left(\alpha_{m}\right)$ approaches the mass quality $(x)$ and the homogeneous model is applicable at this case. 


\subsection{Dimensionless parameters}

Dimensionless groups are useful in arriving at key basic relations among system variables that are valid for various fluids under various operating conditions. Dimensionless groups can be divided into two types: (a) Dimensionless groups based on empirical considerations, and (b) Dimensionless groups based on fundamental considerations. The first type has been derived empirically, often on the basis of experimental data. This type has been proposed in literature on the basis of extensive data analysis. The extension to other systems requires rigorous validation, often requiring modifications of constants or exponents. The convection number $(\mathrm{Co})$, and the boiling number $\left(K_{f}\right)$ are examples of this type. Although the LockhartMartinelli parameter $(X)$ is derived from fundamental considerations of the gas and the liquid phase friction pressure gradients, it is used extensively as an empirical dimensionless group in correlating experimental results on pressure drop, void fraction, as well as heat transfer coefficients.

On the other hand, fundamental considerations of the governing forces and their mutual interactions lead to the second type that provides important insight into the physical phenomena. The Capillary number $(\mathrm{Ca})$, and the Weber number $(\mathrm{We})$ are examples of this type.

It should be noted that using of dimensionless groups is important in obtaining some correlations for different parameters in two-phase flow. For example, Kutateladze (1948) combined the critical heat flux (CHF) with other parameters through dimensional analysis to obtain a dimensionless group. Also, Stephan and Abdelsalam (1980) utilized eight dimensionless groups in developing a comprehensive correlation for saturated pool boiling heat transfer.

Also, the dimensionless groups are used in obtaining some correlations for two-phase frictional pressure drop such as Friedel (1979), Lombardi and Ceresa (1978), Bonfanti et al. (1979), and Lombardi and Carsana (1992).

Moreover, a dimensional analysis can be used to resolve the equations of electrohydrodynamics (EHD), in spite of their complexity, in two-phase flow. The two dimensionless EHD numbers that will result from the analysis of the electric body force are the EHD number or conductive Rayleigh number and the Masuda number or dielectric Rayleigh number (Cotton et al., 2000, Chang and Watson, 1994, and Cotton et al., 2005).

The use of traditional dimensionless numbers in two-phase flow is very limited in correlating data sets (Kleinstreuer, 2003). However, a large number of dimensionless groups found in literature to represent two phase-flow data into more convenient forms. Examples of these dimensionless groups are discussed below.

\section{Archimedes Number (Ar)}

The Archimedes number $(A r)$ is defined as

$$
A r=\frac{\rho_{l}\left(\rho_{l}-\rho_{g}\right) g d^{3}}{\mu_{l}^{2}}
$$


And represents the ratio of gravitational force to viscous force. It is used to determine the motion of fluids due to density differences $\left(\rho-\rho_{g}\right)$.

Quan (2011) related the Archimedes number $(A r)$ to the inverse viscosity number $\left(N_{f}\right)$ as follows:

$$
N_{f}=A r^{1 / 2}=\frac{\sqrt{\rho_{l}\left(\rho_{l}-\rho_{g}\right) g d^{3}}}{\mu_{l}}
$$

Recently, Hayashi et al. (2010 and 2011) used the inverse viscosity number $\left(N_{f}\right)$ in the study of terminal velocity of a Taylor drop in a vertical pipe.

\section{Atwood Ratio (At)}

The Atwood ratio $(A t)$ is defined as

$$
A t=\frac{\rho_{l}-\rho_{g}}{\rho_{l}+\rho_{g}}
$$

The important consideration that one must remember is the Atwood ratio $(A t)$ and the effect of the gravitational potential field, Froude number $(F r)$ on causing a drift or allowing a relative velocity to exist between the phases. If these differences are large, then one should use a separated flow model. For instance, for air-water flows at ambient pressure, the density ratio $\left(\rho l / \rho_{g}\right)$ is $\sim 1000$ while the Atwood ratio $(A t)$ is $\sim 1$. As a result, a separated flow model may be dictated. On the other hand, when the density ratio $\left(\rho_{l} / \rho_{g}\right)$ approaches 1, a homogenous model becomes more appropriate for wide range of applications.

\section{Bond Number (Bo)}

The Bond number $(\mathrm{Bo})$ is defined as:

$$
B o=\frac{g d^{2}\left(\rho_{l}-\rho_{g}\right)}{4 \sigma}
$$

And represents the ratio of gravitational (buoyancy) and capillary force scales. The length scale used in its definition is the pipe radius. The Bond number $(B o)$ is used in droplet atomization and spray applications. The gravitational force can be neglected in most cases of liquid-gas two-phase flow in microchannels because $B o \ll 1$. As a result, the other forces like surface tension force, the gas inertia and the viscous shear force exerted by the liquid phase are found to be the most critical forces in the formation of two-phase flow patterns.

In addition, $\mathrm{Li}$ and $\mathrm{Wu}$ (2010) analyzed the experimental results of adiabatic two-phase pressure drop in micro/mini channels for both multi and single-channel configurations from 
collected database of 769 data points, covering 12 fluids, for a wide range of operational conditions and channel dimensions. The researchers observed a particular trend with the Bond number $(B o)$ that distinguished the data in three ranges, indicating the relative importance of surface tension. When $1.5 \leq B o$, in the region dominated by surface tension, inertia and viscous forces could be ignored. When $1.5<B o \leq 11$, surface tension, inertia force, and viscous force were all important in the micro/mini-channels. However, when $11<B o$, the surface tension effect could be neglected.

Recently, $\mathrm{Li}$ and $\mathrm{Wu}$ (2010) obtained generalized adiabatic pressure drop correlations in evaporative micro/mini-channels. The researchers observed a particular trend with the Bond number $(B o)$ that distinguished the entire database into three ranges: $B o<0.1,0.1 \leq B o$ and $B o R e l^{0.5} \leq 200$, and $B o R e l^{0.5}>200$. Using the Bond number, they established improved correlations of adiabatic two-phase pressure drop for small Bond number regions. The newly proposed correlations could predict the database well for the region where BoRel $^{0.5} \leq 200$.

\section{Bodenstein Number (Bod)}

The Bodenstein number $(B o d)$ is defined as follows:

$$
\operatorname{Bod}=\frac{U_{b} d}{D}
$$

And represents the ratio of the product of the bubble velocity and the microchannel diameter to the mass diffusivity. For example, Salman et al. (2004) developed numerical model for the study of axial mass transfer in gas-liquid Taylor flow at low values of this dimensionless group. The researchers found that their model was suitable for Bod $<500$. Also, for Bod $>10$, their model could be approximated by a simple analytical expression.

\section{Capillary Number $(C a)$}

The Capillary number $(\mathrm{Ca})$ is defined as:

$$
C a=\frac{\mu_{l} U}{\sigma}
$$

And is a measure of the relative importance of viscous forces and capillary forces. Frequently, it arises in the analysis of flows containing liquid drops or plugs. In the case of liquid plugs in a capillary tube, the Capillary number $(\mathrm{Ca})$ can be viewed as a measure of the scaled axial viscous drag force and the capillary or wetting force. The Capillary number $(\mathrm{Ca})$ is useful in analyzing the bubble removal process. For two-phase flow in microchannels, $\mathrm{Ca}$ is expected to play a critical role because both the surface tension and the viscous forces are important in microchannel flows. 
This dimensionless group is used in flow pattern maps. For example, Suo and Griffith (1964) used the Capillary number $(\mathrm{Ca})$ as a vertical axis in their flow pattern maps. The researchers gave a transition from slug flow to churn flow by $\mathrm{CaR} e^{2}=2.8 \times 10^{5}$ that agreed more or less with aeration of the slugs at the development of turbulence.

In addition, Taha and Cui (2006a) showed that in CFD modeling of slug flow inside square capillaries at low $\mathrm{Ca}$, both the front and rear ends of the bubbles were nearly spherical. With increasing $\mathrm{Ca}$, the convex bubble end inverted gradually to concave. As the $\mathrm{Ca}$ increased, the bubble became longer and more cylindrical. At higher $\mathrm{Ca}$ numbers, they had cylindrical bubbles.

The Capillary number $(\mathrm{Ca})$ controls principally the liquid film thickness $(\delta)$ surrounds the gas phase in gas-liquid two-phase plug flows or the immiscible liquid phase in liquid-liquid two-phase plug flows. In the literature, the is a number of well known models for the film thickness in a gas-liquid Taylor flow such as Fairbrother and Stubbs (1935), Marchessault and Mason (1960), Bretherton (1961), Taylor (1961), Irandoust and Andersson (1989), Bico and Quere (2000), and Aussillous and Quere (2000). Kreutzer et al. (2005a, 2005b) reviewed a number of correlations for liquid film thickness available in the literature. Moreover, Angeli and Gavriilidis (2008) reviewed additional relationships for the liquid film thickness. Recently, Howard et al. (2011) studied Prandtl and capillary effects on heat transfer performance within laminar liquid-gas slug flows. The researchers focused on understanding the mechanisms leading to enhanced heat transfer and the effect of using various Prandtl number fluids, leading to variations in Capillary number. They found that varying Prandtl and Capillary numbers caused notable effects in the transition region between entrance and fully developed flows.

For liquid-liquid immiscible flows, Grimes et al. (2007) investigated the validity of the Bretherton (1961) and Taylor (1961) laws through an extensive experimental program in which a number of potential carrier fluids were used to segment aqueous droplets over a range of flow rates. The researchers observed that there were significant discrepancies between measured film thicknesses and those predicted by the Bretherton (1961) and Taylor (1961) laws, and that when plotted against capillary number, film thickness data for the fluids collapsed onto separate curves. By multiplying the capillary number $(\mathrm{Ca})$ by the ratio of the liquid plug viscosity $\left(\mu_{p}\right)$ to the liquid film viscosity $(\mu l)$, the data for the different fluids collapsed onto a single curve with very little scatter.

Table 1 shows different equations for dimensionless film thickness $(\delta / R)$.

It should be noted that most of the expressions available in the literature are correlating the dimensionless liquid film thickness $(\delta / R)$ against the Capillary number $(\mathrm{Ca})$. Recently, Han and Shikazono (2009a, 2009b) measured the local liquid film thickness in microchannels by laser confocal method. For larger Capillary numbers $(\mathrm{Ca}>0.02)$, inertial effects must be considered and hence the researchers suggested an empirical correlation of the dimensionless bubble diameter by considering capillary number $(\mathrm{Ca})$ and Weber number (We). The Han and Shikazono (2009a) correlation was 


$$
\cdot \frac{\delta}{R}=\left\{\begin{array}{cc}
\frac{1.34 \mathrm{Ca}^{2 / 3}}{13+13 \mathrm{Ca}^{2 / 3}+0.504 \mathrm{Ca}^{0.672} \mathrm{Re}^{0.5890}-0.352 \mathrm{We}^{0.629}} & \mathrm{Re}<2000 \\
\frac{212\left(\frac{\mu^{2}}{\rho \sigma d}\right)^{2 / 3}}{149\left(\frac{\mu^{2}}{\rho \sigma d}\right)^{2 / 3} 7773\left(\frac{\mu^{2}}{\rho \sigma d}\right)^{0.672} 0-500} 0\left(\frac{\mu^{2}}{\rho \sigma d}\right)^{0.629} & R e>2000
\end{array}\right.
$$

\begin{tabular}{|c|c|c|}
\hline Researcher & $\delta / R$ & Notes \\
\hline Fairbrother and Stubbs (1935) & $\frac{\delta}{R}=0.5 \mathrm{Ca}^{1 / 2}$ & $5 \times 10^{-5} \leq \mathrm{Ca} \leq 3 \times 10^{-1}$ \\
\hline $\begin{array}{l}\text { Marchessault and Mason } \\
\qquad(1960)\end{array}$ & $\frac{\delta}{R}=\left(0.89-\frac{0.05}{\mathrm{U}_{\mathrm{g}}^{1 / 2}}\right) \mathrm{Ca}^{1 / 2}$ & $\begin{array}{c}7 \times 10^{-6} \leq \mathrm{Ca} \leq 2 \times 10^{-4} \\
U_{g} \text { in } \mathrm{cm} / \mathrm{s}\end{array}$ \\
\hline Bretherton (1961) & $\frac{\delta}{R}=1.34 \mathrm{Ca}^{2 / 3}$ & $10^{-3} \leq \mathrm{Ca} \leq 10^{-2}$ \\
\hline $\begin{array}{l}\text { Irandoust and Andersson } \\
\text { (1989) }\end{array}$ & $\frac{\delta}{R}=0.36\left[1-\exp \left(-3.08\left(\mathrm{Ca}^{0.54)}\right)\right]\right.$ & $9.5 \times 10^{-4} \leq \mathrm{Ca} \leq 1.9$ \\
\hline Bico and Quere (2000) & $\frac{\delta}{R}=1.34(2 \mathrm{Ca})^{2 / 3}$ & $\begin{array}{l}\text { Bretherton (1961) is corrected } \\
\text { by a factor of } 2^{2 / 3} \text { for } \mu_{c}>\mu_{d}\end{array}$ \\
\hline Aussillous and Quere (2000) & $\frac{\delta}{R}=\frac{1.34 \mathrm{Ca}^{2 / 3}}{1+2.5\left(1.34 \mathrm{Ca}^{2 / 3}\right)}$ & $\begin{array}{c}10^{-3} \leq \mathrm{C} a \leq 1.4 \\
\text { approaches Bretherton (1961) } \\
\text { for } \mathrm{C} a \rightarrow 0\end{array}$ \\
\hline Grimes et al. (2007) & $\frac{\delta}{R}=5 \mathrm{Ca}^{2 / 3}$ & $\begin{array}{c}10^{-5} \leq C a \leq 10^{-1} \\
C a=\mu_{p} U / \sigma\end{array}$ \\
\hline
\end{tabular}

Table 1. Different Equations for Dimensionless Film Thickness $(\delta / R)$.

In fact, the Weber number includes the capillary number $(C a)$ and Reynolds number $(R e)$ (Sobieszuk et al., 2010). Therefore, the term $\left(\mu^{2} / \rho \sigma d\right)$ in the second equation of Eq. (26) for $R e>$ 2000 is equal to $\left(\mathrm{Ca}^{2} / \mathrm{We}\right)$ or $(\mathrm{Ca} / \mathrm{Re})$. As the capillary number approached zero $(\mathrm{Ca} \rightarrow 0)$, the first equation of Eq. (26) for Re $<2000$ should follow Bretherton's theory (1961), so the coefficient in the numerator was taken as 1.34 . The other coefficients were obtained by least linear square method from their experimental data. If Reynolds number became larger than 2000, liquid film thickness remained constant due to the flow transition from laminar to turbulent. As a result, liquid film thickness was fixed to the value at $R e=2000$. The second equation of Eq. (26) for $R e$ $>2000$ could be obtained from the first equation by substituting $R e=2000$. Capillary number $(\mathrm{Ca})$ and Weber number $(\mathrm{We})$ should be also replaced with the values when Reynolds number $=2000$. The first equations of Eq. (26) were replaced as follows:

$$
C a=\operatorname{Re} \times\left(\frac{\mu^{2}}{\rho \sigma d}\right)=2000 \times\left(\frac{\mu^{2}}{\rho \sigma d}\right) \quad(\operatorname{Re}=2000)
$$




$$
W e=\operatorname{Re} . C a=2000^{2} \times\left(\frac{\mu^{2}}{\rho \sigma d}\right) \quad(\operatorname{Re}=2000)
$$

In Eqs. (27) and (28), $\left(\mu^{2} / \rho \sigma d\right)$ was a constant value if pipe diameter and fluid properties were fixed. The researchers mentioned that their correlation, Eq. (26), could predict $\delta$ within the range of $\pm 15 \%$ accuracy.

In addition, Yun et al. (2010) used the Weber number (We) to correlate the maximum and minimum film thickness ( $\delta_{\max }$ and $\delta_{\min }$ ) because the maximum and the minimum film thickness could be evaluated approximately and calculated statistically from the shade boundaries of Taylor bubbles observed in the images. On the other hand, it was difficult to determine the mean film thickness from the 2-D optical images of slug flow due to the irregular shapes of liquid film around Taylor bubbles in rectangular microchannels. Their maximum and minimum film thickness $\left(\delta_{\max }\right.$ and $\left.\delta_{\text {min }}\right)$ correlations were

$$
\begin{gathered}
\frac{\delta_{\max }}{R}=0.78 W e^{0.09} \\
\frac{\delta_{\min }}{R}=0.04 W e^{0.62}
\end{gathered}
$$

\section{Cahn number $(C n)$}

The Cahn number $(\mathrm{Cn})$ is defined as:

$$
C n=\frac{\delta}{d}
$$

And represents the ratio of the interface thickness $(\delta)$ and the tube diameter $(d)$. For example, He et al. (2010) used this dimensionless group in their dimensionless governing equations for heat transfer modeling of gas-liquid slug flow without phase change in a micro tube.

\section{Convection Number (Co)}

The Convection number $(\mathrm{Co})$ is a modified Lockhart-Martinelli parameter $(X)$. It is defined as:

$$
C o=\left(\frac{1-x}{x}\right)^{0.9}\left(\frac{\rho_{g}}{\rho_{l}}\right)^{0.5}
$$

This dimensionless number was introduced by Shah (1982) in correlating flow boiling data. It was not based on any fundamental considerations. For example, based on more than 10 
000 experimental data points for various fluids, including water, refrigerants, and cryogents, Kandlikar (1990) proposed a generalized heat transfer correlation for convective boiling in both vertical and horizontal tubes. One of the dimensionless numbers used in his correlation was the convection number $(\mathrm{Co})$.

\section{Courant Number (Cou)}

A very important step in numerical simulation is transient time step sizing. The Courant number $(\mathrm{Cou})$ is a dimensionless group that can be used to adjust the time step. It is defined as follows:

$$
\operatorname{Cou}=\frac{U \Delta t}{\Delta x}
$$

And represents a comparison between the particle moving distance during the assumed time step and control volume dimension. A low Cou value means a small time step size $(\Delta t)$ and consequently a large simulation time. On the other hand, a high Cou value leads to an unstable numeric approach. As a result, there is a need to optimize Cou using appropriate time step size $(\Delta t)$. Furthermore, as the mesh becomes finer $(\Delta x)$, the time step $(\Delta t)$ should be decreased as well in order to hold Cou in its safe range. A typical time step $(\Delta t)$ order of magnitude of $1 \times 10^{-5}(\mathrm{~s})$ or $1 \times 10^{-6}(\mathrm{~s})$ has been used by the researchers. For example, Cherlo et al. (2010) performed the three-dimensional simulation in their numerical investigations of two-phase (liquid-liquid) flow behavior in rectangular microchannels.

A wiser time step adjustment is using a variable time step by implementing a fixed Courant number ( $\mathrm{Cou}$ ) that is available in ANSYS Fluent. For example, Gupta et al. (2009) applied this technique in the CFD modeling of Taylor flow in microchannels. In this method, the time step $(\Delta t)$ is being modified based on the critical cells size and local velocity components to hold the maximum Courant number $(\mathrm{Cou} \max )$ to a fixed value.

\section{EHD Number $\left(E_{h d}\right)$}

The EHD number $(E h d)$ or conductive Rayleigh number is defined as:

$$
\mathrm{E}_{\mathrm{hd}}=\frac{\mathrm{I}_{\mathrm{o}} \mathrm{L}^{3}}{\rho_{\mathrm{o}} v^{2} \mu_{\mathrm{c}} A}
$$

\section{$E_{M}$ Number}

The $E_{M}$ is defined as:

$$
\mathrm{E}_{\mathrm{M}}=\frac{\mathrm{h}_{\mathrm{lg}}}{\frac{\sigma \mathrm{d}^{2}}{\rho_{l} d^{3}}}
$$


And represents the ratio of two energies. The numerator of the term represents the latent heat of vaporization that can further be referred as latent energy per unit mass. The denominator of the term represents the surface tension energy per unit mass. Sabharwall et al. (2009) expressed this dimensionless number as the ratio of latent heat of vaporization to the capillary pressure and used it in phase-change thermosyphon and heat-pipe heat exchangers.

\section{$E_{r}$ Number}

The $E_{r}$ is defined as:

$$
\mathrm{E}_{\mathrm{r}}=\frac{\mathrm{h}_{\mathrm{lg}}}{\mathrm{U}_{\mathrm{s}}^{2}}
$$

And relates the ratio of thermal to kinetic energies. Thermal energy is the energy that is required by the fluid for phase change from the liquid to vapor state, and the square of the velocity represents the kinetic energy head. Sabharwall et al. (2009) expressed this dimensionless number as the ratio of latent heat of vaporization to the pressure drop across the heat pipes and thermosyphons and used it in phase-change thermosyphon and heatpipe heat exchangers.

\section{Eötvös Number (Eo)}

The Eötvös number $(E o)$ is defined as:

$$
E o=\frac{g d^{2}\left(\rho_{l}-\rho_{g}\right)}{\sigma}
$$

And represents the ratio of gravitational (buoyancy) and capillary force scales. The length scale used in its definition is the pipe diameter.

Brauner and Moalem-Maron (1992) identified the range of 'small diameters' conduits, regarding two-phase flow pattern transitions. The researchers used the Eötvös number $(E o)$ to characterize the surface tension dominance in the two-phase flow in microchannels. They took $E o<(2 \pi)^{2}$ as the criterion for the surface tension dominance.

Recently, Ullmann and Brauner (2007) reexamined the channel diameter effect on the flow regime transitions in mini channels and suggested that new mechanistic models be expressed in terms of the non-dimensional Eötvös number. In their definition of Eötvös number, they multiplied the surface tension $(\sigma)$ in the denominator in Eq. (37) by the factor 8. The researchers suggested that in small Eötvös number systems (of the order of 0.04), the negligibly small bubble velocity, even in vertical systems, led to flow regimes resembling those obtained in conventional channels under microgravity conditions. They used the experimental flow regime data presented by Triplett et al. (1999) for air-water in $1.097 \mathrm{~mm}$ Pyrex pipe, corresponding to an Eötvös number of 0.021 , to calibrate and determine the efficacy of their approach for small Eötvös number configurations. 


\section{Euler Number $(E u)$}

The Euler number $(E u)$ is often written in terms of pressure differences $(\Delta p)$ and is defined as:

$$
E u=\frac{\Delta p}{\rho U^{2}}
$$

And represents the ratio of pressure forces to inertial forces. It expresses the relationship between the pressure drop and the kinetic energy per volume, and is used to characterize losses in the flow, where a perfect frictionless flow corresponds to $E u=1$.

\section{Fourier Number (Fo)}

The Fourier number $(F o)$ is defined as:

$$
F o=\frac{\alpha t}{d^{2}}
$$

And represents the ratio of the heat conduction rate to the rate of thermal energy storage.

When used in connection with mass transfer, the thermal diffusivity $(\alpha)$ is replaced by the mass diffusivity $(D)$.

$$
F o=\frac{D t}{d^{2}}
$$

Using the above definition of the Fourier number $(F o)$ with the liquid film thickness $(\delta)$ as the characteristic length, Pigford (1941) analyzed in his Ph. D. thesis the transient mass transfer to a falling film in laminar flow. His analysis is most conveniently found on the book of Sherwood et al. (1975). In addition, van Baten and Krishna (2004) formulated a mass transfer model of penetration theory for the film for shorter unit cells (or higher velocities) using Eq. (40) with $d=\delta$.

\section{Froude Number $(F r)$}

The Froude number $(F r)$ is defined as:

$$
F r=\frac{\rho U^{2}}{\rho g d}=\frac{U^{2}}{g d}
$$

And represents a measure of inertial forces and gravitational forces. When $F r<1$, small surface waves can move upstream; when $F r>1$, they will be carried downstream; and when $F r=1$ (said to be the critical Froude number), the velocity of flow is equal to the velocity of surface waves.

Also, there is $\left(F r^{*}\right)$, which is defined as: 


$$
F r^{*}=\frac{F r}{A t}=\left(\frac{\rho_{l}+\rho_{g}}{\rho_{l}-\rho_{g}}\right) \frac{U^{2}}{g d}
$$

In addition, the Froude number $(F r)$ is frequently defined as $F r=U /(g d)^{0.5}$.

\section{Electric Froude Number $\left(F r_{e}\right)$}

The electric Froude number $\left(F r_{e}\right)$ is defined as:

$$
\mathrm{Fr}_{\mathrm{e}}=\frac{\mathrm{xG}}{\left(\rho_{g}\left[\left(\rho_{l}-\rho_{g}\right) d_{o} g-f_{e}^{\prime \prime}\right]\right)^{1 / 2}}
$$

This dimensionless group was given by Chang (1989) and Chang (1998).

\section{Froude Rate $(F t)$}

The Froude rate $(F t)$ is defined as:

$$
F t=\left(\frac{x^{3} G^{2}}{\rho_{g}^{2} g d(1-x)}\right)^{0.5}
$$

And represents the ratio of the vapor kinetic energy to the energy required to lift the liquid phase around the tube. This parameter was derived by Hulburt and Newell (1997). Graham et al. (1999) obtained an expression for the void fraction in terms of the Lockhart-Martinelli parameter for turbulent-turbulent flow $\left(X_{t t}\right)$ and the Froude rate $(F t)$. Also, Thome (2003) deduced the transition from annular flow (viscous forces predominate) to intermittent flow (gravitational forces predominate) with the aid of his maps using the combination of two parameters: the Froude rate $(F t)$, and the Lockhart-Martinelli parameter for turbulentturbulent flow $\left(X_{t t}\right)$. In addition, Wilson et al. (2003) obtained an expression for the void fraction in terms of the Lockhart-Martinelli parameter for turbulent-turbulent flow $\left(X_{t t}\right)$ and the Froude rate (Ft) for smooth tube, $18^{\circ}$ Helix, and $0^{\circ}$ Helix, respectively.

\section{Galileo Number (Ga)}

The Galileo number $(G a)$ is defined as:

$$
G a=\frac{g d^{3}}{v^{2}}
$$

And represents the ratio of gravitational and viscous force scales. The Galileo number $(G a)$ is an important number in two-phase gas-liquid flow in determining the motion of a bubble/droplet under the action of gravity in the gravity-driven viscous flow. For instance, Haraguchi et al. (1994) expressed the condensation heat transfer coefficient in terms of Nusselt number as a combination of forced convection condensation and gravity controlled 
convection condensation terms. They expressed the gravity controlled convection condensation term as a function of the Galileo number $(G a l)$.

The modified Galileo number $\left(G a^{*}\right)$ is defined as:

$$
G a^{*}=\frac{\rho \sigma^{3}}{\mu^{4} g}
$$

And accounts for the influences of surface tension and viscosity. The modified Galileo number $\left(G a^{*}\right)$ is sometimes referred to as the "film number". For example, $\mathrm{Hu}$ and Jacobi (1996) reported experiments that explored viscous, surface tension, inertial, and gravitational effects on the falling-film mode transitions. Their study covered a variety of fluids including water, ethylene glycol, hydraulic oil, water/ethylene glycol mixture, and alcohol, tube diameters, tube pitches, flow rates and with/without concurrent gas flow. Based on their 1000 experimental observations, the researchers provided new flow classifications, a novel flow regime map, and unambiguous transition criteria for every of the mode transitions. Over the range of their experiments, they found that the mode transitions were relatively independent of geometric effect (tube diameter and spacing). In a simplified map neglecting hysteresis (transition with an increasing flow rate compared with that with a decreasing flow rate), the coordinates of their flow mode map were the film Reynolds number $\left(R e_{f}\right)$ versus the modified Galileo number $\left(G a^{*}\right)$. The mixed mode zones of jet-sheet and droplet-jet were transition zones between the three dominant modes of sheet, jet, and droplet in which both modes were present. Their four flow transition expressions between these five zones were given by the film Reynolds number $\left(R e_{f}\right)$ as a function of the modified Galileo number ( $\left.G a^{*}\right)$ (valid for passing through the transition in either direction). Their map was applicable to plain tubes for air velocities less than $15 \mathrm{~m} / \mathrm{s}$.

\section{Graetz Number $(G z)$}

The Graetz number $(G z)$ is defined as:

$$
G r=\frac{d}{L} \operatorname{Re} \operatorname{Pr}
$$

When used in connection with mass transfer the Prandtl number $(P r)$ is replaced by the Schmidt number $(S c)$ that expresses the ratio of the momentum diffusivity to the mass diffusivity (Kreutzer, 2003).

$$
G r=\frac{d}{L} \operatorname{Re} S c
$$

\section{Dimensionless Vapor Mass Flux $\left(J_{g}\right)$}

The dimensionless vapor mass flux $\left(J_{g}\right)$ is defined as follows: 


$$
J_{g}=\frac{G x}{\sqrt{d g \rho_{g}\left(\rho_{l}-\rho_{g}\right)}}
$$

In two-phase flow, transition criteria for flow regimes are determined using the dimensionless vapor mass flux $\left(J_{g}\right)$ and the Lockhart-Martinelli parameter for the turbulentturbulent flow $\left(X_{t t}\right)$. For example, Breber et al. (1980) used the dimensionless vapor mass flux $\left(J_{g}\right)$ in the prediction of horizontal tube-side condensation of pure components using flow regime criteria. Also, Sardesai et al. (1981) used the dimensionless vapor mass flux $\left(J_{g}\right)$ in the determination of flow regimes for condensation of a vapor inside a horizontal tube. In addition, Tandon et al. $(1982,1985)$ used the dimensionless vapor mass flux $\left(J_{g}\right)$ in the prediction of flow patterns during condensation in a horizontal tube. Moreover, Cavallini et al. (2002) allowed an assessment of the limits of the two-phase flow structures of the condensation of refrigerants in channels with the aid of the dimensionless vapor mass flux $\left(J_{g}\right)$, and the Lockhart-Martinelli parameter for the turbulent-turbulent flow $\left(X_{t t}\right)$.

\section{Jacob Number $(\mathrm{Ja})$}

The Jacob number $(J a)$ is defined as:

$$
\mathrm{J} a=\frac{{ }^{c_{p}} \Delta T}{h_{\lg }}
$$

And represents the ratio of the sensible heat for a given volume of liquid to heat or cool through the temperature difference $(\Delta T)$ in arriving to its saturation temperature, to the latent heat required in evaporating the same volume of vapor. It is used in film condensation and boiling. For instance, $J a$ may be used in studying the influences of liquid superheat prior to initiation of nucleation in microchannels. Also, it may be useful in studying the subcooled boiling conditions. The Jacob number $(\mathrm{Ja})$ can be modified to produce the modified Jacob number $\left(J a^{*}\right)$ by multiplying it by the density ratio $\left(\rho_{l} / \rho_{g}\right)$ (Yang et al., 2000).

$$
\mathrm{J} a^{*}=\frac{\rho_{l}}{\rho_{g}} \mathrm{~J} a=\frac{\rho_{l} c_{p} \Delta T}{\rho_{g} h_{\mathrm{lg}}}
$$

Yang et al. (2000) used both the Jacob number $(J a)$ and the modified Jacob number $\left(J a^{*}\right)$ in their study on bubble dynamics for pool nucleate boiling.

Recently, Charoensawan and Terdtoon (2007) modified the Jacob number (Ja) by adding the influence of filling ratio $(F R)$ in their study on the thermal performance of horizontal closedloop oscillating heat pipes.

$$
\mathrm{J} a^{*}=\frac{F R}{1-F R} \mathrm{~J} a=\frac{F R c_{p} \Delta T}{(1-F R) h_{\mathrm{lg}}}
$$




\section{Boiling Number $\left(K_{f}\right)$}

The Boiling number $\left(K_{f}\right)$ is defined as:

$$
\mathrm{K}_{\mathrm{f}}=\frac{q}{G h_{\mathrm{lg}}}
$$

In this dimensionless number, heat flux $(q)$ is non-dimensionalized with mass flux $(G)$ and latent heat $\left(h_{l}\right)$. It is based on empirical considerations. It can be used in empirical treatment of flow boiling because it combines two important flow parameters, $q$ and $G$. It is used as one of the parameters for correlating the flow boiling heat transfer in both macro-scale and micro-scale. For example, Lazarek and Black (1982) proposed the nondimensional correlation for the flow boiling Nusselt number for their heat transfer experiments on R-113 as a function of the all-liquid Reynolds number (Relo), and the Boiling number (Kf). Also, Tran et al. (1996) obtained a correlation for the heat transfer coefficient in their experiments on R-12 and R-113 as a function of the all-liquid Weber number (Welo), the Boiling number $\left(K_{f}\right)$, and the liquid to vapor density ratio $\left(\rho_{l} / \rho_{g}\right)$ to account for variations in fluid properties

\section{New Non-Dimensional Constants of Kandlikar $\left(K_{1}, K_{2}\right.$, and $\left.K_{3}\right)$}

These three new nondimensional groups, $K_{1}, K_{2}$, and $K_{3}$ are relevant to flow boiling phenomenon in microchannels. K1 and K2 were derived by Kandlikar (2004). The new nondimensional constant (K1) is defined as:

$$
\mathrm{K}_{1}=\frac{\left(\frac{q}{h_{\mathrm{lg}}}\right)^{2} \frac{d}{\rho_{g}}}{\frac{G^{2} d}{\rho_{l}}}=\left(\frac{q}{G h_{\mathrm{lg}}}\right)^{2} \frac{\rho_{l}}{\rho_{g}}=\mathrm{K}_{\mathrm{f}}^{2} \frac{\rho_{l}}{\rho_{g}}
$$

And represents the ratio of the evaporation momentum force, and the inertia force. This dimensionless group includes the Boiling number $\left(K_{f}\right)$ and the liquid to vapor density ratio $\left(\rho / \rho_{8}\right)$. The Boiling number $(\mathrm{Kf})$ alone does not represent the true influence of the evaporation momentum, and its coupling with the density ratio $(\rho \mathrm{l} / \rho \mathrm{g})$ is important in representing the evaporation momentum force. A higher value of $\mathrm{K} 1$ means that the numerator (i.e. the evaporation momentum forces) is dominant and is likely to alter the interface movement.

The new non-dimensional constant $\left(K_{2}\right)$ is defined as:

$$
\mathrm{K}_{2}=\frac{\left(\frac{q}{h_{\lg }}\right)^{2} \frac{d}{\rho_{g}}}{\sigma}=\left(\frac{q}{h_{\lg }}\right)^{2} \frac{d}{\rho_{g} \sigma}
$$

And represents the ratio of the evaporation momentum force, and the surface tension force. Kandlikar (2004) mentioned that the contact angle was not included in $K_{2}$ although the 
actual force balance in a given situation might involve more complex dependence on contact angles and surface orientation. It should be recognized that the contact angles play an important role in bubble dynamics and contact line movement and need to be taken into account in a comprehensive analysis.

A higher value of $K_{2}$ means that the numerator (i.e. the evaporation momentum forces) is dominant and causes the interface to overcome the retaining surface tension force. Kandlikar (2001) used effectively the group $K_{2}$ in developing a model for the critical heat flux $(\mathrm{CHF})$ in pool boiling. He replaced the characteristic dimension $(d)$ with the departure bubble diameter.

Kandlikar (2004) mentioned that these two groups were able to represent some of the key flow boiling characteristics, including the critical heat flux (CHF). In his closing remarks, he mentioned that the usage of the new non-dimensional groups $K_{1}$ and $K_{2}$ in conjunction with the Weber number $(\mathrm{We})$ and the Capillary number $(\mathrm{Ca})$ was expected to provide a better tool for analyzing the experimental data and developing more representative models.

Awad (2012a) mentioned that similar to the combination of the nondimensional groups, $\mathrm{K}_{2} \mathrm{~K}_{1} 0.75$ (Kandlikar, 2004) that used in representing the flow boiling CHF data by Vandervort et al. (1994), these two new nondimensional groups, $K_{1}$ and $K_{2}$, can be combined using Eqs. (54) and (55) as:

$$
\frac{\mathrm{K}_{2}}{\mathrm{~K}_{1}}=\frac{\left(\frac{q}{h_{\mathrm{lg}}}\right)^{2} \frac{d}{\rho_{g} \sigma}}{\left(\frac{q}{G h_{\mathrm{lg}}}\right)^{2} \frac{\rho_{l}}{\rho_{g}}}=\frac{d G^{2}}{\rho_{l} \sigma}=W e_{l o}
$$

i.e. the ratio of $K_{2}$ and $K_{1}$ is equal to the all liquid Weber number $\left(W e_{0}\right)$. As a result, it is enough to use the new non-dimensional groups $K_{1}$ and $K_{2}$ in conjunction with the Capillary number $(\mathrm{Ca})$ only to provide a better tool for analyzing the experimental data and developing more representative models for heat transfer mechanisms during flow boiling in microchannels because $K_{2} / K_{1}=W e l$.

Moreover, it should be noted that the ratio of $K_{2}$ and $K_{1}\left(K_{2} / K_{1}\right)$ and the Capillary number (Ca) can be combined as (Awad, 2012a):

$$
\frac{\mathrm{K}_{2} / \mathrm{K}_{1}}{C a}=\frac{\mathrm{We} e_{l o}}{C a}=\operatorname{Re}_{l o}
$$

i.e. the ratio of $\left(K_{2} / K_{1}\right)$ and $C a$ is equal to the all liquid Reynolds number $\left(\operatorname{Re} l_{0}\right)$.

Recently, $K_{3}$ was derived by Kandlikar (2012). The new non-dimensional constant $\left(K_{3}\right)$ is defined as:

$$
\mathrm{K}_{3}=\frac{\text { Evaporation Momentum Force }}{\text { Viscous Force }}
$$


And represents the ratio of the evaporation momentum force, and the viscous force. Kandlikar (2012) mentioned that this nondimensional group $K_{3}$ had not been independently used yet, but it was relevant if the evaporation momentum and viscous forces were considered in a process. $K_{3}$ could also be represented as:

$$
\mathrm{K}_{3}=\mathrm{K}_{1} \operatorname{Re}=\frac{\mathrm{K}_{2}}{\mathrm{Ca}}
$$

In his summary, Kandlikar (2012) mentioned that recognizing the evaporation momentum force as an important force during the boiling process opened up the possibilities of three new relevant nondimensional groups, $K_{1}, K_{2}$, and $K_{3}$. Any two of these groups could be represented by combining the third one with one of the other relevant nondimensional groups $R e, W e$, and $C a$.

\section{Kapitza Number $(K a)$}

The Kapitza number $(K a)$ is defined as:

$$
K a=\frac{\mu^{4} g}{\rho \sigma^{3}}
$$

And accounts for the influences of viscosity and surface tension. Using Eqs. (46) and (60), it should be noted that the Kapitza number $(K a)$ is equal to the inverse of the modified Galileo number $\left(G a^{*}\right)$.

$$
K a=G a^{*-1}
$$

The Kapitza number $(\mathrm{Ka})$ is used in wave on liquid film. For example, Mudawwar and ElMasri (1986) found that it was impossible to obtain universal correlations of the heat transfer coefficients for different fluids in terms of Reynolds and Prandtl numbers alone because the heat transfer data across freely-falling turbulent liquid films had a strong dependence on the Kapitza number $(\mathrm{Ka})$ below $R e=10000$. On the other hand, the researchers recommended turbulent-film correlations based on $\operatorname{Re}$ and $\operatorname{Pr}$ similar to those used in conventional internal or external flows for higher Reynolds numbers ( $R e>15000)$.

\section{Knudsen Number (Kn)}

At microscales, the no-slip boundary condition can be applied in many situations specially when there is a liquid flow inside microchannels. Deciding on slip or no-slip boundary condition is dependent on a dimensionless group that is called Knudsen number $(K n)$. It is defined as:

$$
K n=\frac{\lambda}{L}
$$

And represents the ratio of the molecular mean free path length $(\lambda)$ to a representative physical length scale such as the hydraulic diameter. However, a slip condition, Navier slip 
condition can be applied to avoid numerical clutches where there is a moving contact line. For example, Chen et al. (2009) applied this technique in their numerical study on the formation of Taylor bubbles in capillary tubes. More fundamental details can be found in Renardy et al. (2001) and Spelt (2005). The Knudsen number $(K n)$ is an important number in two-phase gas-liquid flow in determining the continuum approximation.

\section{von Karman Number $(K r)$}

The von Karman number $(K r)$ is defined as:

$$
K r=\operatorname{Re} f^{1 / 2}
$$

i.e. it is the product of the Reynolds number $(R e)$ and the square root of the friction factor $\left(f^{1 / 2}\right)$. It is does not contain the velocity $(U)$, but it is determined from the pipe dimensions $(d$ and $L$ ), fluid properties ( $\rho$ and $\mu$ ), and pressure drop $(\Delta p)$. Computation of the von Karman number $(\mathrm{Kr})$ in problem in which the flow is the only variable to be determined saves a solution by trial and error. However, this trial and error is relatively simple and takes only a few steps. A plot in which $f, f^{1 / 2}$ or $f^{1 / 2}$ is plotted versus $K r$ with relative roughness $(\varepsilon)$ as a third parameter can be used in order to avoid the trial and error solution.

On the other hand, Charoensawan and Terdtoon (2007) defined the von Karman number $(K r)$ as:

$$
K r=\operatorname{Re}^{2} f
$$

i.e. it is the product of the Reynolds number square $\left(R e^{2}\right)$ and the friction factor $(f)$. Charoensawan and Terdtoon (2007) found that one of the influence dimensionless groups on the thermal performance of horizontal closed-loop oscillating heat pipes was the von Karman number $(K r)$.

\section{Kutateladze Number $(K u)$}

The Kutateladze number $(K u)$ is defined as:

$$
K u=U \rho^{1 / 2}\left[g \sigma\left(\rho_{l}-\rho_{g}\right)\right]^{-1 / 4}
$$

And represents a balance between the dynamic head, surface tension, and gravitational force. For example, Kutateladze (1972) used the Kutateladze number $(K u)$ in the Kutateladze two-phase flow stability criterion, in which the inertia, buoyancy, and surface tension forces were balanced for the prediction of flooding limit of open two-phase systems.

Recently, Charoensawan and Terdtoon (2007) defined the Kutateladze number $(\mathrm{Ku})$ as:

$$
K u=\frac{q}{h_{\mathrm{lg}} \rho_{g}\left[\frac{g \sigma\left(\rho_{l}-\rho_{g}\right)}{\rho_{g}^{2}}\right]^{1 / 4}}
$$


The researchers developed successfully the thermal performance correlation of a horizontal closed-loop oscillating heat pipe (HCLOHP) in the non-dimensional form of power function using the curve fitting. In their correlation, they presented the Kutateladze number $(K u)$ as a function of liquid Prandtl number $(\operatorname{Pr} l)$, modified Jacob number $\left(J a^{*}\right)$ with adding the influence of filling ratio, Bond number (Bo), von Karman number $(K r)$, and $k_{c} / k_{a}$ (the ratio of the thermal conductivities of the cooling fluid at the required temperature and the ambient air at $25^{\circ} \mathrm{C}$ ). From their non-dimensional correlation, they concluded that $K u$ or dimensionless group representing the thermal performance of HCLOHP improved with increasing $P r l, K a$ and $k_{c} / k_{a}$ and with decreasing $J a^{*}$ and $B o$.

\section{Laplace Number $(L a)$}

The Laplace number $(L a)$ is also known as the Suratman number $(S u)$. It is defined as:

$$
L a=S u=\sqrt{\frac{\sigma}{g d^{2}\left(\rho_{l}-\rho_{g}\right)}}
$$

And represents the ratio of capillary and gravitational (buoyancy) force scales. The length scale used in its definition is the pipe diameter.

In addition, the Laplace number $(L a)$ is known as the confinement number $(C o)$. The threshold to confined bubble flow is one of the most widely-used criterions to distinguish between macro and microscale flow boiling. Following the classification by Kew and Cornwell (1997), channels are classified as micro-channels if Co $\geq 0.5$.

The confinement number $(\mathrm{Co})$ can represent the ratio of capillary length $\left(L_{c}\right)$ and the pipe diameter (Phan et al., 2011).

$$
\begin{gathered}
C o=\frac{L_{c}}{d} \\
L_{c}=\sqrt{\frac{\sigma}{g\left(\rho_{l}-\rho_{g}\right)}}
\end{gathered}
$$

In Eq. (69), the capillary length $\left(L_{c}\right)$ scales all the phenomena involving liquid-vapor interfaces, such as bubble growth and detachment, interface instabilities and oscillation wavelengths. Also, it is used as a characteristic boiling length to scale the heater size. As $L c$ increases with decreasing gravity, it is clear that bubbles will become "larger" and heaters will become "smaller" in low gravity, and vice versa. This should be accounted for in evaluating experimental results, as it is well known that boiling on "small" heaters has various features.

From Eqs. (23), (37), and (67), it is clear that three dimensionless numbers, Bo, Eo, and La are related as follows: 


$$
E o=4 B o=L a^{-2}
$$

When the pipe size is large, the Laplace constant $(L a)$ is a useful property length scale for multiphase flow calculations compared to the bubble diameter.

Also, it is defined as:

$$
L a=S u=\frac{\rho \sigma d}{\mu^{2}}
$$

The above definition is used in flow pattern maps. For example, Jayawardena et al. (1997) proposed a flow pattern map to obtain flow transition boundaries for microgravity twophase flows. The researchers used bubble-slug and slug-annular flow pattern transitions on the Suratman number $(\mathrm{Su})$ of the system. The bubble-slug transition occurred at a transitional value of the gas to liquid Reynolds number ratio $\left(R e_{g} / R e_{l}\right)$ that decreased with increasing Suratman number $(\mathrm{Su})$ and increased with increasing Suratman number $(\mathrm{Su})$ at slug-annular transitions for low Suratman number systems. For high Suratman number systems, the slug-annular transition occurred at a transitional value of the gas Reynolds number $\left(R e_{g}\right)$ that increased with increasing Suratman number $(\mathrm{Su})$.

In two-phase flow, presenting the Chisholm constant $(C)$ as a function of the Laplace number $(L a)$ in order to represent the hydraulic diameter $\left(d_{h}\right)$ in a dimensionless form overcame the main disadvantage in some correlations available in the open literature, which is the dimensional specification of $d_{h}$, as it is easy to miscalculate $C$ if the proper dimensions are not used for $d_{h}$.

\section{Lewis Number (Le)}

The Lewis number $(L e)$ is defined as:

$$
L e=\frac{\alpha}{D}=\frac{S c}{\operatorname{Pr}}
$$

And represents the ratio of the thermal diffusivity to the mass diffusivity.

The Lewis number $(L e)$ controls the relative thickness of the thermal and concentration boundary layers. When $L e$ is small, this corresponds to the thickness of the concentration boundary layer is much bigger than the thermal boundary layer. On the other hand, when $\mathrm{Le}$ is high, this corresponds to the thickness of the concentration boundary layer is much smaller than the thermal boundary layer.

\section{Lo Number}

The Lo number is defined as:

$$
L o=\frac{G^{2} d}{\rho_{m} \sigma}\left(\frac{\mu_{g}}{\mu_{l}}\right)^{0.5}
$$


This dimensionless number is used first in CISE-DIF-2 correlation (Lombardi and Ceresa, 1978). In CISE-DIF-2 correlation, a remarkable analogy with single-phase correlations was evident if the Reynolds number $(R e)$ was substituted by the Lo number. Also, this dimensionless number is used in CISE-DIF-3 correlation (Bonfanti et al., 1979). Later, this dimensionless number is used in CESNEF-2 correlation (Lombardi and Ceresa, 1992).

\section{Masuda Number $\left(M_{a}\right)$}

The Masuda number $(M a)$ or dielectric Rayleigh number is defined as:

$$
\mathrm{M}_{\mathrm{a}}=\frac{\varepsilon_{\mathrm{o}} \mathrm{E}_{\mathrm{o}}^{2} \mathrm{~T}_{\mathrm{o}}\left(\partial \varepsilon_{\mathrm{s}} / \partial T\right)_{\rho} \mathrm{L}^{2}}{2 \rho_{\mathrm{o}} v^{2}}
$$

Using the analogy to free convective flows, Cotton et al. (2005) mentioned that the combined effects of electric and forced convection must be considered when $\left(E n d / R e^{2}\right) \sim 1$ and/or $\left(M_{d} / R e^{2}\right) \sim 1$. If the inequalities $\left(E_{h d} / R e^{2}\right)<1$ or $\left(M_{d} / R e^{2}\right)<<1$ are satisfied, electric convection influences may be neglected, and conversely, if $\left(E h d / R e^{2}\right) \gg>1$ or $\left(M_{d} / R e^{2}\right)>>1$, forced convection influences may be neglected. This is exactly analogous to buoyancy driven flow and a similar argument may be made by comparing the EHD numbers to the Grashof number in the absence of forced convection. This order of magnitude analysis helps determine the range and extent to which EHD may affect the flow and must be identified to determine the voltage levels required to induce the migration of the liquid in order to influence heat transfer. Based on dimensionless analysis (Chang and Watson, 1994) it is expected that $E h d / R e l^{2} \sim \geq 0.1$ is sufficient to define the minimum condition above which electric fields significantly affect the liquid flow.

\section{HEM Mach Number (Ma)}

The Homogeneous Equilibrium Model (HEM) Mach number $(M a)$ is defined as:

$$
M a=G^{2}\left[\frac{(1-x)^{2}}{\rho_{l}^{2} c_{l}^{2}}+\frac{x^{2}}{\rho_{g}^{2} c_{g}^{2}}\right]
$$

\section{Morton Number (Mo)}

The Morton number $(M o)$ is defined as:

$$
M o=\frac{g \mu_{c}^{4}\left(\rho_{c}-\rho_{p}\right)}{\rho_{c}^{2} \sigma^{3}}
$$

And uses together with the Eötvös number $(E o)$ to characterize the shape of bubbles or drops moving in a surrounding fluid or continuous phase. For example, Taha and Cui (2006b) found that in their CFD modeling of slug flow in vertical tubes by decreasing the 
Morton number $(\mathrm{Mo})$ under a constant value of Eötvös number (Eo), the curvature of the bubble nose increases and the bubble tail flattens that results in an increment of the liquid film thickness around the bubble. In addition, the curvature of bubble nose increases as Eo goes up.

For the case of $\rho_{p} \ll<\rho_{c}$, the Morton number $(\mathrm{Mo})$ can be simplified to

$$
M o=\frac{g \mu_{c}^{4}}{\rho_{c} \sigma^{3}}
$$

\section{Nusselt Number $(\mathrm{Nu})$}

The Nusselt number $(\mathrm{Nu})$ is defined as:

$$
N u=\frac{(Q / A) d}{k\left(T_{w}-T_{m}\right)}=\frac{h d}{k}
$$

And can be viewed as either the dimensionless heat transfer rate or dimensionless heat transfer coefficient. It represents the ratio of convective to conductive heat transfer across (normal to) the boundary. $\mathrm{Nu} \sim 1$, namely convection and conduction of similar magnitude, is characteristic of "slug flow" or laminar flow. A larger Nusselt number corresponds to more active convection, with turbulent flow typically in the range of 100-1000.

\section{Ohnesorge Number $(\mathrm{Oh})$}

The Ohnesorge number $(\mathrm{Oh})$ is defined as:

$$
O h=\frac{\mu_{l}}{\sqrt{\sigma d \rho_{l}}}=\frac{\sqrt{W e}}{\operatorname{Re}} \approx \frac{\text { viscous forces }}{\sqrt{\text { inertia . surface tension }}}
$$

And relates the viscous forces to inertial and surface tension forces. The combination of these three forces into one masks the individual effects of every force. Often, it is used to relate to free surface fluid dynamics like dispersion of liquids in gases and in spray technology (Ohnesorge, 1936, Lefebvre, 1989). Also, it is used in analyzing liquid droplets and droplet atomization processes. Larger Ohnesorge numbers indicate a greater effect of the viscosity.

Using Eqs. (67) and (79), it is clear that there is an inverse relationship, between the Laplace number $(\mathrm{La})$ and the Ohnesorge number $(\mathrm{Oh})$ as follows:

$$
O h=\frac{1}{\sqrt{L a}}
$$

Historically, it is more correct to use the Ohnesorge number $(\mathrm{Oh})$, but often mathematically neater to use the Laplace number $(L a)$. 


\section{Peclet Number $(\mathrm{Pe})$}

For diffusion of heat (thermal diffusion), the Peclet number is defined as:

$$
P e=\operatorname{Re} \operatorname{Pr}=\frac{U d}{\alpha}
$$

For diffusion of particles (mass diffusion), it is defined as:

$$
P e=\operatorname{Re} S c=\frac{U d}{D}
$$

For example, Muradoglu et al. (2007) studied the influences of the Peclet number $(\mathrm{Pe})$ on the axial mass transfer (dispersion) in the liquid slugs. The researchers found that "convection" and "molecular diffusion" control the axial dispersion for various Peclet numbers $(P e)$. They introduced three various regimes of $P e$ :

1. Convection-controlled regime when $P e>10^{3}$.

2. Diffusion-controlled regime when $P e<10^{2}$.

3. Transition regime when $10^{2} \leq P e \leq 10^{3}$.

\section{Phase Change Number $(P h)$}

The phase change number $(\mathrm{Ph})$ is defined as follows:

$$
P h=\frac{c_{p}\left(T_{s}-T_{w, i}\right)}{h_{\mathrm{lg}}}
$$

And represents the ratio of the enthalpy change due to the temperature difference between the saturation temperature and inner wall temperature to the latent heat of vaporization. For example, Haraguchi et al. (1994) expressed the condensation heat transfer coefficient in terms of Nusselt number as a combination of forced convection condensation and gravity controlled convection condensation terms. They expressed the gravity controlled convection condensation term as a function of the phase change number $(P h l)$.

\section{Prandtl Number $(P r)$}

The Prandtl number (Pr) is defined as:

$$
\operatorname{Pr}=\frac{v}{\alpha}=\frac{\mu c_{p}}{k}
$$

And represents a measure of the rate of momentum diffusion versus the rate of thermal diffusion. It should be noted that Prandtl number contains no such length scale in its definition and is dependent only on the fluid and the fluid state. As a result, Prandtl number is often found in property tables alongside other properties like viscosity and thermal conductivity. It is used to characterize heat transfer in fluids. Typical values for $\mathrm{Pr}$ are: 


$$
\begin{array}{cc}
\operatorname{Pr} \ll<1 & \text { Liquid Metals } \\
\operatorname{Pr} \approx 1 & \text { Gases } \\
\operatorname{Pr} \gg>1 & \text { Viscous Liquids }
\end{array}
$$

Low $\mathrm{Pr}$ means that conductive transfer is strong while high $\operatorname{Pr}$ means that convective transfer is strong. For example, heat conduction is very effective compared to convection for mercury (i.e. thermal diffusivity is dominant). On the other hand, convection is very effective in transferring energy from an area, compared to pure conduction for engine oil (i.e. momentum diffusivity is dominant).

In heat transfer problems, the Prandtl number controls the relative thickness of the momentum and thermal boundary layers. When $P r$ is small, it means that the heat diffuses very quickly compared to the velocity (momentum). This means that for liquid metals the thickness of the thermal boundary layer is much bigger than the velocity boundary layer. On the other hand, when $\mathrm{Pr}$ is high, it means that the heat diffuses very slowly compared to the velocity (momentum). This means that for viscous liquids the thickness of the thermal boundary layer is much smaller than the velocity boundary layer.

As seen, for example, in the two definitions of Graetz number $(\mathrm{Gz})$ and Peclet number $(\mathrm{Pe})$, the mass transfer analog of the Prandtl number $(\mathrm{Pr})$ is the Schmidt number $(\mathrm{Sc})$.

\section{Reynolds Number (Re)}

The Reynolds number $(R e)$ is defined as:

$$
\operatorname{Re}=\frac{\rho U d}{\mu}
$$

And is traditionally defined as the ratio of inertial to viscous force scales. Often, it is most used to determine whether the flow is laminar or turbulent.

Recently, Shannak (2009) analyzed the historical definition of dimensionless number as a ratio of the most important forces that acts in single-phase flow to be applicable for the multiphase flow. He presented new expressions for the multiphase flow like Reynolds number $(R e)$ and the Froude number $(F r)$ as a function of the primary influencing parameters. Therefore, the presented extension for Reynolds number and Froude number in his study could be simply extrapolated and used as well as more extensive applied for all other dimensions numbers. Pressure drop, friction factors and flow maps of two- and multiphase flow could be simply presented and graphically showed as a function of such new defined numbers.

\section{Ca/Re Number}

The ratio of the Capillary number $(\mathrm{Ca})$ and Reynolds number $(\mathrm{Re})$ appears as a group in plug flows. It results in a group that is independent of flow velocity: 


$$
\frac{C a}{\operatorname{Re}}=\frac{\mu^{2}}{\rho d \sigma}=L a^{-1}=S u^{-1}
$$

This dimensionless group in Eq. (87) is used in flow pattern maps. For example, Jayawardena et al. (1997) plotted $\left(R e_{g} / R e_{l}\right)$ or $R e_{g}$ versus $(R e l / C a)\left(i . e .(C a / R e l)^{-1}=S u\right)$ in their flow pattern maps. Using this plot, the boundaries for a large set of experimental data, obtained using various fluids and geometries, could be accurately predicted.

Also, the $\mathrm{Ca} / \mathrm{Re}$ number is associated with Taylor plug flows. When combined with dimensionless liquid slug length $\left(L^{*}\right)=L_{s} / d$, it provides a measure of the effect that plug characteristics have on pressure drop or fluid friction. Walsh et al. (2009) showed that when:

$$
\begin{aligned}
& L^{*}\left(\frac{C a}{\operatorname{Re}}\right)^{0.33} \gg 1 \quad \text { Taylor Flow } \\
& L^{*}\left(\frac{C a}{\operatorname{Re}}\right)^{0.33} \quad<1 \quad \text { Poiseuille Flow }
\end{aligned}
$$

\section{Equivalent All Liquid Reynolds Number $\left(R e_{e q}\right)$}

The equivalent all liquid Reynolds number $\left(R e_{e q}\right)$ is defined as:

$$
\begin{gathered}
\operatorname{Re}_{e q}=\frac{G_{e q} d}{\mu_{l}} \\
G_{e q}=G\left[(1-x)+x\left(\frac{\rho_{l}}{\rho_{g}}\right)^{0.5}\right]
\end{gathered}
$$

This dimensionless number was proposed by Akers et al. (1959) and used, for example, in the empirical correlations of Yan and Lin (1998) and Ma et al. (2004) for the two-phase frictional pressure gradient.

\section{Film Reynolds Number $\left(R e_{f}\right)$}

The film Reynolds number $\left(R e_{f}\right)$ is defined as:

$$
\operatorname{Re}_{\mathrm{f}}=\frac{2 \Gamma}{\mu}
$$

This dimensionless group is used as a vertical coordinates in the flow mode map of $\mathrm{Hu}$ and Jacobi (1996).

\section{Particle Reynolds Number $\left(R e_{p}\right)$}

The particle or relative Reynolds number $\left(\operatorname{Re}_{p}\right)$ is defined as: 


$$
\operatorname{Re}_{p}=\frac{\rho_{c}\left|U_{c}-U_{p}\right| d_{p}}{\mu_{c}}
$$

The particle Reynolds number $\left(R e_{p}\right)$ is an important parameter in many industrial applications with small droplets/bubbles in two-phase, two component flow because it determines whether the flow falls into the category of the Stokes flow or not. Also, this number is a benchmark to determine the appropriate drag coefficient $\left(C_{D}\right)$.

If $R e_{p} \ll 1$, the two-phase flow would be termed Stokes flow. In the Stokes flow regime, viscous bubbles or drops remain spherical; regardless of the Eötvös number $(E o)$ value. Even at low particle Reynolds numbers, a wake is formed behind the sphere. This is a steady-state wake, which becomes stronger as the Reynolds number increases and the inertia of the flow around the bubbles/droplets overcomes the viscosity effects on the surface of the bubbles/droplets (Crowe, 2006).

\section{Richardson Number $(R i)$}

The Richardson number $(R i)$ is defined as:

$$
R i=\frac{\Delta \rho g d}{\rho U^{2}}
$$

And represents the ratio of buoyancy forces to inertial forces. It is clear that the Richardson number $(R i)$ can be obtained from combining the density ratio $(\Delta \rho / \rho)$ with the Froude number $(F r)$.

\section{Schmidt Number $(S c)$}

The Schmidt number $(S c)$ is defined as:

$$
S c=\frac{v}{D}
$$

And represents the ratio of the momentum diffusivity to the mass diffusivity.

In mass transfer problems, the Schmidt number $(S c)$ controls the relative thickness of the momentum and concentration boundary layers. When $S c$ is small, it means that the mass diffuses very quickly compared to the velocity (momentum). This corresponds to the thickness of the concentration boundary layer is much bigger than the velocity boundary layer. On the other hand, when $S c$ is high, it means that the mass diffuses very slowly compared to the velocity (momentum). This corresponds to the thickness of the concentration boundary layer is much smaller than the velocity boundary layer.

As seen, for example, in the two definitions of Graetz number $(\mathrm{Gz})$ and Peclet number $(\mathrm{Pe})$, the heat transfer analog of the Schmidt number $(S c)$ is the Prandtl number $(P r)$. 


\section{Sherwood Number (Sh)}

The Sherwood number (Sh) is also called the mass transfer Nusselt number) and is defined as:

$$
S h=\frac{K d}{D}
$$

And represents the ratio of convective to diffusive mass transport. It is used in mass-transfer operation.

For example, Kreutzer (2003) calculated the liquid-solid mass transfer with a finite-element method, arriving at different values than reported by Duda and Vrentas (1971). These results gave an expression for the length-averaged mass transfer from a circulating vortex to the wall, without a lubricating film in between:

$$
S h=\sqrt{40^{2}\left[1+0.28\left(\frac{\mathrm{L}_{\text {slug }}}{\mathrm{d}}\right)^{-4 / 3}\right]^{2}+\left[90+104\left(\frac{\mathrm{L}_{\text {slug }}}{\mathrm{d}}\right)^{-4 / 3}\right]\left[\frac{\mathrm{dRe} \mathrm{Sc}}{\mathrm{L}}\right]}
$$

Equation (96) is defined per unit slug volume and should be multiplied with the liquid holdup to obtain a mass transfer coefficient based on channel volume. In addition, Eq. (96) is only valid for the region in which the circulating vortex has at least circulated once.

\section{Stanton Number (St)}

In heat transfer problem, the Stanton number $(S t)$ is also called modified Nusselt number and is defined as:

$$
S t=\frac{h}{\rho U c_{p}}=\frac{N u}{\operatorname{RePr}}=\frac{N u}{P e}
$$

And represents the ratio of the Nusselt number $(\mathrm{Nu})$ to the Peclet number $(\mathrm{Pe})$.

In mass transfer problem, the Stanton number $(S t)$ is also called modified Sherwood number and is defined as:

$$
S t=\frac{K}{U}=\frac{S h}{\operatorname{Re} S c}=\frac{S h}{P e}
$$

And represents the ratio of the Sherwood number $(\mathrm{Nu})$ to the Peclet number $(\mathrm{Pe})$.

\section{Stefan Number (Ste)}

The Stefan number (Ste) is defined as:

$$
\text { Ste }=\frac{c_{p} \Delta T}{h_{s l}}
$$


And represents the ratio of sensible heat to latent heat. It is used in melting and solidification.

\section{Stokes Number (Stk)}

The Stokes number $(S t k)$ is defined as:

$$
S t k=\frac{\tau_{p}}{\tau_{c}}=\frac{\rho_{p} d_{p}^{2} / 18 \mu_{c}}{d / U_{c}}
$$

And represents the ratio of the particle momentum response time over a flow system time. The Stokes number (Stk) is a very important parameter in liquid-particle motion and particle dynamics, where particles are suspended in a fluid flow. Also, the Stokes number (Stk) can be further related to the slip ratio $(S)$ as follows:

$$
S \approx \frac{1}{1+S t k}
$$

From Eq. (101), it is clear that if the Stokes number (Stk) tends to be zero, there would be noslip between the two phases (i.e. $S=1$ ).

There are three kinds of situations can be observed for particles (bubbles/droplets) suspended in fluid, namely: Case i) If $S t k<<1$, the response time of the particles $\left(\tau_{p}\right)$ is much less than the characteristic time associated with the flow field $\left(\tau_{c}\right)$. In this case, the particles will have ample time to respond to changes in flow velocity. Case ii) $S t k \sim 0$, where the two phases are in thermodynamic or velocity equilibrium. Case c) if $S t k>>1$, the response time of the particles $\left(\tau_{p}\right)$ is much higher than the characteristic time associated with the flow field $\left(\tau_{c}\right)$. In this case, the particle will have essentially no time to respond to the fluid velocity changes and the particle velocity will be little affected by fluid velocity change (Crowe, 2006).

\section{Strouhal Number (Str)}

The Strouhal number (Str) is defined as:

$$
S t r=\frac{f d}{U}
$$

In their study of the inclination effects on wave characteristics in annular gas-liquid flows, Al-Sarkhi et al. (2012) correlated reasonably the Strouhal number (Str) for all inclination angles as a function of the modified Lockhart-Martinelli parameter $\left(X^{*}\right)$.

\section{Weber Number $(W e)$}

The Weber number $(W e)$ is defined as: 


$$
W e=\frac{\rho U^{2} d}{\sigma}
$$

And represents a measure of inertial forces to interfacial forces. The Weber number $(W e)$ is useful in analyzing the formation of droplets and bubbles. If the surface tension of the fluid decreases, bubbles/droplets will have the tendency to decrease because of higher momentum transfer between the phases.

This dimensionless group is used in flow pattern maps. Thus, the influence of pipe diameter on the flow regimes is well accounted for through the use of the Weber number dimensionless groups. For example, Zhao and Rezkallah (1993) and updated later with new literature data by Rezkallah $(1995,1996)$ showed that three different regimes at a microgravity environment $\left(g=0.0981 \mathrm{~m} / \mathrm{s}^{2}\right.$; on average) might be identified: (1) a surface tension dominated regime with bubbly and slug flow, (2) an inertia dominated regime with annular flow and (3) a transitional regime in between with frothy slug-annular flow. Then, the boundary between the regimes was determined by the Weber number $\left(W e_{g}\right)$ that was based on gas properties and gas superficial velocity. Roughly, the surface tension dominated regime (regime 1) was delimited by $W e_{g}<1$ and the inertial regime (regime 2) was delimited by $W e_{g}>20$. Rezkallah (1996) mentioned that the experimental data could be better predicted using the mapping coordinates; $W e_{g}$, and $W e_{l}$ that were based on the actual gas and liquid velocities rather than the superficial ones. The transition from bubble/slug type flows to transitional flow was shown to occur at a constant value of $W e_{g}$ (based on the actual gas velocity) of about 2 , while the transition from frothy slug-annular type flows to fully-developed annular flow was shown to take place at $W e_{g}=20$.

In addition, Akbar et al. (2003) found an important resemblance between two-phase flow in microchannels and in common large channels at microgravity. In both system types the surface tension, inertia, and the viscosity are important factors, while buoyancy is suppressed. As a result, the researchers used for microchannels two-phase flow regime maps that had previously been developed for microgravity with the mapping coordinates; $W e_{g}$, and $W e l$ that were based on the superficial gas and liquid velocities.

The Weber number $(W e)$ can be related to the Reynolds number $(R e)$, Eötvös number $(E o)$, and Morton Number $(\mathrm{Mo})$ as:

$$
W e=\operatorname{Re}^{2}\left(\frac{M o}{E o}\right)^{-0.5}
$$

Also, the Weber number (We) can be expressed by using a combination of the Froude number $(F r)$, Morton number $(M o)$, and Reynolds number $(R e)$ as:

$$
W e=\left(F r M o \operatorname{Re}^{4}\right)^{1 / 3}
$$

In addition, the Weber number (We) can be expressed by using a combination of the Capillary number $(C a)$, and Reynolds number $(R e)$ as (Sobieszuk et al., 2010): 


$$
W e=C a \operatorname{Re}
$$

From Eq. (106), it is clear that the $C a / R e$ number can be expressed as:

$$
\frac{C a}{\operatorname{Re}}=L a^{-1}=S u^{-1}=\frac{W e / \operatorname{Re}}{\operatorname{Re}}=\frac{W e}{\operatorname{Re}^{2}}
$$

It should be noted that the length scale of the dispersed phase (bubble diameter) can be used as the characteristic length instead of the pipe diameter $(d)$ in these dimensionless groups depending on the specific application.

\section{Two-Phase Flow Frictional Multiplier}

The two-phase flow frictional multiplier is defined as the ratio of the two-phase flow frictional pressure gradient to some reference single-phase flow frictional pressure gradient, usually based on one of the components flowing by itself. The reference phase can be either the liquid phase pressure gradient that results in $\phi t^{2}$ or the gas phase pressure gradient that results in $\phi_{s}^{2}$.

In some models, the reference pressure gradient is based on the total mass flow as either a liquid or gas. If the reference phase pressure gradient is based on the liquid phase properties and the total mass flow, this results in $\phi_{t^{2}}$ or if the reference phase pressure gradient is based on the gas phase properties and the total mass flow, this results in $\phi_{80}{ }^{2}$. The definitions of different two-phase frictional multipliers will be presented later in Table 4.

Finally, the Lockhart-Martinelli parameter $(X)$ is defined as:

$$
X=\frac{\phi_{g}}{\phi_{l}}
$$

From Eq. (108), it should be noted that $\phi_{s}=\phi x$ when $X=1$ although some correlations available in the literature such as Goto et al. correlation (2001) of their obtained data for all kinds of the refrigerant and the tube during the evaporation and the condensation do not satisfy this condition (Awad, 2007b).

For the definition of two-phase frictional multipliers and Lockhart-Martinelli parameter $(X)$ in liquid-liquid flow, the liquid with higher density is used similar to the liquid phase in gas-liquid two-phase flow while the liquid with lower density is used similar to the gas phase in gas-liquid two-phase flow (Awad and Butt (2009a)).

Muzychka and Awad (2010) mentioned that the Lockhart-Martinelli parameter $(X)$ can be viewed as a reference scale that defines the extent to which the two-phase flow frictional pressure drop is characterized, i.e. dominated by liquid phase or dominated by gas phase:

$$
\begin{array}{cc}
X \ll 1 & \text { Gas Flow } \\
X \approx 1 & \text { Two-Phase Flow } \\
X>1 & \text { Liquid Flow }
\end{array}
$$


The Lockhart-Martinelli parameter for turbulent-turbulent flow $\left(X_{t t}\right)$ can be related to the Convection number $(\mathrm{Co})$ as:

$$
X_{t t}=\operatorname{Co}\left(\frac{\mu_{l}}{\mu_{g}}\right)^{0.125}
$$

From Eq. (110), it should be noted that the Lockhart-Martinelli parameter for turbulentturbulent flow $\left(X_{t t}\right)$ is equal to the Convection number $(\mathrm{Co})$ at the critical state.

The modified Lockhart-Martinelli parameter $\left(X^{*}\right)$ is defined as:

$$
\begin{gathered}
X^{*}=\sqrt{\frac{\rho_{g}}{\rho_{l}}} \frac{\dot{m}_{l}}{m_{g}}=\sqrt{\frac{\rho_{l}}{\rho_{g}}} \frac{U_{l}}{U_{g}}=\frac{F r_{l}}{F r_{g}} \\
F r_{l}=\sqrt{\frac{\rho_{l} U_{l}^{2}}{\left(\rho_{l}-\rho_{g}\right) g d \cos \theta}} \\
F r_{g}=\sqrt{\frac{\rho_{g} U_{g}^{2}}{\left(\rho_{l}-\rho_{g}\right) g d \cos \theta}}
\end{gathered}
$$

For example, Al-Sarkhi et al. (2012) studied inclination effects on wave characteristics in annular gas-liquid flows. The researchers proposed correlations for wave celerity, frequency, and liquid film Reynolds number as a function of the modified LockhartMartinelli parameter $\left(X^{*}\right)$.

\section{Two-Phase Heat Transfer Multiplier (E)}

The two-phase heat transfer multiplier $(E)$ is defined as follows:

$$
E=\frac{h_{t p, r, o}}{h_{1, r, o}}
$$

And represents the ratio of two-phase heat transfer coefficient of refrigerant-oil mixture to liquid-phase heat transfer coefficient of refrigerant-oil mixture. It is defined to quantify and analyze the oil influence on two-phase heat transfer performance.

Besides the two-phase heat transfer multiplier $(E)$, there is also the enhanced factor $(E F)$. It is defined as:

$$
\mathrm{EF}=\frac{\mathrm{h}_{\mathrm{tp}, \mathrm{r}, \mathrm{o}}}{\mathrm{h}_{\mathrm{tp}, \mathrm{r}}}
$$


And represents the ratio of heat transfer coefficient of refrigerant-oil mixture to that of pure refrigerant. It is generally used to address oil effect on heat transfer.

Wei et al. (2007) mentioned that the measured data of heat transfer coefficient of refrigerantoil mixtures can be normalized by using (a) the two-phase heat transfer coefficient of pure refrigerant, and (b) the liquid-phase heat transfer coefficient of refrigerant-oil mixture.

For more dimensionless groups, the reader can see (Catchpole and Fulford, 1966) and (Fulford and Catchpole, 1968). In the first paper, Catchpole and Fulford (1966) compiled 210 dimensionless groups. Their constituent variables provided guide for solution of design and development problems where dimensional analysis was utilized as practical tool. In the second paper, Fulford and Catchpole (1968) compiled and tabulated 75 dimensionless groups, published in literature since authors' extensive compilation in March 1966, for interpolation into previous listing. The researchers gave table of alphabetical list of new groups with serial No., name, symbol, definition, significance, field of use, and reference. Also, they gave tables for identifying dimensionless groups with parameter, symbol, dimensions, exponent and groups.

\subsection{Scale analysis}

Scale analysis is the art of examining the magnitude order of terms appearing in the governing equations. The objective of scale analysis is to use the basic principles in order to produce the magnitude order. For example, in two-phase flow, Kandlikar (2010a) presented a scaling analysis to identify the relative effects of various forces on the boiling process at microscale. There were five major forces that come into play. There were inertia, surface tension, shear, gravity, and evaporation momentum forces. Also, Kandlikar (2010b) applied scale analysis to identify the relevant forces leading to the critical heat flux (CHF) condition during saturated flow boiling in microchannels and minichannels. Using these forces (the evaporation momentum, surface tension, shear, inertia, and gravity forces), the researcher developed a local parameter model to predict the flow boiling $\mathrm{CHF}$.

\section{Flow patterns in two-phase flow}

Flow patterns in two-phase flow depend on different flow parameters, including the physical properties of fluids (the density of the gas and liquid phases ( $\rho_{g}$ and $\rho$ ), the viscosity of the gas and liquid phases $\left(\mu_{g}\right.$ and $\left.\mu l\right)$, and the surface tension $\left.(\sigma)\right)$, the flow rate of the gas and liquid phases $\left(\dot{Q}_{g}\right.$ and $\left.\dot{Q}_{l}\right)$, as well as the geometrical dimensions of the flow system. For example, Weisman et al. (1979) obtained extensive new data on the transitions between two-phase flow patterns during co-current gas liquid flow in horizontal lines. The researchers varied fluid properties in a systematic manner to determine the effects of liquid viscosity, liquid density, interfacial tension and gas density. Line sizes varied from 1.2 to 5 $\mathrm{cm}$ for most of the tests. They supplemented visual observations by an analysis of pressure drop fluctuations and hence their present data were believed to be less subjective than most past observations. They compared the transition data from their present tests, as well as 
available literature data, to the most frequently used transition line correlations. In almost all cases serious deficiencies were observed. Revised dimensionless correlations that fit their present data, and those previously available, were presented.

Physically, the formation of specific flow patterns is governed by the competition of different forces in the system such as inertia, viscous, gravitational, and surface tension forces. Flow patterns in two-phase flow at both horizontal and vertical orientations are discussed below.

\section{Flow pattern maps}

Flow pattern maps are an attempt, on a two-dimensional graph, to separate the space into areas corresponding to the different flow patterns. Simple flow pattern maps use the same axes for all flow patterns and transitions while complex flow pattern maps use different axes for different transitions. Flow pattern maps exist for both horizontal and vertical flow.

\subsection{Flow pattern map in a horizontal two-phase flow}

Flow Patterns maps are constructed of liquid superficial velocity $\left(U_{l}\right)$ versus gas superficial velocity $\left(U_{g}\right)$. In these maps, experimentally determined flow patterns are plotted with different markers, and the boundaries, i.e., the transitions of one flow pattern to the other, are plotted by lines. Which flow pattern actually occurs in a system depends on many factors such as the gas and liquid properties $\left(\rho_{g}, \mu_{g}, \rho, \mu l, \sigma\right)$, pipe geometry (at least $d$ ) and gas and liquid superficial velocities $\left(U_{g}, U_{l}\right)$. The number of relevant dimensionless groups is large, and most experimental flow maps in the literature are applicable only to the specific systems in which they were obtained. Most of the transitions depend on a disturbance to grow, and the amplitude of the disturbances introduced has a profound influence on the flow map.

The Baker map is an example of flow pattern map for horizontal flow in a pipe. Figure 1 shows Baker flow pattern map for horizontal flow in a pipe. This map was first suggested by Baker (1954), and was subsequently modified by Scott (1964). The axes are defined in terms of $G_{g} / \lambda$ and $G l \psi$, where

$$
\begin{gathered}
G_{g}=\frac{\dot{m}_{g}}{A} \\
G_{l}=\frac{\dot{m}_{l}}{A} \\
\lambda=\left(\frac{\rho_{g}}{\rho_{\text {air }}} \frac{\rho_{l}}{\rho_{\text {water }}}\right)^{\frac{1}{2}}
\end{gathered}
$$




$$
\psi=\frac{\sigma_{\text {water }}}{\sigma}\left(\frac{\mu_{l}}{\mu_{\text {water }}}\left[\frac{\rho_{\text {water }}}{\rho_{l}}\right]^{2}\right)^{\frac{1}{3}}
$$

The dimensionless parameters $\lambda$ and $\psi$, were introduced to account for variations in the density, surface tension, and dynamic viscosity of the flowing media. These parameters are functions of the fluid properties normalized with respect to the properties of water and air at standard conditions. Both $\lambda$ and $\psi$ reduce to 1 for water/air mixtures at standard conditions. The Baker map is reasonably well for water/air and oil/gas mixtures in small diameter $(<0.05 \mathrm{~m})$ pipes.

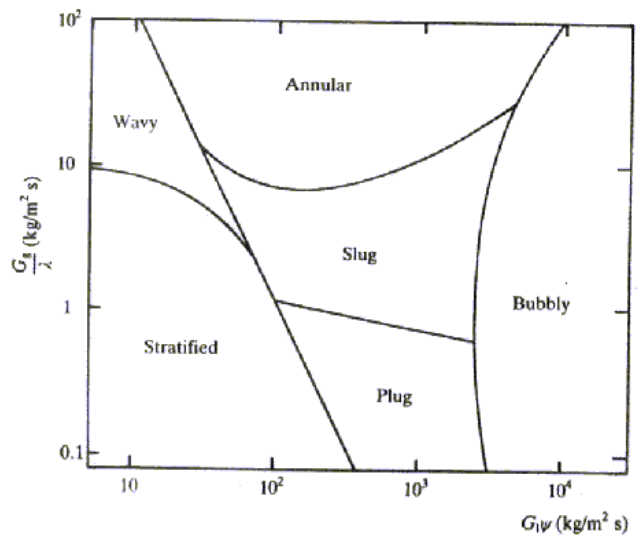

Figure 1. Baker Flow Pattern Map for Horizontal Flow in a Pipe (Whalley, 1987).

The Taitel and Dukler (1976) map is the most widely used flow pattern map for horizontal two-phase flow. This map is based on a semi-theoretical method, and it is computationally more difficult to use than other flow maps. The horizontal coordinate of the Taitel and Dukler (1976) map is the Lockhart-Martinelli parameter (X), Eq. (108). The vertical coordinates of the Taitel and Dukler (1976) map are $K$ on the left hand side and $T$ or $F$ on the right hand side. They are defined as follows:

$$
\begin{gathered}
F=\sqrt{\frac{\rho_{g}}{\rho_{l}-\rho_{g}}} \frac{U_{g}}{\sqrt{d g \cos \theta}} \\
K=\left[\frac{\rho_{g} U_{g}^{2}}{\left(\rho_{l}-\rho_{g}\right) d g \cos \theta} \frac{d U_{l}}{v_{l}}\right]^{1 / 2} \\
T=\left[\frac{(d p / d z)_{f, l}}{\left(\rho_{l}-\rho_{g}\right) g \cos \theta}\right]^{1 / 2}
\end{gathered}
$$


It should be noted that determination of the flow regime using Taitel and Dukler's (1976) map requires $(d p / d z)_{f, l}$ and $(d p / d z)_{f, g}$ that should be determined using appropriate flow models. Taitel and Dukler (1976) concluded that the different transitions were controlled by the grouping tabulated below:

i. $\quad$ Stratified to annular $-X, F$.

ii. Stratified to intermittent $-X, F$.

iii. Intermittent to bubble $-X, T$.

iv. Stratified smooth to Stratified wavy $-X, K$.

It should be noted that the Taitel and Dukler (1976) map was obtained for adiabatic twophase flow; however, the transition boundaries between various flow regimes depend on the heat flux. Nevertheless, this flow map is often used to determine the flow patterns for evaporation and condensation inside pipes, for which external heating or cooling is required. As with any extrapolation, application of this flow map to forced convective boiling or condensation inside a pipe may not yield reliable results. Taitel (1990) presented a good review about flow pattern transition in two-phase flow.

\subsection{Flow pattern map in a vertical two-phase flow}

The Hewitt and Roberts (1969) map is an example of flow pattern map for vertical flow in a pipe. Figure 2 shows Hewitt and Roberts flow pattern map for vertical upflow in a pipe. Since the axes are defined in terms of $G_{g} / \rho_{g}$ and $G_{l} / \rho l$ (phase momentum flux). So all the transitions are assumed to depend on the phase momentum fluxes. Wispy annular flow is a sub-category of annular flow that occurs at high mass flux when the entrained drops are said to appear as wisps or elongated droplets. The Hewitt and Roberts map is reasonably well for all water/air and water/steam systems over a range of pressures in small diameter pipes. For both horizontal and vertical maps, it should be noted also that the transitions between adjacent flow patterns do not occur suddenly but over a range of flow rates. So, the lines should really be replaced by rather broad transition bands.

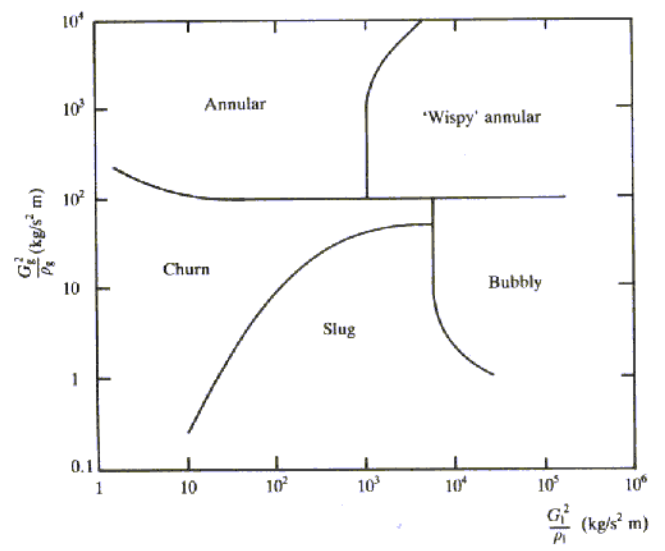

Figure 2. Hewitt and Roberts Flow Pattern Map for Vertical Upflow in a Pipe (Whalley, 1987). 


\section{Pressure drop in two-phase flow}

The pressure drop, which is the change of fluid pressure occurring as a two-phase flow passes through the system. The pressure drop is very important parameter in the design of both adiabatic systems and systems with phase change, like boilers and condensers. In natural circulation systems, the pressure drop dictates the circulation rate, and hence the other system parameters. In forced circulation systems, the pressure drop governs the pumping requirement.

In addition, the pressure drop is very important in pipelines because co-current flow of liquid and vapor (gas) create design and operational problems due to formation of different types of two-phase flow patterns. Estimation of pressure drop in these cases helps the piping designer in reaching an optimum line size and a better piping system design.

Not only accurate prediction of pressure drop is extremely important when designing both horizontal and vertical two-phase flow systems, but also it is extremely important when designing inclined two-phase flow systems like directional wells or hilly terrain pipelines. Pipe inclination has an appreciable effect on flow patterns, slippage between phases and energy transfer between phases. There is no method for performing these calculations, which is accurate for all flow conditions. Historically, pressure drop in inclined flow has often been calculated using horizontal or vertical two-phase flow correlations. This is often satisfactory if the pipe inclination is very near to the horizontal case or the vertical case. However, this may not be the case in many applications.

The total measured pressure drop in two-phase flow $(\Delta p)$ consists of three contributions. The first contribution is the frictional pressure drop $\left(\Delta p_{f}\right)$. The second contribution is the acceleration pressure drop $\left(\Delta p_{a}\right)$. The third contribution is the gravitational pressure drop $\left(\Delta p_{\text {grav }}\right)$.

$$
\Delta p=\Delta p_{f}+\Delta p_{a}+\Delta p_{\text {grav }}
$$

The acceleration pressure drop $\left(\Delta p_{a}\right)$ can be neglected in the adiabatic flow. For flow in a horizontal pipe, the gravitational pressure drop $\left(\Delta p_{\text {grav }}\right)$ is zero. Thus, the total measured pressure drop $(\Delta p)$ in the adiabatic experiments in horizontal pipes comes from the frictional pressure drop $\left(\Delta p_{f}\right)$ only. Two-phase pressure drop can be measured for gas-liquid adiabatic

flow or it can also be measured for vapor-liquid nonadiabatic, boiling or condensing flow. Laboratory measurements tend to be made with adiabatic gas-liquid flow, for instance, airwater flow, rather than vapor-liquid flow with phase change because of ease and low cost of operation.

The frictional pressure drop results from the shear stress between the flowing fluid and the pipe wall and also from the shear stress between the liquid and gas phases. To compute the frictional component of pressure drop, either the two-phase friction factor or the two-phase frictional multiplier must be known. It is necessary to know the void fraction (the ratio of gas flow rate to total flow rate) to compute the acceleration, and gravitational components of pressure drop (ASHRAE, 1993). 
The acceleration component of pressure drop $\left(\Delta p_{a}\right)$ reflects the change in kinetic energy of the flow. Assuming the vapor and liquid velocities to be uniform in each phase, the acceleration component of pressure drop can be obtained by the application of a simplified momentum equation in the form:

$$
\Delta p_{a}=G^{2}\left\{\left[\frac{\left(1-x_{o}\right)^{2}}{\rho_{l}\left(1-\alpha_{o}\right)}+\frac{x_{o}^{2}}{\rho_{g} \alpha_{o}}\right]-\left[\frac{\left(1-x_{i}\right)^{2}}{\rho_{l}\left(1-\alpha_{i}\right)}+\frac{x_{i}^{2}}{\rho_{g} \alpha_{i}}\right]\right\}
$$

The gravitational component of pressure gradient can be expressed in terms of the void fraction as follows:

$$
\left(\frac{d p}{d z}\right)_{\text {grav }}=g\left[\alpha \rho_{g}+(1-\alpha) \rho_{l}\right] \sin \theta
$$

Using Eq. (125) and knowing that $\alpha_{m}=\beta$, the gravitational component of pressure gradient based on the homogeneous model can be expressed as follows:

$$
\left(\frac{d p}{d z}\right)_{\text {grav }, m}=\frac{g \sin \theta}{\frac{x}{\rho_{g}}+\frac{1-x}{\rho_{l}}}
$$

\subsection{Two-phase frictional multiplier}

The two-phase frictional pressure drop $\left(\Delta p_{f}\right)$ can be expressed in terms of two-phase frictional multiplier. This representation method is often useful for calculation and comparison needs. For example, the two-phase frictional pressure drop $\left(\Delta p_{f}\right)$ can be expressed in terms of the single-phase frictional pressure drop for the total flow considered as liquid $\left(\Delta p_{f, l o}\right)$ using two-phase frictional multiplier for total flow assumed liquid in the pipe $\left(\phi_{0}{ }^{2}\right)$. The single-phase frictional pressure drop for the total flow considered as liquid is computed from the total mass flux $(G)$ and the physical properties of the liquid. The concept of all-liquid frictional pressure drop is useful because it allows the correlation to be tied into single-phase results at one end and eliminates any ambiguity about the physical properties to use, especially viscosity. Moreover, the all-liquid frictional pressure drop is chosen over the all-gas frictional pressure drop, because the liquid density generally does not vary in a problem, while the gas density changes with pressure. Also, the correlation of frictional pressure drop in terms of the parameter $\left(\phi t^{2}\right)$ is more convenient for boiling and condensation problems than $\left(\phi t^{2}\right)$. The parameter $\left(\phi_{x^{2}}{ }^{2}\right)$ was first introduced by Martinelli and Nelson (1948). Table 2 shows definitions of different two-phase frictional multipliers.

The relationship between two-phase frictional multiplier for all flow as liquid $\left(\phi_{t^{2}}\right)$ and twophase frictional multiplier for liquid fraction only $\left(\phi t^{2}\right)$ is:

$$
\phi_{l o}^{2}=\phi_{l}^{2}(1-x)^{2-n}
$$




\begin{tabular}{|c|c|c|c|c|}
\hline $\begin{array}{c}\text { Two-Phase Frictional } \\
\text { Multiplier }\end{array}$ & Mass Flux & Density & $\begin{array}{c}\text { Reynolds } \\
\text { Number }\end{array}$ & Symbol \\
\hline All flow as liquid & $G_{l}+G_{g}$ & $\rho_{l}$ & $\left(G_{l}+G_{g}\right) d / \mu_{l}$ & $\phi_{l l^{2}}$ \\
\hline Liquid fraction only & $G_{l}$ & $\rho_{l}$ & $G_{l} d / \mu_{l}$ & $\phi_{l}{ }^{2}$ \\
\hline Gas fraction only & $G_{g}$ & $\rho_{g}$ & $G_{g} d / \mu_{g}$ & $\phi_{g}{ }^{2}$ \\
\hline All flow as gas & $G_{l}+G_{g}$ & $\rho_{g}$ & $\left(G_{l}+G_{g}\right) d / \mu_{g}$ & $\phi_{g o}{ }^{2}$ \\
\hline
\end{tabular}

Table 2. Definitions of Different Two-Phase Frictional Multipliers.

Also, the relationship between two-phase frictional multiplier for all flow as gas $\left(\phi_{g} 0^{2}\right)$ and two-phase frictional multiplier for gas fraction only $\left(\phi_{g}{ }^{2}\right)$ is:

$$
\phi_{g o}^{2}=\phi_{g}^{2} x^{2-n}
$$

In addition, the relationship between two-phase frictional multiplier for all flow as gas $\left(\phi_{80}{ }^{2}\right)$ and two-phase frictional multiplier for all flow as liquid $\left(\phi t^{2}\right)$ can be obtained using Eqs. (108), (127), and (128) as follows:

$$
\phi_{g o}^{2}=\phi_{l o}^{2} X^{2}\left(\frac{x}{1-x}\right)^{2-n}
$$

In Eqs. (127-129), $n=1$ for laminar-laminar flow while $n=0.25$ for turbulent-turbulent flow.

Moreover, the relationship between two-phase frictional multiplier for all flow as liquid $\left(\phi_{l 0}{ }^{2}\right)$ and two-phase frictional multiplier for all flow as gas $\left(\phi_{g 0^{2}}\right)$ can be related to physical property coefficient $(I)$ introduced by Chisholm (1973) as follows:

$$
\frac{\phi_{l o}^{2}}{\phi_{g o}^{2}}=\frac{\Delta p_{f, g o}}{\Delta p_{f, l o}}=\Gamma^{2}
$$

\subsection{Some forms of dimensionless two-phase frictional pressure drop $\left(\Delta p_{f}^{*}\right)$}

Keilin et al. (1969) expressed two-phase frictional pressure drop $\left(\Delta p_{f}\right)$ in a dimensionless form as follows:

$$
\Delta p_{f}^{*}=\frac{\Delta p_{f}}{x \Delta p_{f, g o}+(1-x) \Delta p_{f, l o}}
$$

The above expression satisfies the following limiting conditions:

$$
\text { at } x=0, D p_{f}=D p_{f, l o} \text { and } D p_{f}^{*}=0 ; \quad \text { at } x=1, D p_{f}=D p_{f, g o} \text { and } D p_{f}^{*}=1 \text {; }
$$

The dimensionless two-phase frictional pressure drop $\left(\Delta p_{f}^{*}\right)$ can be expressed as a function of two-phase frictional multipliers as follows: 


$$
\Delta p_{f}^{*}=\frac{\phi_{l o}^{2}}{1-x+x\left(\phi_{l o}^{2} / \phi_{g o}^{2}\right)}
$$

For turbulent-turbulent flow, and using the Blasius equation (1913) to define the friction factor, Eq. (133) can be expressed as follows:

$$
\Delta p_{f}^{*}=\frac{\left[1-x+x\left(\frac{\rho_{l}}{\rho_{g}}\right)\right]\left[1-x+x\left(\frac{\mu_{l}}{\mu_{g}}\right)\right]^{-0.25}}{1-x+x\left(\frac{\rho_{l}}{\rho_{g}}\right)\left(\frac{\mu_{g}}{\mu_{l}}\right)^{0.25}}
$$

Borishansky et al. (1973) expressed two-phase frictional pressure drop $\left(\Delta p_{f}\right)$ in a dimensionless form as follows:

$$
\Delta p_{f}^{*}=\frac{\Delta p_{f}-\Delta p_{f, l o}}{\Delta p_{f, g o}-\Delta p_{f, l o}}
$$

The above expression satisfies the following limiting conditions:

$$
\text { at } \mathrm{x}=0, D p_{f}=D p_{f, l o} \text { and } D p_{f}^{*}=0 ; \quad \text { at } x=1, D p_{f}=D p_{f, g o} \text { and } D p_{f}^{*}=1 \text {; }
$$

The dimensionless two-phase frictional pressure drop $\left(\Delta p_{f}^{*}\right)$ can be expressed as a function of two-phase frictional multipliers as follows:

$$
\Delta p_{f}^{*}=\frac{\phi_{l o}^{2}-1}{\left(\phi_{l o}^{2} / \phi_{g o}^{2}\right)-1}
$$

For turbulent-turbulent flow, and using the Blasius equation (1913) to define the friction factor, Eq. (137) can be expressed as follows:

$$
\Delta p_{f}^{*}=\frac{\left[1-x+x\left(\frac{\rho_{l}}{\rho_{g}}\right)\right]\left[1-x+x\left(\frac{\mu_{l}}{\mu_{g}}\right)\right]^{-0.25}-1}{\left(\frac{\rho_{l}}{\rho_{g}}\right)\left(\frac{\mu_{g}}{\mu_{l}}\right)^{0.25}-1}
$$

\section{Methods of analysis}

Two-phase flows obey all of the basic equations of fluid mechanics (continuity equation, momentum equation, and energy equation). However, the equations for two-phase flows are more complicated than those of single-phase flows. The techniques for analyzing onedimensional two-phase flows include correlations, the phenomenological models, simple 
analytical model, and other methods such as integral analysis, differential analysis, computational fluid dynamics (CFD), and artificial neural network (ANN).

\subsection{Correlations}

The basic procedure used in predicting the frictional pressure drop in two-phase flow is developing a general correlation based on statistical evaluation of the data. The main disadvantage of this procedure is the difficulty in deciding on a method of properly weighing the fit in each flow pattern. For example, it is difficult to decide whether a correlation giving a poor fit with stratified flow and a good fit with annular flow is a better correlation than one giving a fair fit for both kinds of flow. Although the researchers that deal with two-phase flow problems still continue to use general correlations, alternate procedures must be developed to improve the ability to predict the pressure drop. In addition, correlations fitted to data banks that contain measurements with a number of liquid-gas combinations for different flow conditions and pipe diameters often have the disadvantage of containing a large number of constants and of being inconvenient in use. The correlation developed by Bandel (1973), is an example of this type of correlations.

The prediction of frictional pressure drop in two-phase flow can also be achieved by empirical correlations. Correlating the experimental data in terms of chosen variables is a convenient way of obtaining design equations with a minimum of analytical work. There are a considerable number of empirical correlations for the prediction of frictional pressure drop in two-phase flow. Although the empirical correlations require a minimum of knowledge of the system characteristics, they are limited by the range of data available for correlation construction. Most of these empirical correlations can be used beyond the range of the data from that they were constructed but with poor reliability (Dukler et al., 1964). Also, deviations of several hundred percent between predicted and measured values may be found for conditions outside the range of the original data from that these correlations were derived (Dukler et al., 1964).

The prediction of void fraction in two-phase flow can also be achieved by empirical correlations. There are a considerable number of empirical correlations for the prediction of void fraction. The empirical correlations are usually presented in terms of the slip ratio $(S)$.

\subsection{Phenomenological models}

The phenomenological models can be developed based on the interfacial structure. Including phenomenon specific information like interfacial shear stress and slug frequency is used to obtain a complete picture of the flow. To reduce the dependence on empirical data, modeling on a theoretical basis is used. However, some empiricism is still required. The prediction of pressure gradient, void fraction, and the heat transfer coefficient simultaneously means that the phenomenological model is now preferred. For design purposes, the phenomenological models are often brought together within a framework provided by a flow pattern map such as Taitel, and Dukler (1976) flow pattern map. These flow pattern-based phenomenological models take into consideration the interfacial 
structure and the phase velocity distribution for every individual two-phase flow pattern. Quiben and Thome (2007) mentioned that the flow pattern-based phenomenological models are able to provide a more accurate prediction of the frictional pressure drop than the homogeneous and separated flow models. For example, the researchers developed an empirical correlation for the interfacial friction factor $\left(f_{i}\right)$ in annular flow by considering the effects of the liquid film thickness, interfacial wave, viscosity ratio of the gas and liquid phases and the liquid inertia. Their correlation was

$$
f_{i}=0.67\left(\frac{\delta}{d}\right)^{1.2}\left[\frac{\left(\rho_{l}-\rho_{g}\right) g \delta^{2}}{\sigma}\right]^{-1.4}\left(\frac{\mu_{g}}{\mu_{l}}\right)^{0.08}\left(\frac{\rho_{l} U_{l}^{2} d}{\sigma}\right)^{-0.034}
$$

In Eq. (139), the expression $\left(\left(\rho-\rho_{8}\right) g \delta / \sigma\right)$ came from manipulation of the Helmholtz instability equation using $\delta$ as the scaling factor for the most dangerous wavelength for the formation of interfacial waves. The Quiben and Thome (2007) model predicted a maximum in the frictional pressure drop but no explicit value of $x_{\operatorname{maz}}$ was proposed. According to their theory, the maximum occurred either in the annular flow regime or at the annular-to-dryout transition or at the annular-to-mist flow transition depending on the conditions.

Recently, Revellin and Haberschill (2009) presented an alternative approach for the prediction of frictional pressure drop during flow boiling of refrigerants in horizontal tubes over the entire range of vapor quality. The researchers developed an explicit expression (never proposed before) for the vapor quality corresponding to the maximum pressure drop $\left(x_{\text {maz }}\right)$. This maximum was obtained by a flow regime analysis. Based on this maximum and on the pressure drop for liquid and vapor, they developed a simple linear function for predicting the frictional pressure drop. They mentioned that their method presented the best accuracy and predicts almost $86 \%$ of the data within a $\pm 30 \%$ error band. Their method did not include any new empirical parameters and could be used for a wide range of experimental conditions. Furthermore, the experimental data were also segregated into flow regimes and compared to every individual prediction method. The linear approach presented the best statistics for every flow regime.

For two-phase flow in microchannels, phenomenological models were developed primarily for the slug and annular flow patterns due to their dominance on the two-phase flow maps as well as their direct engineering relevance (Kreutzer et al., 2005a, Gunther and Jensen, 2006, Angeli, and Gavriilidis, 2008). For example, Kreutzer et al. (2005b) developed a phenomenological model for pressure drop in gas-liquid plug flow that includes the effects of plug length $\left(L_{s}\right)$, Reynolds number $(R e)$ and Capillary number $(C a)$. Later, Walsh et al. (2009) improved this model by considering additional data and the data of Kreutzer et al. (2005b). The proposed model of Walsh et al. (2009) is the asymptotic superposition of singlephase Poiseuille flow and an empirically derived result for Taylor flow. Their model takes the form:

$$
f \operatorname{Re}=16+\frac{1.92}{L^{*}}\left(\frac{\operatorname{Re}}{C a}\right)^{0.33}
$$


Where $L^{*}=L_{s} / d$ is the dimensionless liquid plug length and the Reynolds number $(R e)$ is computed based on the velocity and properties of the liquid slug. The transition from Taylor flow to Poiseuille flow occurs when:

$$
L^{*}\left(\frac{C a}{\operatorname{Re}}\right)^{0.33}>1
$$

Below this critical value, significant contribution to the total pressure drop occurs due to the Laplace pressure contributions from the bubble train.

Walsh et al. (2009) mentioned that their plug flow model was found to have accuracy of $4.4 \% \mathrm{rms}$ when compared with the data.

As shown in Fig. 3, the author suggests that the plug flow model of Walsh et al. (2009), Eq. (140), can be extended in order to calculate total pressure drop in two phase slug/bubble flows in mini scale capillaries for non-circular shapes as follows:

$$
f \operatorname{Re}=\left\{\begin{array}{lc}
16\left[1+\frac{0.12}{L^{*}}\left(\frac{\mathrm{Re}}{\mathrm{Ca}}\right)^{0.33}\right] & \text { circular } \\
24\left[1+\frac{0.12}{L^{*}}\left(\frac{\mathrm{Re}}{\mathrm{Ca}}\right)^{0.33}\right] & \text { parallel plates } \\
14.23\left[1+\frac{0.12}{L^{*}}\left(\frac{\mathrm{Re}}{\mathrm{Ca}}\right)^{0.33}\right] & \text { square }
\end{array}\right.
$$

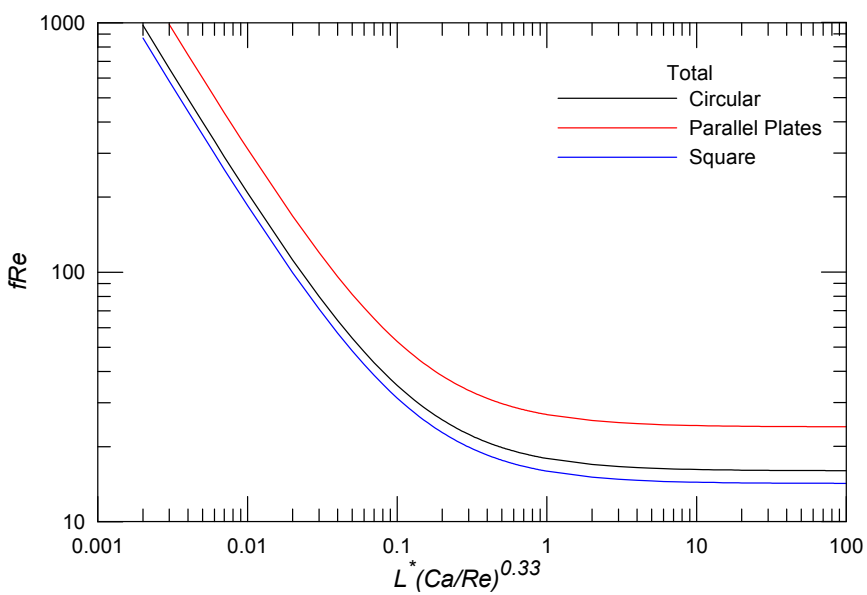

Figure 3. The Extension of the Plug Flow Model of Walsh et al. (2009), Eq. (140), for Total Pressure Drop in Two Phase Slug/Bubble Flows in Mini Scale Capillaries for Different Shapes (Circular, Parallel Plates, Square). 
Moreover, instead of 16, 24, and 14.23 for circular, parallel plates, and square, respectively, the Shah and London (1978) relation for $(f R e)$ for laminar flow forced convection in rectangular ducts as a function of the aspect ratio $(A R)$ :

$$
\mathrm{fRe}=24\left(1-1.3553 A \mathrm{R}+1.9467 A \mathrm{R}^{2}-1.7012 A \mathrm{R}^{3}+0.9564 A \mathrm{R}^{4}-0.2537 A \mathrm{R}^{5}\right)
$$

Equation (142) still needs verifications using experimental/numerical data to check if the constant multiplied by term $(\mathrm{Re} / \mathrm{Ca})^{0.33} / \mathrm{L}^{*}$ is 0.12 or not for non-circular shapes. Dividing both sides of Eq. (142) by the Poiseuille flow limit, which is 16, 24, and 14.23 for circular, parallel plates, and square, respectively, we obtain

$$
\frac{f \operatorname{Re}}{f \operatorname{Re}_{\text {Poise }}}=\left\{\begin{array}{lc}
1+\frac{0.12}{L^{*}}\left(\frac{\mathrm{Re}}{C a}\right)^{0.33} & \text { circular } \\
1+\frac{0.12}{L^{*}}\left(\frac{\mathrm{Re}}{C a}\right)^{0.33} & \text { parallel plates } \\
1+\frac{0.12}{L^{*}}\left(\frac{\mathrm{Re}}{C a}\right)^{0.33} & \text { square }
\end{array}\right.
$$

It is clear from Eq. (144) that the normalized variable (fRe/fRepoise) has the same value for different shapes such as circular, parallel plates, and square.

Recently, Talimi et al. (2012) reviewed numerical studies on the hydrodynamic and heat transfer characteristics of two-phase flows in small tubes and channels. These flows were non-boiling gas-liquid and liquid-liquid slug flows. Their review began with some general notes and important details of numerical simulation setups. Then, they categorized the review into two groups of studies: circular and non-circular channels. Various aspects like slug formation, slug shape, flow pattern, pressure drop and heat transfer were of interest.

The prediction of void fraction in two-phase flow can also be achieved by using models for specific flow regimes. The Taitel and Dukler (1976) model is an example for this type of model.

It should be noted that the precision and accuracy of phenomenological models are equal to those of empirical methods, while the probability density function is less sensitive to changes in fluid system (Tribbe and Müller-Steinhagen, 2000).

\subsection{Simple analytical models}

Simple analytical models are quite successful method for organizing the experimental results and for predicting the design parameters. Simple analytical models take no account of the details of the flow. Examples of simple analytical models include the homogeneous flow model, the separated flow model, and the drift flux model.

\subsubsection{The homogeneous flow model}

The homogeneous flow model provides the simplest technique for analyzing two-phase (or multiphase) flows. In the homogeneous model, both liquid and vapor phases move at the 
same velocity (slip ratio $=1$ ). Consequently, the homogeneous model has also been called the zero slip model. The homogeneous model considers the two-phase flow as a singlephase flow having average fluid properties depending on quality. Thus, the frictional pressure drop is calculated by assuming a constant friction coefficient between the inlet and outlet sections of the pipe.

Using the homogeneous modeling approach, the frictional pressure gradient can be calculated using formulas from single-phase flow theory using mixture properties $\left(\rho_{m}\right.$ and $\left.\mu_{m}\right)$. For flow in pipes and channels, it can be obtained using the familiar equations:

$$
f=\left(\frac{d}{2 \rho U^{2}}\right)\left(\frac{d p}{d z}\right)_{f}
$$

\subsubsection{Simple friction models}

Since the homogeneous flow model is founded on using single-phase flow models with appropriate mixture models for $\rho_{m}$ and $\mu_{m}$, some useful results for laminar, turbulent, and transition flows in circular and non-circular shapes are provided. The models given below are for the Fanning friction factor that is related to the Darcy friction factor by means of $f=f_{D} / 4$.

\subsection{Hagen-Poiseuille model}

For Redh < 2300, the Hagen-Poiseuille flow (White, 2005) gives:

$$
f \operatorname{Re}_{d_{h}}=\left\{\begin{array}{cc}
16 & \text { circular } \\
24 & \text { parallel plates } \\
14.23 & \text { square }
\end{array}\right.
$$

Moreover, instead of 16, 24, and 14.23 for circular, parallel plates, and square, respectively, Eq. (146) that represents the Shah and London (1978) relation for (fRe) for laminar flow forced convection in rectangular ducts as a function of the aspect ratio $(A R)$ can be used.

For two-phase flow, Awad and Muzychka (2007, 2010b) used the Hagen-Poiseuille flow to represent the Fanning friction factor based on laminar-laminar flow assumption.

\subsection{Blasius model}

For turbulent flow, the value of the Fanning friction factor cannot be predicted from the theory alone, but it must be determined experimentally. Dimensional analysis shows that the Fanning friction factor is a function of the Reynolds number (Redh) and relative roughness $\left(\varepsilon / d_{h}\right)$. For turbulent flow in smooth pipes, Blasius (1913) obtained the relationship between the Fanning friction factor $(f)$ and the Reynolds number (Redh) as

$$
f=\frac{0.079}{\operatorname{Re}_{d_{h}}^{0.25}} \quad 3000<\operatorname{Re}_{\mathrm{d}_{\mathrm{h}}}<100000
$$


For two-phase flow, Awad and Muzychka (2005a) used the Blasius equation to represent the Fanning friction factor for obtaining the lower bound of two-phase frictional pressure gradient based on turbulent-turbulent flow assumption.

\subsection{Drew et al. model}

Drew et al. (1932) obtained a relationship between the Fanning friction factor $(f)$ and the Reynolds number (Redh) with a deviation of $\pm 5 \%$ using their own experimental data and those of other investigators on smooth pipes. Their relationship was

$$
f=0.0014+\frac{0.125}{\operatorname{Re}_{d_{h}}^{0.32}} \quad 3000<\operatorname{Re}_{d_{\mathrm{h}}}<3000000
$$

\subsection{Petukhov model}

Petukhov (1970) developed a single correlation that encompassed the large Reynolds number range for friction factor in turbulent pipe flow with variable physical properties. His correlation was

$$
f=0.25\left(0.790 \ln \operatorname{Re}_{d_{h}}-2.0\right)^{-2} \quad 3000 \leq \operatorname{Re}_{\mathrm{d}_{\mathrm{h}}} \leq 5000000
$$

\subsection{Glielinski model}

Glielinski (1976) derived an equation for the calculation of heat and mass transfer coefficients in the case of pipe and channel flow, taking into account the experimental data for high Reynolds and Prandtl numbers. His equation was valid for the transition region and for the range of fully developed turbulent flows. His equation for the friction factor was:

$$
f=\frac{0.25}{(1.82 \ln \operatorname{Re}-1.64)^{2}}
$$

Also, Glielinski (1976) used his friction factor equation to calculate the Nusselt number $(\mathrm{Nu})$ as follows:

$$
N u=\frac{(\mathrm{f} / 2)(\operatorname{Re}-1000) \operatorname{Pr}}{1+12.7(\mathrm{f} / 2)^{1 / 2}\left(\operatorname{Pr}^{2 / 3}-1\right)}
$$

This heat transfer correlation was valid for $0.5<\operatorname{Pr}<10^{6}$ and $\operatorname{Re}>3000$. Later, Gnielinski (1999) provided an alternative approach to the Nusselt numbers prediction in the transition region based on a complex linear interpolation between $R e=2300$ and 10000 .

\subsection{Swamee and Jain model}

Swamee and Jain (1976) proposed an alternate form of the turbulent friction model developed by Colebrook (1939). It allows the influence of pipe or channel wall roughness to be considered. Swamee and Jain (1976) reported that it provided accuracy within $\pm 1.5 \%$ when compared with the Colebrook model. The Swamee and Jain model is: 


$$
f=\frac{1}{16\left[\log \left(\frac{\varepsilon / d_{h}}{3.7}+\frac{5.74}{\operatorname{Re}_{d_{h}}^{0.9}}\right)\right]^{2}}
$$

\subsection{Churchill model}

Since the definitive picture of the transition process and the transition mechanism are still unclear, the laminar to turbulent transition region should be considered a metastable and complicated region. The transition region is a varying mixture of various transport mechanisms and the mixed degree relies on the Reynolds number value and other conditions. In this study, Churchill (1977) developed a model to define the Fanning friction factor. In his model, he developed a correlation of the Moody chart (1944). His correlation spanned the entire range of laminar, transition, and turbulent flow in pipes. The Churchill model equations that define the Fanning friction factor were

$$
\begin{gathered}
f=2\left[\left(\frac{8}{\operatorname{Re}_{d_{h}}}\right)^{12}+\frac{1}{(a+b)^{3 / 2}}\right]^{1 / 12} \\
a=\left[2.457 \ln \frac{1}{\left(7 / \operatorname{Re}_{d_{h}}\right)^{0.9}+\left(0.27 \varepsilon / d_{h}\right)}\right]^{16} \\
b=\left(\frac{37530}{\operatorname{Re}_{d_{h}}}\right)^{16}
\end{gathered}
$$

The Churchill model can be used due to its simplicity and accuracy of prediction. It is preferable since it encompasses all Reynolds numbers and includes roughness effects in the turbulent regime. Also, when a computer is used, the Churchill model equations are more recommended than the Blasius equations to define the Fanning friction factor (Chisholm, 1983). The Churchill model may be extended to non-circular shapes, by introducing the more general Poiseuille constant $(P o)$. The factor of eight appearing above in Eq. (153) can be replaced by $f \operatorname{Re} h / 2$.

For two-phase flow, Awad and Muzychka (2004a) presented a simple two-phase frictional multiplier calculation method using the Churchill model to define the Fanning friction factor to take into account the effect of the mass flux on $\phi w^{2}$. Also, Awad and Muzychka (2004b) used the Churchill model to calculate the single-phase friction factors $\left(f_{l}\right.$ and $\left.f_{8}\right)$. These friction factors were used to calculate single-phase frictional pressure gradients for liquid and gas flowing alone. Two-phase frictional pressure gradient was then expressed using a nonlinear superposition of the asymptotic single-phase frictional pressure gradients for liquid and gas flowing alone. Moreover, Awad and Muzychka (2008, 2010b) calculated 
the friction factor for the case of minichannels and microchannels using the Churchill model to allow for prediction over the full range of laminar-transition-turbulent regions.

\subsection{Phillips model}

Phillips (1987) was not aware of published results of the developing turbulent flow average friction factor for $x / d_{h}>20$. Therefore, he decided to re-integrate the curves of the local friction factor. He obtained the following equation for the average turbulent friction factor:

$$
\begin{gathered}
f=A \operatorname{Re}^{B} \\
A=0.09290+\frac{1.01612}{x / d_{h}} \\
B=-0.26800-\frac{0.31930}{x / d_{h}}
\end{gathered}
$$

Equation (156) applies for circular pipes. In order to obtain the friction factor for rectangular ducts, $R e$ is replaced by $R e^{*}$ as follows:

$$
\begin{gathered}
\operatorname{Re}^{*}=\frac{\rho U d_{e l}}{\mu} \\
d_{e l}=\left[\left(\frac{2}{3}\right)+\left(\frac{11}{24 A R}\right)\left(2-\frac{1}{A R}\right)\right] d_{h}
\end{gathered}
$$

Recently, Ong and Thome (2011) found that the single-phase friction factor for turbulent flow in small horizontal circular channels compared well with the correlation by Philips (1987).

\subsection{García et al. model}

García et al. (2003) took data from 2435 gas-liquid flow experiments in horizontal pipelines, including new data for heavy oil. The definition of the Fanning friction factor for gas-liquid flow used in their study is based on the mixture velocity and density. Their universal (independent of flow type) composite (for all Reynolds number) correlation for gas-liquid Fanning friction factor (FFUC) was

$$
\begin{gathered}
f_{m}=0.0925 \operatorname{Re}_{m}^{-0.2534}+\frac{13.98 \operatorname{Re}_{m}^{-0.9501}-0.0925 \operatorname{Re}_{m}^{-0.2534}}{\left(1+\left(\frac{\operatorname{Re}_{m}}{293}\right)^{4.864}\right)^{0.1972}} \\
\operatorname{Re}_{m}=\frac{U_{m} d}{v_{l}}
\end{gathered}
$$




$$
U_{m}=U_{l}+U_{g}
$$

The standard deviation of the correlated friction factor from the measured value was estimated to be $29.05 \%$ of the measured value. They claimed that the above correlation was a best guess for the pressure gradient when the flow type was unknown or different flow types were encountered in one line.

It should be noted that García et al. (2003) definition of the mixture Reynolds number is not suitable at high values of the dryness fraction. For example, for single-phase gas flow of airwater mixture at atmospheric conditions, García et al. (2003) definition gives $R_{m}=14.9 R e_{8}$ instead of $R e_{m}=R e_{g}$.

\subsection{Fang et al. model}

Fang et al. (2011) evaluated the existing single-phase friction factor correlations. Also, the researchers obtained new correlations of single-phase friction factor for turbulent pipe flow. For turbulent flow in smooth pipes, they proposed the following correlation:

$$
f=0.0625\left[\log \left(\frac{150.39}{\operatorname{Re}^{0.98865}}-\frac{152.66}{\operatorname{Re}}\right)\right]^{-2}
$$

In the range of $R e=3000-10^{8}$, their new correlation had the mean absolute relative error (MARE) of $0.022 \%$. For turbulent flow in both smooth and rough pipes, they proposed the following correlation:

$$
\mathrm{f}=0.4325\left[\ln \left(0.234 \varepsilon^{1.1007}-\frac{60.525}{\operatorname{Re}^{1.1105}}+\frac{56.291}{\operatorname{Re}^{1.0712}}\right)\right]^{-2}
$$

In the range of $R e=3000-108$ and $\varepsilon=0.0-0.05$, the new correlation had the MARE of $0.16 \%$.

\subsubsection{Effective density models}

For the homogeneous model, the density of two-phase gas-liquid flow $\left(\rho_{m}\right)$ can be expressed as follows:

$$
\rho_{m}=\left(\frac{x}{\rho_{g}}+\frac{1-x}{\rho_{l}}\right)^{-1}
$$

Equation (166) can be derived knowing that the density is equal to the reciprocal of the specific volume and using thermodynamics relationship for the specific volume

$$
v_{m}=(1-x) v_{l}+x v_{g}
$$

Equation (166) can also be obtained based on the volume averaged value as follows:

$$
\rho_{m}=\alpha_{m} \rho_{g}+\left(1-\alpha_{m}\right) \rho_{l}=\left(\frac{x}{\rho_{g}}+\frac{1-x}{\rho_{l}}\right)^{-1}
$$


Equation (166) satisfies the following limiting conditions between $\left(\rho_{n}\right)$ and mass quality $(x)$ :

$$
\left.\begin{array}{ll}
x=0, & \rho_{m}=\rho_{l} \\
x=1, & \rho_{m}=\rho_{g}
\end{array}\right\}
$$

There are other definitions of two-phase density $\left(\rho_{m}\right)$. For example, Dukler et al. (1964) defined two-phase density $\left(\rho_{m}\right)$ as follows:

$$
\rho_{m}=\rho_{l} \frac{\left(1-\alpha_{m}\right)^{2}}{H_{l}} \alpha_{m}+\rho_{g} \frac{\alpha_{m}^{2}}{1-H_{l}}
$$

Also, Oliemans (1976) defined two-phase density $\left(\rho_{m}\right)$ as follows:

$$
\rho_{m}=\frac{\rho_{l}\left(1-\alpha_{m}\right)+\rho_{g}\left(1-H_{l}\right)}{\left(1-\alpha_{m}\right)+\left(1-H_{l}\right)}
$$

In addition, Ouyang (1998) defined two-phase density $\left(\rho_{m}\right)$ as follows:

$$
\rho_{m}=\rho_{l} H_{l}+\rho_{g}\left(1-H_{l}\right)
$$

\subsubsection{Effective viscosity models}

In the homogeneous model, the mixture viscosity for two-phase flows $\left(\mu_{m}\right)$ has received much attention in literature. There are some common expressions for the viscosity of twophase gas-liquid flow $\left(\mu_{m}\right)$. The expressions available for the two-phase gas-liquid viscosity are mostly of an empirical nature as a function of mass quality $(x)$. The liquid and gas are presumed to be uniformly mixed due to the homogeneous flow. The possible definitions for the viscosity of two-phase gas-liquid flow $\left(\mu_{m}\right)$ can be divided into two groups. In the first group, the form of the expression between $\left(\mu_{m}\right)$ and mass quality $(x)$ satisfies the following important limiting conditions:

$$
\left.\begin{array}{ll}
x=0, & \mu_{m}=\mu_{l} \\
x=1, & \mu_{m}=\mu_{g}
\end{array}\right\}
$$

In the second group, the form of the expression between $\left(\mu_{m}\right)$ and mass quality $(x)$ does not satisfy the limiting conditions of Eq. (173). In gas-liquid two-phase flows the most commonly used formulas are summarized below in Table 3.

In Table 3, it should be noted the following:

i. Awad and Muzychka (2008) Definition 4 is based on the Arithmetic Mean (AM) for Awad and Muzychka (2008) Definition 1 and Awad and Muzychka (2008) Definition 2.

ii. Muzychka et al. (2011) Definition 1 is based on the Geometric Mean (GM) for Awad and Muzychka (2008) Definition 1 and Awad and Muzychka (2008) Definition 2.

iii. Muzychka et al. (2011) Definition 2 is based on the Harmonic Mean (HM) for Awad and Muzychka (2008) Definition 1 and Awad and Muzychka (2008) Definition 2. 
An Overview of Heat Transfer Phenomena

\begin{tabular}{|c|c|}
\hline Researcher & Model \\
\hline Arrhenius (1887) & $\mu_{m}=\mu_{l}^{1-\alpha_{m}} \mu_{g}^{\alpha_{m}}$ \\
\hline Bingham (1906) & $\mu_{m}=\left(\frac{1-\alpha_{m}}{\mu_{l}}+\frac{\alpha_{m}}{\mu_{g}}\right)^{-1}$ \\
\hline $\begin{array}{l}\text { MacAdams et al. } \\
\qquad(1942)\end{array}$ & $\mu_{m}=\left(\frac{x}{\mu_{g}}+\frac{1-x}{\mu_{l}}\right)^{-1}$ \\
\hline $\begin{array}{l}\text { Davidson et al. } \\
\text { (1943) }\end{array}$ & $\mu_{m}=\mu_{l}\left[1+x\left(\frac{\rho_{l}}{\rho_{g}}-1\right)\right]$ \\
\hline $\begin{array}{l}\text { Vermeulen et al. } \\
\qquad(1955)\end{array}$ & $\mu_{m}=\frac{\mu_{l}}{\alpha_{m}}\left[1+\left(\frac{1.5 \mu_{g}\left(1-\alpha_{m}\right)}{\mu_{l}+\mu_{g}}\right)\right]$ \\
\hline Akers et al. (1959) & $\mu_{m}=\mu_{l}(1-x)+x\left(\frac{\rho_{l}}{\rho_{g}}\right)$ \\
\hline $\begin{array}{c}\text { Hoogendoorn } \\
\text { (1959) }\end{array}$ & $\mu_{m}=\mu_{l}^{H_{l}} \mu_{g}{ }^{1-H_{l}}$ \\
\hline $\begin{array}{c}\text { Cicchitti et al. } \\
\text { (1960) }\end{array}$ & $\mu_{m}=x \mu_{g}+(1-x) \mu_{l}$ \\
\hline Bankoff (1960) & $\mu_{m}=H_{l} \mu_{l}+\left(1-H_{l}\right) \mu_{g}$ \\
\hline Owen (1961) & $\mu_{m}=\mu_{l}$ \\
\hline Dukler et al. (1964) & $\mu_{m}=\rho_{m}\left[x \frac{\mu_{g}}{\rho_{g}}+(1-x) \frac{\mu_{l}}{\rho_{l}}\right]$ \\
\hline Oliemans (1976) & $\mu_{m}=\frac{\mu_{l}\left(1-\alpha_{m}\right)+\mu_{g}\left(1-H_{l}\right)}{\left(1-\alpha_{m}\right)+\left(1-H_{l}\right)}$ \\
\hline $\begin{array}{c}\text { Beattie and } \\
\text { Whalley (1982) }\end{array}$ & $\begin{array}{l}\mu_{m}=\mu_{l}\left(1-\alpha_{m}\right)\left(1+2.5 \alpha_{m}\right)+\mu_{g} \alpha_{m} \\
=\mu_{l}-2.5 \mu_{l}\left(\frac{x \rho_{l}}{x \rho_{l}+(1-x) \rho_{g}}\right)^{2}+\left(\frac{x \rho_{l}\left(1.5 \mu_{l}+\mu_{g}\right)}{x \rho_{l}+(1-x) \rho_{g}}\right)\end{array}$ \\
\hline Lin et al. (1991) & $\mu_{m}=\frac{\mu_{l} \mu_{g}}{\mu_{g}+x^{1.4}\left(\mu_{l}-\mu_{g}\right)}$ \\
\hline $\begin{array}{l}\text { Fourar and Bories } \\
\qquad(1995)\end{array}$ & $\mu_{m}=\rho_{m}\left(\sqrt{x \frac{\mu_{g}}{\rho_{m}}}+\sqrt{(1-x) \frac{\mu_{l}}{\rho_{l}}}\right)^{2}$ \\
\hline $\begin{array}{l}\text { García et al. (2003, } \\
\text { 2007) }\end{array}$ & $\mu_{m}=\mu_{l}\left(\frac{\rho_{m}}{\rho_{l}}\right)=\frac{\mu_{l} \rho_{g}}{x \rho_{l}+(1-x) \rho_{g}}$ \\
\hline
\end{tabular}




\begin{tabular}{|c|c|}
\hline $\begin{array}{c}\text { Researcher } \\
\text { Awad and } \\
\begin{array}{c}\text { Muzychka (2008) } \\
\text { Definition 1 }\end{array}\end{array}$ & Model \\
\hline $\begin{array}{c}\text { Awad and } \\
\text { Muzychka (2008) } \\
\text { Definition 2 }\end{array}$ & $\mu_{m}=\mu_{l} \frac{2 \mu_{l}+\mu_{g}-2\left(\mu_{l}-\mu_{g}\right) x}{2 \mu_{l}+\mu_{g}+\left(\mu_{l}-\mu_{g}\right) x}$ \\
\hline $\begin{array}{c}\text { Awad and } \\
\text { Muzychka (2008) } \\
\text { Definition 3 }\end{array}$ & $\mu_{m}=\mu_{g} \frac{2 \mu_{g}+\mu_{l}-2\left(\mu_{g}-\mu_{l}\right)(1-x)}{2 \mu_{g}+\mu_{l}+\left(\mu_{g}-\mu_{l}\right)(1-x)}$ \\
\hline $\begin{array}{c}\text { Awad and } \\
\text { Muzychka (2008) } \\
\text { Definition 4 }\end{array}$ & $\mu_{m}=\left[\frac{\mu_{l}}{2} \frac{2 \mu_{l}+\mu_{g}-2\left(\mu_{l}-\mu_{g}\right) x}{2 \mu_{l}+\mu_{g}+\left(\mu_{l}-\mu_{g}\right) x}+\frac{\mu_{g}}{2} \frac{2 \mu_{g}+\mu_{l}-2\left(\mu_{g}-\mu_{l}\right)(1-x)}{2 \mu_{g}+\mu_{l}+\left(\mu_{g}-\mu_{l}\right)(1-x)}\right]$ \\
\hline $\begin{array}{c}\text { Muzychka et al. } \\
\text { (2011) }\end{array}$ & $\mu_{m}=\left[\mu_{l} \frac{2 \mu_{l}+\mu_{g}-2\left(\mu_{l}-\mu_{g}\right) x}{2 \mu_{l}+\mu_{g}+\left(\mu_{l}-\mu_{g}\right) x} * \mu_{g} \frac{2 \mu_{g}+\mu_{l}-2\left(\mu_{g}-\mu_{l}\right)(1-x)}{2 \mu_{g}+\mu_{l}+\left(\mu_{g}-\mu_{l}\right)(1-x)}\right]$ \\
\hline $\begin{array}{c}\text { Definition 1 } \\
\text { Muzychka et al. } \\
\text { (2011) } \\
\text { Definition 2 }\end{array}$ & $\mu_{m}=\left[2 \mu_{l} \frac{2 \mu_{l}+\mu_{g}-2\left(\mu_{l}-\mu_{g}\right) x}{2 \mu_{l}+\mu_{g}+\left(\mu_{l}-\mu_{g}\right) x} * \mu_{g} \frac{2 \mu_{g}+\mu_{l}-2\left(\mu_{g}-\mu_{l}\right)(1-x)}{2 \mu_{g}+\mu_{l}+\left(\mu_{g}-\mu_{l}\right)(1-x)}\right] /$ \\
\hline
\end{tabular}

Table 3. The Most Commonly Used Formulas of the Mixture Viscosity in Gas-Liquid Two-Phase Flow.

The relationships between the Arithmetic Mean (AM), the Geometric Mean (GM), and the Harmonic Mean (HM) are as:

$$
\begin{gathered}
G M^{2}=2 . A M \cdot H M \\
H M<G M<A M \quad 0<x<1
\end{gathered}
$$

Agrawal et al. (2011) investigated recently new definitions of two-phase viscosity, based on its analogy with thermal conductivity of porous media, for transcritical capillary tube flow, with $\mathrm{CO}_{2}$ as the refrigerant. The researchers computed friction factor and pressure gradient quantities based on the proposed two-phase viscosity model using homogeneous modeling approach. They assessed the proposed new models based on test results in the form of temperature profile and mass flow rate in a chosen capillary tube. They showed that all the proposed models of two-phase viscosity models showed a good agreement with the existing models like McAdams et al. (1942), Cicchitti et al. (1960), etc. They found that the effect of the viscosity model to be insignificant unlike to other conventional refrigerants in capillary tube flow.

Banasiak and Hafner (2011) presented a one-dimensional mathematical model of the R744 two-phase ejector for expansion work recovery. The researchers computed friction factor and pressure gradient quantities based on the proposed two-phase viscosity model using 
homogeneous modeling approach. They approximated the two-phase viscosity according to the Effective Medium Theory. This formulation was originally derived for the averaged thermal conductivity and successfully tested by Awad and Muzychka (2008) for the average viscosity of vapor-liquid mixtures for different refrigerants. They predicted the friction factor $(f)$ using the Churchill model (1977).

In liquid-liquid two-phase flows, Taylor (1932) presented the effective viscosity for a dilute emulsion of two immiscible incompressible Newtonian fluids by

$$
\mu_{m}=\mu_{c}\left(1+2.5 \alpha \frac{\mu_{d}+0.4 \mu_{c}}{\mu_{d}+\mu_{c}}\right)=\mu_{c}\left(1+\alpha \frac{1+2.5\left(\mu_{d} / \mu_{c}\right)}{1+\left(\mu_{d} / \mu_{c}\right)}\right)
$$

If the viscosity of the dispersed phase $\left(\mu_{d}\right)$ is much lower than the continuous liquid $\left(\mu_{c}\right)$, like when water is mixed with silicone oil, the value of $(\mu d / \mu)$ would be much smaller than 1 . Hence, Eq. (176) can be simplified as

$$
\mu_{m}=\mu_{c}(1+\alpha)
$$

If the viscosity of the dispersed phase $\left(\mu_{d}\right)$ is much higher than the continuous liquid $\left(\mu_{c}\right)$, the value of $\left(\mu_{a} / \mu_{c}\right)$ would be much greater than 1 . Hence, Eq. (176) can be simplified as

$$
\mu_{m}=\mu_{c}(1+2.5 \alpha)
$$

Equation (178) is the well known Einstein model (1906, 1911). It is frequently used in prediction of nano fluid viscosity.

Instead of Eq. (178) being a first order equation in $\alpha$, can be written as a virial series,

$$
\mu_{m}=\mu_{c}\left(1+K_{1} \alpha+K_{2} \alpha^{2}+K_{3} \alpha^{3}+\ldots\right)
$$

Where $K_{1}, K_{2}, K_{3}, \ldots$. are constants. For example, $K_{1}=2.5, K_{2}=-11.01$ and $K_{3}=52.62$ in the Cengel (1967) definition for viscosity of liquid-liquid dispersions in laminar and turbulent flow. For more different definitions of the viscosity of emulsion, the reader can see Chapter 3: Physical Properties of Emulsions in the book by Becher (2001).

For different definitions of the viscosity of solid-liquid two-phase flow that are commonly used in the nanofluid applications, the reader can see, for example, Table 2: Models for effective viscosity in Wang and Mujumdar (2008a). Also, Wang and Mujumdar (2008b) reported that there were limited rheological studies in the literature in comparison with the experimental studies on thermal conductivity of nanofluids.

Similar to the idea of bounds on two-phase flow developed by Awad and Muzychka (2005a, 2005b, and 2007), these different definitions of two-phase viscosity can be used for bounding the data in an envelope using the homogeneous model. For example, Cicchitti et al. (1960), represents the upper bound while Dukler et al. (1964), represents the lower bound in gasliquid two-phase flow. Using the different definitions of a certain property such as thermal 
conductivity in bounding the data is available in the open literature. For instance, Carson et al. (2005) supported the use of different definitions as thermal conductivity bounds by experimental data from the literature.

The homogeneous flow modeling approach can be used for the case of bubbly flows with appropriate mixture models for density and viscosity in order to obtain good predictive results. For example, this approach has been examined by Awad and Muzychka (2008), Cioncolini et al. (2009), and $\mathrm{Li}$ and $\mathrm{Wu}$ (2010) for both microscale and macroscale flows.

The homogenous flow modeling approach using the different mixture models reported earlier, typically provides an accuracy within 15\% rms, (Awad and Muzychka (2008), Cioncolini et al. (2009), and $\mathrm{Li}$ and $\mathrm{Wu}(2010)$ ).

In the two-phase homogeneous model, the selection of a suitable definition of two-phase viscosity is inevitable as the Reynolds number would require this as an input to calculate the friction factor. It is possible, as argued by Collier and Thome (1994), that the failure of establishing an accepted definition is that the dependence of the friction factor on two-phase viscosity is small.

The opinion of the author is that which definition of two-phase viscosity to use depends much on the two-phase flow regime and less on the physical structure of the two-phase viscosity itself. As a matter of fact, till today some water-tube boiler design methods still use single-phase water viscosity in the homogeneous model with good accuracy. This could be explained by the high mass flux and mass quality always below 0.1 .

\subsubsection{The separated flow model}

In the separated model, two-phase flow is considered to be divided into liquid and vapor streams. Hence, the separated model has been referred to as the slip flow model. The separated model was originated from the classical work of Lockhart and Martinelli (1949) that was followed by Martinelli and Nelson (1948). The Lockhart-Martinelli method is one of the best and simplest procedures for calculating two-phase flow pressure drop and hold up. One of the biggest advantages of the Lockhart-Martinelli method is that it can be used for all flow patterns. However, relatively low accuracy must be accepted for this flexibility. The separated model is popular in the power plant industry. Also, the separated model is relevant for the prediction of pressure drop in heat pump systems and evaporators in refrigeration. The success of the separated model is due to the basic assumptions in the model are closely met by the flow patterns observed in the major portion of the evaporators.

The separated flow model may be developed with different degrees of complexity. In the simplest situation, only one parameter, like velocity, is allowed to differ for the two phases while conservation equations are only written for the combined flow. In the most sophisticated situation, separate equations of continuity, momentum, and energy are written for each phase and these six equations are solved simultaneously, together with rate equations which describe how the phases interact with each other and with the walls of the pipe. Correlations or simplifying assumptions are introduced when the number of variables to be determined is greater than the available number of equations. 
For void fraction, the separated model is used by both analytical and semi-empirical methods. In the analytical theories, some quantities like the momentum or the kinetic energy is minimized to obtain the slip ratio (S). The momentum flux model and the Zivi model (1964) are two examples of this technique, where the slip ratio $(S)$ equals $\left(\rho / \rho_{g}\right)^{1 / 2}$ and $\left(\rho_{l} / \rho_{g}\right)^{1 / 3}$.

For two-phase flow modeling in microchannels and minichannels, it should be noted that the literature review on this topic can be found in tabular form in a number of textbooks such as Celata (2004), Kandlikar et al. (2006), Crowe (2006), Ghiaasiaan (2008), and Yarin et al. (2009).

For two-phase frictional pressure gradient, a number of models have been developed with varying the sophistication degrees. These models are all reviewed in this section in a chorological order starting from the oldest to the newest.

\subsubsection{Lockhart-Martinelli model}

Lockhart and Martinelli (1949) presented data for the simultaneous flow of air and liquids including benzene, kerosene, water, and different types of oils in pipes varying in diameter from $0.0586 \mathrm{in}$. to $1.017 \mathrm{in}$. There were four types of isothermal two-phase, two-component flow. In the first type, flow of both the liquid and the gas were turbulent. In the second type, flow of the liquid was viscous and flow of the gas was turbulent. In the third type, flow of the liquid was turbulent and flow of the gas was viscous. In the fourth type, flow of both the liquid and the gas were viscous. The data used by Lockhart and Martinelli consisted of experimental results obtained from a number of sources as detailed in their original paper and covered 810 data sets including 191 data sets that are for inclined and vertical pipes and 619 data sets for horizontal flow (Cui and Chen (2010)).

Lockhart and Martinelli (1949) correlated the pressure drop resulting from these different flow mechanisms by means of the Lockhart-Martinelli parameter $(X)$. The LockhartMartinelli parameter $(X)$ was defined as:

$$
X^{2}=\frac{(d p / d z)_{f, l}}{(d p / d z)_{f, g}}
$$

In addition, they expressed the two-phase frictional pressure drop in terms of factors, which multiplied single-phase drops. These multipliers were given by:

$$
\begin{aligned}
& \phi_{l}^{2}=\frac{(d p / d z)_{f}}{(d p / d z)_{f, l}} \\
& \phi_{g}^{2}=\frac{(d p / d z)_{f}}{(d p / d z)_{f, g}}
\end{aligned}
$$

Using the generalized Blasius form of the Fanning friction factor, the frictional component single-phase pressure gradient could be expressed as 


$$
\begin{aligned}
& \left(\frac{d p}{d z}\right)_{f, l}=\frac{2 C_{l} \mu_{l}^{n} U_{l}^{2-n} \rho_{l}^{1-n}}{d^{1+n}} \\
& \left(\frac{d p}{d z}\right)_{f, g}=\frac{2 C_{g} \mu_{g}^{n} U_{g}^{2-n} \rho_{g}^{1-n}}{d^{1+n}}
\end{aligned}
$$

Values of the exponent $(n)$ and the constants $C_{l}$ and $C_{g}$ for different flow conditions are given in Table 4 .

\begin{tabular}{|c|c|c|c|c|}
\hline & $\begin{array}{c}\text { turbulent- } \\
\text { turbulent }\end{array}$ & $\begin{array}{c}\text { laminar- } \\
\text { turbulent }\end{array}$ & $\begin{array}{c}\text { turbulent- } \\
\text { laminar }\end{array}$ & $\begin{array}{c}\text { laminar- } \\
\text { laminar }\end{array}$ \\
\hline$n$ & 0.2 & 1.0 & 0.2 & 1.0 \\
\hline$C_{l}$ & 0.046 & 16 & 0.046 & 16 \\
\hline$C_{g}$ & 0.046 & 0.046 & 16 & 16 \\
\hline$R e_{l}$ & $>2000$ & $<1000$ & $>2000$ & $<1000$ \\
\hline$R e_{g}$ & $>2000$ & $>2000$ & $<1000$ & $<1000$ \\
\hline
\end{tabular}

Table 4. Values of the Exponent $(n)$ and the Constants $C_{l}$ and $C_{g}$ for Different Flow Conditions.

Also, they presented the relationship of $\phi x$ and $\phi_{g}$ to $X$ in graphical forms. They proposed tentative criteria for the transition of the flow from one type to another. Equations to calculate the parameter $(X)$ under different flow conditions are given in Table 5 .

\begin{tabular}{|c|c|}
\hline Flow Condition & $X$ \\
\hline turbulent-turbulent & $X_{t t}^{2}=\left(\frac{1-x}{x}\right)^{1.8}\left(\frac{\rho_{g}}{\rho_{l}}\right)\left(\frac{\mu_{l}}{\mu_{g}}\right)^{0.2}$ \\
\hline laminar-turbulent & $X_{l t}^{2}=\operatorname{Re}_{g}^{-0.8}\left(\frac{C_{l}}{C_{g}}\right)\left(\frac{1-x}{x}\right)\left(\frac{\rho_{g}}{\rho_{l}}\right)\left(\frac{\mu_{l}}{\mu_{g}}\right)$ \\
\hline turbulent- laminar & $X_{t l}^{2}=\operatorname{Re}_{l}^{0.8}\left(\frac{C_{l}}{C_{g}}\right)\left(\frac{1-x}{x}\right)\left(\frac{\rho_{g}}{\rho_{l}}\right)\left(\frac{\mu_{l}}{\mu_{g}}\right)$ \\
\hline laminar-laminar & $X_{l l}^{2}=\left(\frac{1-x}{x}\right)\left(\frac{\rho_{g}}{\rho_{l}}\right)\left(\frac{\mu_{l}}{\mu_{g}}\right)$ \\
\hline
\end{tabular}

Table 5. Equations to Calculate the Parameter $(X)$ under Different Flow Conditions.

It should be noted that Lockhart and Martinelli (1949) only presented the graphs for $\phi_{s}$ versus $X$ for the $t-t, 1-t$ and $1-1$ flow mechanisms of liquid-gas, and the graph of $\mathrm{t}-1$ flow mechanisms of liquid-gas (the third type) was not given.

Recently, Cui and Chen (2010) used 619 data sets for horizontal flow to recalculate the original data of Lockhart-Martinelli following the procedures of Lockhart-Martinelli. Once 
the researchers separated the data into the four flow mechanisms based on the superficial Reynolds number of the gas phase $\left(R e_{g}\right)$ and liquid phase $\left(R e_{l}\right)$ respectively, the corresponding values of $X, \phi_{s}$ and $\phi_{t}$ were calculated, and the data points were plotted on the $\phi_{s}-X$ diagram. They compared these data points with the four Lockhart-Martinelli correlation curves respectively. They commented that there was no mention of how the correlation curves were developed from the data points and there was also no evidence of any statistical analysis in the original Lockhart-Martinelli paper. It appeared that the curves were drawn by following the general trend of the data points. Furthermore, from the original graph of the correlation curves given in the original Lockhart-Martinelli paper, it was noted that the middle and some of the right-hand portions of the curves were shown as "solid lines" while the left-hand portion of the curves were drawn as "dashed lines". It was obvious that the "dashed lines" were not supported by data points and were extrapolations. They mentioned that computers and numerical analysis were not so readily accessible when the Lockhart-Martinelli paper was published in 1949. With the help of modern computers, the goodness of fit of data to empirical correlations could be analyzed and new empirical curves that better fit the existing data points might be obtained using the non-linear least squares method. The $t-1$ curve had a percentage error significantly lower than for the other curves. However, this did not necessarily mean that the $\mathrm{t}-\mathrm{l}$ curve was the best-fitted correlation because there were only nine data points associated with this curve. Also, these data points were in a very narrow range of $10<X<100$ while the empirical correlation given was for the range $0.01<X<100$. The $t-t, 1-t$ and $1-1$ curves had similar but larger values of percentage error compared with the $t-1$ curve.

Moreover, Cui and Chen (2010) re-categorized the Lockhart-Martinelli data according to flow pattern. In order to re-categorize the Lockhart-Martinelli data according to flow pattern, the researchers needed to make use of the Mandhane-Gregory-Aziz (1974) flow pattern map because the original Lockhart-Martinelli data had no information on flow patterns. Having calculated the superficial velocities of the gas phase $\left(U_{g}\right)$ and liquid phase $\left(U_{l}\right)$ respectively, the Lockhart-Martinelli data were plotted as scatter points on the Mandhane-Gregory-Aziz (1974) flow pattern map with the $X$-axis " $U_{g}$ " was the superficial velocity of the gas phase, while the Y-axis " $U_{l}$ " was the superficial velocity of the liquid phase. It was clear that the data used by Lockhart-Martinelli fell into five categories in terms of flow patterns: A, Annular flow; B, Bubbly flow; W, Wave flow; S, Slug flow and Str, Stratified flow. There were no data in the D, Dispersed flow region. They observed that the majority of the data fell within the annular, slug and wavy flow patterns. A few points fell within the stratified flow and the bubbly flow patterns. Also, in every flow pattern, the distribution of data points based on the four flow mechanisms of $t-t, t-1,1-t$ and $1-1$ flow was presented. After all the data had been re-categorized according to flow pattern, Cui and Chen (2010) compared the new data groups with the Lockhart-Martinelli curves. Again, the "Mean Absolute Percentage Error", which referred to the vertical distance between the data point and the curve expressed as a percentage deviation from the curve, was used for making the comparison. The $\mathrm{t}$-t curve was the best correlation for the annular (13.4\% error), bubbly $(9.0 \%$ error) and slug (15.8\% error) data used by Lockhart-Martinelli. The wavy data showed an error greater than about $20 \%$ when compared with any one of the Lockhart- 
Martinelli curves, while the stratified data was best represented by the 1-1 curve with an average error of $14.3 \%$. As a result, when the data were categorized according to flow patterns, none of the four curves ( $t-t, t-1,1-t$, and $1-1)$ provided improved correlation, but with the exception of the bubbly flow data that showed an averaged error of $9.7 \%$. It should be noted that the bubbly data points were located at large $X$ values where the four $\phi_{g}-X$ curves tended to merge.

Although the Lockhart-Martinelli correlation related to the adiabatic flow of low pressure air-liquid mixtures, they purposely presented the information in a generalized form to enable the application of the model to single component systems, and, in particular, to steam-water mixtures. Their empirical correlations were shown to be as reliable as any annular flow pressure drop correlation (Collier and Thome, 1994). The Lockhart-Martinelli model (1949) is probably the most well known method, commonly used in refrigeration and wet steam calculations. The disadvantage of this method was its limit to small-diameter pipes and low pressures because many applications of two-phase flow fell beyond these limits.

Since Lockhart and Martinelli published their paper on two-phase or two-component flows in 1949 to define the methodology for presenting two-phase flow data in non-boiling and boiling flows, their paper has received nearly 1000 citations in journal papers alone is a testament to its contribution to the field of two-phase flow.

\subsubsection{Turner model}

In his Ph. D. thesis, Turner (1966) developed the separate-cylinder model by assuming that the two-phase flow, without interaction, in two horizontal separate cylinders and that that the areas of the cross sections of these cylinders added up to the cross-sectional area of the actual pipe. The liquid and gas phases flow at the same flow rate through separate cylinders. The pressure gradient in each of the imagined cylinders was assumed to be equal, and its value was taken to be equal to the two-phase frictional pressure gradient in the actual flow. For this reason, the separate-cylinder model was not valid for gas-liquid slug flow, which gave rise to large pressure fluctuations. The pressure gradient was due to frictional effects only, and was calculated from single-phase flow theory. The separatecylinder model resembled Lockhart and Martinelli correlation (1949) but had the advantage that it could be pursued to an analytical conclusion. The results of his analysis were

$$
\left(\frac{1}{\phi_{l}^{2}}\right)^{1 / n}+\left(\frac{1}{\phi_{g}^{2}}\right)^{1 / n}=1
$$

The values of $n$ were dependent on whether the liquid and gas phases were laminar or turbulent flow. The different values of $n$ are given in Table 6 .

In Table 6, it should be noted the following for turbulent flow (analyzed on a basis of friction factor):

i. $\quad n=2.375$ for $f_{l}=0.079 / R e^{0.25}$ and $f_{g}=0.079 / \operatorname{Re}_{g}{ }^{0.25}$. 
ii. $\quad n=2.4$ for $f_{l}=0.046 / \operatorname{Rel}^{0.2}$ and $f_{g}=0.046 / \operatorname{Reg}_{g}{ }^{0.2}$.

iii. $n=2.5$ for $f_{l}=$ constant (i.e. not function of $R e_{l}$ ) and $f_{8}=$ constant (i.e. not function of $R e_{g}$ ).

\begin{tabular}{|l|c|}
\hline Flow Type & $n$ \\
\hline Laminar Flow & 2 \\
\hline Turbulent Flow (analyzed on a basis of friction factor) & $2.375-2.5$ \\
\hline Turbulent Flows (calculated on a mixing-length basis) & $2.5-3.5$ \\
\hline Turbulent-Turbulent Regime & 4 \\
\hline All Flow Regimes & 3.5 \\
\hline
\end{tabular}

Table 6. Values of Exponent (n) for Different Flow Types.

In the case of the two mixed flow regimes, Awad (2007a) mentioned in his Ph. D. thesis that the generalization of the Turner method could lead to the following implicit expressions:

$$
\phi_{l}^{2}=\left[1+\left(\phi_{l}^{2}\right)^{(3 / 38)}\left(\frac{1}{X^{2}}\right)^{1 / 2.375}\right]^{2}
$$

for the laminar liquid-turbulent gas case $\left(f_{l}=16 / R e l\right.$ and $\left.f_{g}=0.079 / \operatorname{Reg}_{8}{ }^{0.25}\right)$, and

$$
\phi_{l}^{2}=\left[1+\left(\phi_{l}^{2}\right)^{(-3 / 38)}\left(\frac{1}{X^{2}}\right)^{0.5}\right]^{2.375}
$$

for the turbulent liquid-laminar gas case $\left(f_{l}=0.079 / R e^{0.25}\right.$ and $\left.f_{g}=16 / R e_{g}\right)$. Equations (186) and (187) can be solved numerically.

Also, Muzychka and Awad (2010) mentioned that the values of $n$ in Eq. (185) for the case of the two mixed flow regimes were $n=2.05$ for the turbulent liquid-laminar gas case and $n=$ 2.10 for the laminar liquid-turbulent gas case.

Wallis (1969) mentioned in his book that there is no rationale for the good agreement between the analytical results the separate-cylinder model and the empirical results of Lockhart and Martinelli (1949). In spite of this statement, the method is still widely accepted because of its simplicity.

\subsubsection{Chisholm model}

In the following year after Turner (1966) proposed the separate cylinders model in his Ph. D. thesis, Chisholm (1967) proposed a more rigorous analysis that was an extension of the Lockhart-Martinelli model, except that a semi-empirical closure was adopted. Chisholm's rationale for his study was the fact that the Lockhart-Martinelli model failed to produce suitable equations for predicting the two-phase frictional pressure gradient, given that the empirical curves were only presented in graphical and tabular form. In spite of Chisholm's claims, he developed his approach in much the same manner as the Lockhart-Martinelli model. The researcher developed equations in terms of the Lockhart-Martinelli correlating 
groups for the friction pressure drop during the flow of gas-liquid or vapor-liquid mixtures in pipes. His theoretical development was different from previous treatments in the method of allowing for the interfacial shear force between the phases. Also, he avoided some of the anomalies occurring in previous "lumped flow". He gave simplified equations for use in engineering design. His equations were

$$
\begin{aligned}
& \phi_{l}^{2}=1+\frac{C}{X}+\frac{1}{X^{2}} \\
& \phi_{g}^{2}=1+C X+X^{2}
\end{aligned}
$$

The values of $C$ were dependent on whether the liquid and gas phases were laminar or turbulent flow. The values of $C$ were restricted to mixtures with gas-liquid density ratios corresponding to air-water mixtures at atmospheric pressure. The different values of $C$ are given in Table 7 .

\begin{tabular}{|c|c|c|}
\hline Liquid & Gas & $C$ \\
\hline Turbulent & Turbulent & 20 \\
\hline Laminar & Turbulent & 12 \\
\hline Turbulent & Laminar & 10 \\
\hline Laminar & Laminar & 5 \\
\hline
\end{tabular}

Table 7. Values of Chisholm Constant (C) for Different Flow Types.

He compared his predicted values using these values of $C$ and his equation with the Lockhart-Martinelli values. He obtained good agreement with the Lockhart-Martinelli empirical curves.

The meaning of the Chisholm constant $(C)$ can be easily seen if we multiply both sides of Eq. (188) by $(d p / d z)_{f, l}$ or both sides of Eq. (189) by $(d p / d z)_{f, g}$ to obtain:

$$
\left(\frac{d p}{d z}\right)_{f, t p}=\left(\frac{d p}{d z}\right)_{f, l}+\underbrace{C\left[\left(\frac{d p}{d z}\right)_{f, l}\left(\frac{d p}{d z}\right)_{f, g}\right]^{0.5}}_{\text {interfacial }}+\left(\frac{d p}{d z}\right)_{f, g}
$$

The physical meaning of Eq. (190) is that the two-phase frictional pressure gradient is the sum of three components: the frictional pressure of liquid-phase alone, the interfacial contribution to the total two-phase frictional pressure gradient, and the frictional pressure of gas-phase alone. As a result, we may now write

$$
\left(\frac{d p}{d z}\right)_{f, i}=\underbrace{C\left[\left(\frac{d p}{d z}\right)_{f, l}\left(\frac{d p}{d z}\right)_{f, g}\right]^{0.5}}_{\text {interfacial }}
$$


The means that the constant $C$ in Chisholm's model can be viewed as a weighting factor for the geometric mean (GM) of the single-phase liquid and gas only pressure gradients.

The Chisholm parameter $(C)$ is a measure of two-phase interactions. The larger the value, the greater the interaction, hence the Lockhart-Martinelli parameter $(X)$ can involve $1 \mathrm{l}, \mathrm{tl}, \mathrm{lt}$, and $\mathrm{tt}$ regimes. It just causes the data to shift outwards on the Lockhart-Martinelli plot.

The Chisholm constant $(C)$ can be derived analytically for a number of special cases. For instance, Whalley (1996) obtained for a homogeneous flow having constant friction factor:

$$
C=\left[\left(\frac{\rho_{l}}{\rho_{g}}\right)^{0.5}+\left(\frac{\rho_{g}}{\rho_{l}}\right)^{0.5}\right]
$$

that for an air-water combination gives $C \approx 28.6$ that is in good agreement with Chisholm's value for turbulent-turbulent flows. Also, Whalley (1996) shows that for laminar and turbulent flows with no interaction between phases the values of $C \approx 2$ and $C \approx 3.66$ are obtained, respectively.

In addition, Awad and Muzychka $(2007,2010 \mathrm{~b})$ mentioned that a value of $C=0$ can be used as a lower bound for two-phase frictional pressure gradient in minichannels and microchannels. The physical meaning of the lower bound $(C=0)$ is that the two-phase frictional pressure gradient is merely the sum of the frictional pressure of liquid phase alone and the frictional pressure of gas phase alone:

$$
\left(\frac{d p}{d z}\right)_{f, t p}=\left(\frac{d p}{d z}\right)_{f, l}+\left(\frac{d p}{d z}\right)_{f, g}
$$

This means there is no contribution to the pressure gradient through phase interaction. The above result can also be obtained using the asymptotic model for two-phase frictional pressure gradient (Awad and Muzychka (2004b)) with linear superposition. Further, using the homogeneous model with the Dukler et al. (1964) definition of two-phase viscosity for laminar-laminar flow leads to the same result as Eq. (193).The value of $C=0$ is also in agreement with recent models in microchannel flows such as (Mishima and Hibiki correlation (1996) and English and Kandlikar correlation (2006)) that implies that as $d_{h} \rightarrow 0$, $C \rightarrow 0$. The only disadvantage in these mentioned correlations is the dimensional specification of $d_{h}$, as it is easy to miscalculate $C$ if the proper dimensions are not used for $d_{h}$. Other researchers such as Zhang et al. (2010) overcame this disadvantage by representing the hydraulic diameter $\left(d_{h}\right)$ in a dimensionless form using the Laplace number $(L a)$.

Moreover, if a laminar plug flow is assumed, a value of $C=0$ can be easily derived that implies that the total pressure gradient is just the sum of the component pressure gradients based on plug length and component flow rate. This is a reasonable approximation provided that plug lengths are longer than fifteen diameters (Walsh et al., 2009).

In his Ph. D. thesis, Awad (2007a) reviewed additional extended Chisholm type models. 


\subsubsection{Hemeida-Sumait model}

The Lockhart-Martinelli (1949) correlation in its present form cannot be used to study a large set of data because it requires the use of charts and hence cannot be simulated numerically. As a result, Hemeida and Sumait (1988) developed a correlation between Lockhart and Martinelli parameters $\phi$ and $X$ for a two-phase pressure drop in pipelines using the Statistical Analysis System (SAS). To calculate the parameter $\phi$ as a function of $X$ using SAS software, their equation was

$$
\phi=\exp \left[2.303 a+b \operatorname{Ln}(X)+\frac{c}{2.30}(\operatorname{Ln} X)^{2}\right]
$$

Where $a, b$, and $c$ were constants. They selected the values of the constants $a, b$, and $c$ according to the type of fluid and flow mechanisms (Table 8).

\begin{tabular}{|c|c|c|c|}
\hline Parameter & $\boldsymbol{a}$ & $\boldsymbol{b}$ & $\boldsymbol{c}$ \\
\hline$\phi_{,, l l}$ & 0.4625 & 0.5058 & 0.1551 \\
\hline$\phi_{g, l t}$ & 0.5673 & 0.4874 & 0.1312 \\
\hline$\phi_{,, t l}$ & 0.5694 & 0.4982 & 0.1255 \\
\hline$\phi_{s, t t}$ & 0.6354 & 0.4810 & 0.1135 \\
\hline$\phi_{l, l l}$ & 0.4048 & 0.4269 & 0.1841 \\
\hline$\phi_{l, l t}$ & 0.5532 & -0.4754 & 0.1481 \\
\hline$\phi_{t, t l}$ & 0.5665 & -0.4586 & 0.1413 \\
\hline$\phi_{l, t t}$ & 0.6162 & -0.5063 & 0.124 \\
\hline
\end{tabular}

Table 8. Values of $a, b$, and $c$ for Different Flow Mechanisms.

In Table 8, the first subscript refers to whether the liquid is laminar or turbulent while the second subscript refers to whether the gas is laminar or turbulent. Equation (194) enabled the development of a computer program for the analysis of data using the LockhartMartinelli (1949) correlation. Using this program, they analyzed field data from Saudi flow lines. The results showed that the improved Lockhart-Martinelli correlation predicted accurately the downstream pressure in flow lines with an average percent difference of 5.1 and standard deviation of $9.6 \%$.

It should be noted that the Hemeida-Sumait (1988) model is not famous in the literature like other models such as the Chisholm (1967) model although it gave an accurate prediction of two-phase frictional pressure gradient.

\subsubsection{Modified Turner model}

Awad and Muzychka (2004b) arrived at the same simple form as the empirical Turner (1966) model, but with a different physical approach. Rather than model the fluid as two distinct fluid streams flowing in separate pipes, the researchers proposed that the two- phase frictional pressure gradient could be predicted using a nonlinear superposition of the component pressure gradient that would arise from every stream flowing alone in the same 
pipe, through application of the Churchill-Usagi (1972) asymptotic correlation method. This form was asymptotically correct for either phase as the mass quality varied from $0<x<1$. Moreover, rather than approach the Lockhart-Martinelli parameter $(X)$ from the point of view of the four flow regimes using simple friction models, they proposed using the Churchill (1977) model for the friction factor in smooth and rough pipes for all values of the Reynolds number. In this way, the proposed model was more general and contained only one empirical coefficient, the Churchill-Usagi blending parameter. The resulting model takes the form:

$$
\left(\frac{d p}{d z}\right)_{f}=\left[\left(\frac{d p}{d z}\right)_{f, l}^{p}+\left(\frac{d p}{d z}\right)_{f, g}^{p}\right]^{1 / p}
$$

or when written as a two-phase frictional liquid multiplier:

$$
\phi_{l}^{2}=\left[1+\left(\frac{1}{X^{2}}\right)^{p}\right]^{1 / p}
$$

or when written as a two-phase frictional gas multiplier:

$$
\phi_{g}^{2}=\left[1+\left(X^{2}\right)^{p}\right]^{1 / p}
$$

which are the same equations from the Turner approach, when $p=1 / n$. The main exception is that the values of $p$ were developed for different flow regimes using the Churchill friction model to calculate $X$.

The principal advantages of the above approach over the Turner (1966) method are twofold. First, all four Lockhart-Martinelli flow regimes can be handled with ease because the Turner (1966) method leads to implicit relationships for the two mixed regimes. Second, since the friction model used is only a function of Reynolds number and roughness, broader applications involving rough pipes can be easily modeled. Using Eqs. (196) and (197), Awad (2007b) found that $p \approx 0.307$ for large tubes and $p \approx 0.5$ for microchannels, minichannels, and capillaries. The modified Turner model is also a one parameter correlating scheme. Recently, Awad and Butt (2009a, 2009b, and 2009c) have shown that the asymptotic method works well for petroleum industry applications for liquid-liquid flows, flows through fractured media, and flows through porous media. Moreover, Awad and Muzychka (2010a) have shown that the asymptotic method works well for two-phase gas-liquid flow at microgravity conditions.

Approximate equivalence between Eq. (188) and Eq. (196) (or Eq. (189) and Eq. (197)) can be found when $p=0.36,0.3,0.285$, and 0.245 when $C=5,10,12$, and 20, respectively. This yields differences of $3-9 \%$ rms. The special case of $p=1$ leads to a linear superposition of the component pressure gradients that corresponds to $C=0$. This limiting case is only valid for plug flows when plug length to diameter ratios exceed 15 (Walsh et al., 2009). 


\subsubsection{Modified Chisholm models}

Finally, in a recent series of studies by Saisorn and Wongwises (2008, 2009, and 2010), correlation was proposed having the form:

$$
\phi_{l}^{2}=1+\frac{6.627}{X^{0.761}}
$$

for experimental data for slug flow, throat-annular flow, churn flow, and annular-rivulet flow, Saisorn and Wongwises (2008), and

$$
\phi_{l}^{2}=1+\frac{2.844}{X^{1.666}}
$$

for experimental data for annular flow, liquid unstable annular alternating flow (LUAAF), and liquid/annular alternating flow (LAAF), Saisorn and Wongwises (2009). These correlations neglect the $1 / X^{2}$ term that represents the limit of primarily gas flow in the Lockhart-Martinelli (1949) formulation. Neglecting this term ignores this important limiting case, which is an essential contribution in the Lockhart-Matrinelli modeling approach. As a result, at low values of $X$, the proposed correlations undershoot the trend of the data, limiting their use in the low $X$ range. Thus, a more appropriate and generalized form of the above correlations should be:

$$
\phi_{l}^{2}=1+\frac{A}{X^{m}}+\frac{1}{X^{2}}
$$

or

$$
\phi_{g}^{2}=1+A X^{m}+X^{2}
$$

These formulations, Eqs. (200) and (201), can be considered extended Chisholm type models. They will be utilized in the next section as a means of modeling the two-phase flow interfacial pressure gradient.

\subsubsection{Interfacial pressure gradient}

Gas-liquid two-phase flow will be examined from the point of view of interfacial pressure gradient. Recognizing that in a Lockhart-Martinelli reduction scheme, single-phase flow characteristics must be exhibited in a limiting sense, they will be subtracted from the experimental data being considered to illustrate some benefits of using the one and two parameter models.

The two-phase frictional pressure gradient can be defined as a linear combination of three pressure gradients. These are the single-phase liquid, single-phase gas, and interfacial pressure gradient. The rationale for such a choice lies in the definition of the LockhartMartinelli approach, whereby, one obtains single-phase gas flow for small values of the 
Lockhart-Martinelli parameter $(X)$ and single-phase liquid flow for large values of the Lockhart-Martinelli parameter $(X)$. While in the transitional region between $0.01<X<100$, interfacial effects result in a large spread of data depending upon flow regime.

Beginning with

$$
\left(\frac{d p}{d z}\right)_{f, t p}=\left(\frac{d p}{d z}\right)_{f, l}+\left(\frac{d p}{d z}\right)_{f, i}+\left(\frac{d p}{d z}\right)_{f, g}
$$

Rearranging Eq. (202), we obtain

$$
\left(\frac{d p}{d z}\right)_{f, i}=\left(\frac{d p}{d z}\right)_{f, t p}-\left(\frac{d p}{d z}\right)_{f, l}-\left(\frac{d p}{d z}\right)_{f, g}
$$

Dividing both sides of Eq. (203) by the single-phase liquid frictional pressure gradient, we obtain

$$
\phi_{1, i}^{2}=\left(\frac{d p}{d z}\right)_{f, i} /\left(\frac{d p}{d z}\right)_{f, l}=\varphi_{1}^{2}-1-\frac{1}{X^{2}}
$$

On the other hand, dividing both sides of Eq. (203) by the single-phase gas frictional pressure gradient, we obtain

$$
\phi_{g, i}^{2}=\left(\frac{d p}{d z}\right)_{f, i} /\left(\frac{d p}{d z}\right)_{f, g}=\varphi_{g}^{2}-X^{2}-1
$$

Where $\phi_{1, i^{2}}$ and $\phi_{8}, i^{2}$ are two-phase frictional multiplier for the interfacial pressure gradient. This can be viewed as an extended form of the Chisholm model, where the interfacial contribution is what is to be modeled. The data defined using Eqs. (204) and (205) may then be modeled using one, two, or multi-parameter forms. We discuss these approaches below.

It should be noted that this analysis is useful to show that $\phi_{g, i}$ does not exist at high values of $X_{t t}$ for some correlations available in the literature such as the $\phi_{s}$ correlation of Ding et al. (2009) to predict the pressure drop of R410A-oil mixtures in microfin tubes, the $\phi_{s}$ correlation of $\mathrm{Hu}$ et al. (2008) to predict the pressure drop of R410A/POE oil mixture in micro-fin tubes, and the $\phi_{s}$ correlation of $\mathrm{Hu}$ et al. (2009) to predict the pressure drop of R410A/oil mixture in smooth tubes because $\phi_{g, i}^{2}$ has negative values at high values of $X_{t t}$ (Awad, 2010a, Awad, 2010b, and Awad, 2011). Also, it this analysis is useful to show that $\phi$,i does not exist at certain values of $X_{t t}$ for some correlations available in the literature like the $\phi \iota$ correlation of Changhong et al. (2005) to predict the pressure drop in two vertical narrow annuli (Awad, 2012b).

\subsubsection{One parameter models}

Comparison with the Chisholm (1967) formulation gives: 


$$
\phi_{l, i}^{2}=\frac{C}{X}
$$

for the liquid multiplier formulation, or

$$
\phi_{g, i}^{2}=C X
$$

for the gas multiplier formulation.

This represents a simple one parameter model, whereby closure can be found with comparison with experimental data. Also, the simple asymptotic form of Eqs. (196) or (197) represents a one parameter model. If the interfacial effects can be modeled by Chisholm's proposed model or Eqs. (196) or (197), then all of the reduced data should show trends indicated by Eqs. (206) or (207). However, if data do not scale according to Eqs. (206) or (207), i.e. a slope of negative one for the liquid multiplier formulation or positive one for the gas multiplier formulation, then a two parameter model is likely required.

\subsubsection{Two parameter models}

Muzychka and Awad (2010) extended Eqs. (206) and (207) to develop a simple two parameter power law model such that:

$$
\phi_{l, i}^{2}=\frac{A}{X^{m}}
$$

or

$$
\phi_{g, i}^{2}=A X^{m}
$$

leading to Eqs. (200) or (201).

These forms have the advantage that experimental data for a particular flow regime can be fit to the simple power law after removal of the single-phase pressure contributions (Muzychka and Awad (2010)). Also, the advantage of the $A$ and $m$ model over the Chisholm model (1967) is the Chisholm model (1967) is destined to fail as they do not scale with $X$ properly when data deviate from the -1 and +1 slope. For example, this two parameter power law model can be use for the analysis of stratified flow data separated into different categories ( $t-t, 1-t$ and $1-1)$ in Cui and Chen (2010) for their study on a re-examination of the data of Lockhart-Martinelli. The researchers used the 619 data sets for horizontal flow. Their 619 data sets were classified based on the flow patterns as follows: 191 data sets for Annular flow, 277 data sets for Slug flow, 94 data sets for Wavy flow, 32 data sets for Bubbly flow, and 25 data sets for Stratified flow.

The analysis is presented here for the stratified flow data because it has only 25 data points (the lowest number of data points for the different flow patterns: annular (191), slug (277), wavy (94), bubbly (32), and stratified (25)). The interfacial component $\left(\phi_{8, i}\right)$ for stratified flow data of Lockhart-Martinelli is calculated as follows: 


$$
\phi_{g, i}=\left(\phi_{g}^{2}-X^{2}-1\right)^{0.5}
$$

Using this analysis, the interfacial component for the high pink triangle at the right hand side of stratified flow data separated into different categories $(t-t, v-t$ and $v-v$ ) (Cui and Chen (2010)) does not exist. This is because $\left(\phi_{s}{ }^{2}-X^{2}-1\right)<0$ for this point so that the square root of a negative value does not exist. This means that there is an error in the measurement in one data point for the stratified flow at lt flow mechanisms of liquid-gas. In this analysis, the data points of $\mathrm{tt}$, lt, and $1 \mathrm{l}$ flow mechanisms of liquid-gas were fit with only one line instead of three different lines for each flow mechanism of liquid-gas (tt, $1 \mathrm{t}$, and $1 \mathrm{l})$ because $\mathrm{tt}$ has only one data point. As shown in Fig. 4, the fit equation was:

$$
\phi_{g, i}=2.1 X^{0.678}
$$

However, drawing a different line of the interfacial component for the stratified flow for each flow mechanism of liquid-gas (tt, lt, and $1 \mathrm{l})$ will be more accurate. This analysis can be also done for other flow patterns: annular (191), slug (277), wavy (94), and bubbly (32).

It should be noted that the nonexistence of the interfacial component for some data sets for any flow patterns: annular (191), slug (277), wavy (94), bubbly (32), and stratified (25)) means that there is an error in the measurement of some data sets of Lockhart-Martinelli although their paper has received nearly 1000 citations in journal papers.

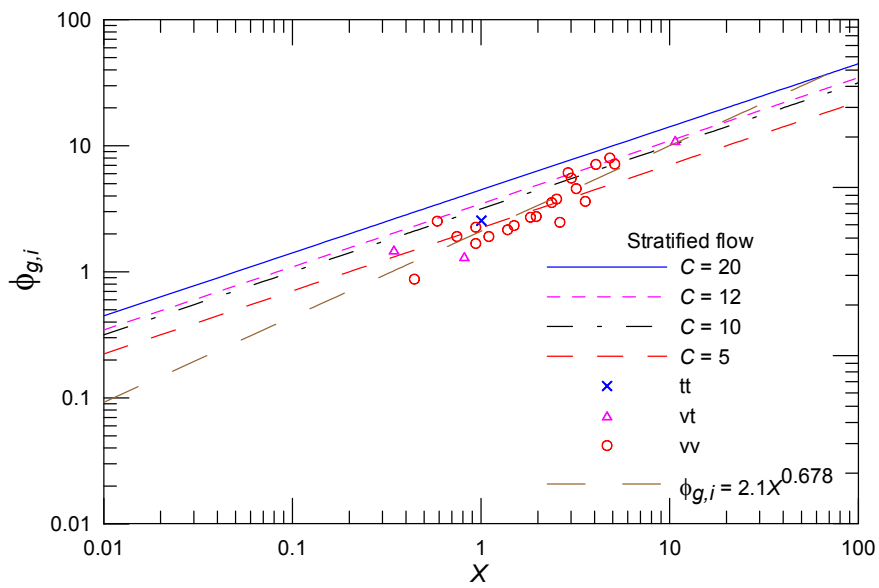

Figure 4. Analysis of Stratified Flow Data Separated into Different Categories $(t-t, v-t$ and $v-v)$ Using Two Parameter Power Law Model (Muzychka and Awad (2010)).

\subsubsection{Multi-parameter models}

Multi-parameter models may be developed using both the Chisholm model and the modified Chisholm models, by correlating the constants $C, A$, and $m$ with other dimensionless parameters. For example, Sun and Mishima (2009) adopted an approach that led to the development of $C$ in the laminar flow region as a function of the following 
dimensionless parameters: the Laplace constant $(L a)$, and the liquid Reynolds number $(R e l)$. Also, Venkatesan et al. (2011) adopted an approach that led to the development of $C$ in circular tubes with $d=0.6,1.2,1.7,2.6$ and $3.4 \mathrm{~mm}$ using air and water as a function of the following dimensionless parameters: Weber number(We), superficial liquid Reynolds number $\left(R e_{l}\right)$, and superficial gas Reynolds number $\left(R e_{g}\right)$. In addition, Kawahara et al. (2011) used their two-phase frictional pressure drop data in a rectangular microchannel with a Tjunction type gas-liquid mixer to correlate the Chisholm constant $(C)$ as a function of the following dimensionless parameters: Bond number $(\mathrm{Bo})$, superficial liquid Reynolds number $(R e l)$, and superficial gas Weber number $(W e g)$. But care must be taken because even with the introduction of additional variables, increased accuracy will not necessarily be obtained.

\subsubsection{The drift flux model}

The drift flux model is a type of separated flow model. In the drift flux model, attention is focused on the relative motion rather than on the motion of the individual phases. The drift flux model was developed by Wallis (1969). The drift flux model has widespread application to bubble flow and plug flow. The drift flux model is not particularly suitable to a flow such as annular flow that has two characteristic velocities in one phase: the liquid film velocity and the liquid drop velocity. However, the drift flux model has been used for annular flows, but with no particular success.

The drift flux model is the fifth example of the existing void fraction models. The Rouhani and Axelsson (1970) model is an instance for this type of model. In the drift-flux model, the void fraction $(\alpha)$ is a function of the gas superficial velocity $\left(U_{g}\right)$, the total superficial velocity $(U)$, the phase distribution parameter $\left(C_{0}\right)$, and the mean drift velocity $\left(u_{g j}\right)$ that includes the effect of the relative velocity between the phases. The form of the drift-flux model is

$$
\alpha=\frac{U_{g}}{C_{o} U+u_{g j}}
$$

The drift-flux correlations often present procedures to compute $C_{o}$ and $u_{g j}$. Since the expressions of $C_{o}$ and $u_{g j}$ are usually functions of the void fraction $(\alpha)$, the predictions of the void fraction $(\alpha)$ are calculated using method of solving of non-linear equation.

\subsubsection{Two-fluid model}

This model is known as the two-fluid model designating two phases or components. This model is an advanced predictive tool for liquid-gas two-phase flow in engineering applications. It is based on the mass, momentum and energy balance equations for every phase (Ishii, 1987). In this model, every phase or component is treated as a separate fluid with its own set of governing balance equations. In general, every phase has its own velocity, temperature and pressure. This approach enables the prediction of important nonequilibrium phenomena of two-phase flow like the velocity difference between liquid and gas phase. This prediction is important for two-phase flows in large shell sides of steam generators and kettle reboilers, where even different gas and liquid velocity directions exist. 


\subsection{Other methods}

There are other methods of analysis like integral analysis, differential analysis, computational fluid dynamics (CFD), and artificial neural network (ANN).

\subsubsection{Integral analysis}

In a one-dimensional integral analysis, the form of certain functions which describe, for instance, the velocity or concentration distribution in a pipe is assumed first. Then, these functions are made to satisfy appropriate boundary conditions and the basic equations of fluid mechanics (continuity equation, momentum equation, and energy equation) in integral form. Single-phase boundary layers are analyzed using similar techniques.

\subsubsection{Differential analysis}

The velocity and concentration fields are deduced from suitable differential equations. Usually, the equations are written for time-average quantities, like in single-phase theories of turbulence.

\subsubsection{Computational Fluid Dynamics (CFD)}

Two-phase flows are encountered in a wide range of industrial and natural situations. Due to their complexity such flows have been investigated only analytically and experimentally. New computing facilities provide the flexibility to construct computational models that are easily adapted to a wide variety of physical conditions without constructing a large-scale prototype or expensive test rigs. But there is an inherent uncertainty in the numerical predictions due to stability, convergence and accuracy. The importance of a well-placed mesh is highlighted in the modeling of two-phase flows in horizontal pipelines (Lun et al., 1996).

Also, with the increasing interest in multiphase flow in microchannels and advancement in interface capturing techniques, there have recently been a number of attempts to apply computational fluid dynamics (CFD) to model Taylor flow such as van Baten and Krishna (2004), Taha and Cui (2006a, 2006b) and Gupta et al. (2009). The CFD package, Fluent was used in these numerical studies of CFD modeling of Taylor flow.

In addition, Liu et al. (2011) developed recently a new two-fluid two-component computational fluid dynamics (CFD) model to simulate vertical upward two-phase annular flow. The researchers utilized the two-phase VOF scheme to model the roll wave flow, and described the gas core by a two-component phase consisting of liquid droplets and gas phase. They took into account the entrainment and deposition processes by source terms of the governing equations. Unlike the previous models, their newly developed model included the influence of liquid roll waves directly determined from the CFD code that was able to provide more detailed and, the most important, more self-standing information for both the gas core flow and the film flow as well as their interactions. They compared predicted results with experimental data, and achieved a good agreement. 


\subsubsection{Artificial Neural Network (ANN)}

In recent years, artificial neural network (ANN) has been universally used in many applications related to engineering and science. ANN has the advantage of self-learning and self-organization. ANN can employ the prior acquired knowledge to respond to the new information rapidly and automatically. When the traditional methods are difficult to be carried out or sometimes the specific models of mathematical physics will not be thoroughly existing, the neural network will be considered as a very good tool to tackle these timeconsuming and complex nonlinear relations because neural network has the excellent characteristics of parallel processing, calculating for complex computation and self-learning. The development of any ANN model involves three basic steps. First, the generation of data required for training. Second, the training and testing of the ANN model using the information about the inputs to predict the values of the output. Third, the evaluation of the ANN configuration that leads to the selection of an optimal configuration that produces the best results based on some preset measures. The optimum ANN model is also validated using a larger dataset. In the area of two-phase flow, the applications of the ANN include the prediction of pressure drop (Osman and Aggour, 2002), identifying flow regimes (Selli and Seleghim, 2007), predicting liquid holdup (Osman, 2004) and (Shippen and Scott, 2004), and the determination of condensation heat transfer characteristics during downward annular flow of R134a inside a vertical smooth tube (Balcilar et. al., 2011).

\section{Summary and conclusions}

This chapter aims to introduce the reader to the modeling of two-phase flow in general, liquid-gas flow in particular, and the prediction of frictional pressure gradient specifically. Different modeling techniques were presented for two-phase flow. Recent developments in theory and practice are discussed. The reader of this chapter is encouraged to pursue the associated journal and text references for additional theory not covered, especially the state of the art and review articles because they contain much useful information pertaining to the topics of interest. Given the rapid growth in the research topic of two-phase flow, new models and further understanding in areas like nano fluids will likely be achieved in the near future. Although, for most design and research applications, the topics covered in this chapter represent the state of the art.

\section{Author details}

M.M. Awad

Mechanical Power Engineering Department, Faculty of Engineering, Mansoura University, Egypt

\section{Acknowledgement}

The author acknowledges his Ph. D. supervisor, Prof. Yuri S. Muzychka, who introduced him to the possibilities of analytical modeling during his $\mathrm{Ph}$. D. thesis. Also, the author gratefully acknowledges ASME International Petroleum Technology Institute (IPTI) 
scholarship awarded to him in 2005 and 2006. In addition, the author wants to thank the Editor, Prof. M. Salim Newaz Kazi, for inviting him to prepare this chapter.

\section{Nomenclature}

$\begin{array}{ll}A & \text { area, m }{ }^{2} \\ A & \text { constant in the modified Chisholm model } \\ A & \text { Phillips parameter } \\ a & \text { Churchill parameter } \\ a & \text { constant in Hemeida and Sumait (1988) correlation } \\ A M & \text { Arithmetic mean } \\ A R & \text { Aspect ratio } \\ A r & \text { Archimedes number } \\ A t & \text { Atwood ratio } \\ B & \text { Phillips parameter } \\ b & \text { Churchill parameter } \\ b & \text { constant in Hemeida and Sumait (1988) correlation } \\ B o & \text { Bond number } \\ B o d & \text { Bodenstein number } \\ C & \text { Chisholm constant } \\ C & \text { constant } \\ c & \text { constant in Hemeida and Sumait (1988) correlation } \\ c & \text { sound speed, m/s } \\ C D & \text { drag coefficient } \\ C_{o} & \text { the phase distribution parameter } \\ C_{p} & \text { constant-pressure specific heat, J/kg.K } \\ C a & \text { Capillary number } \\ C n & \text { Cahn number } \\ C o & \text { Confinement number } \\ C o & \text { Convection number } \\ C o u & \text { Courant number } \\ D & \text { mass diffusivity, m } 2 / \mathrm{s} \\ d & \text { pipe diameter, } \mathrm{m} \\ \mathrm{E} & \text { electric field strength, V/m } \\ E & \text { two-phase heat transfer multiplier } \\ E h d & \text { EHD number or conductive Rayleigh number } \\ E M & \text { dimensionless number } \\ E_{r} & \text { dimensionless number } \\ E F & \text { Enhanced factor } \\ E o & \text { Eötvös number } \\ E u & \text { Euler number } \\ F & \text { parameter in the Taitel and Dukler (1976) map } \\ f & \text { wave frequency, Hz } \\ & \end{array}$




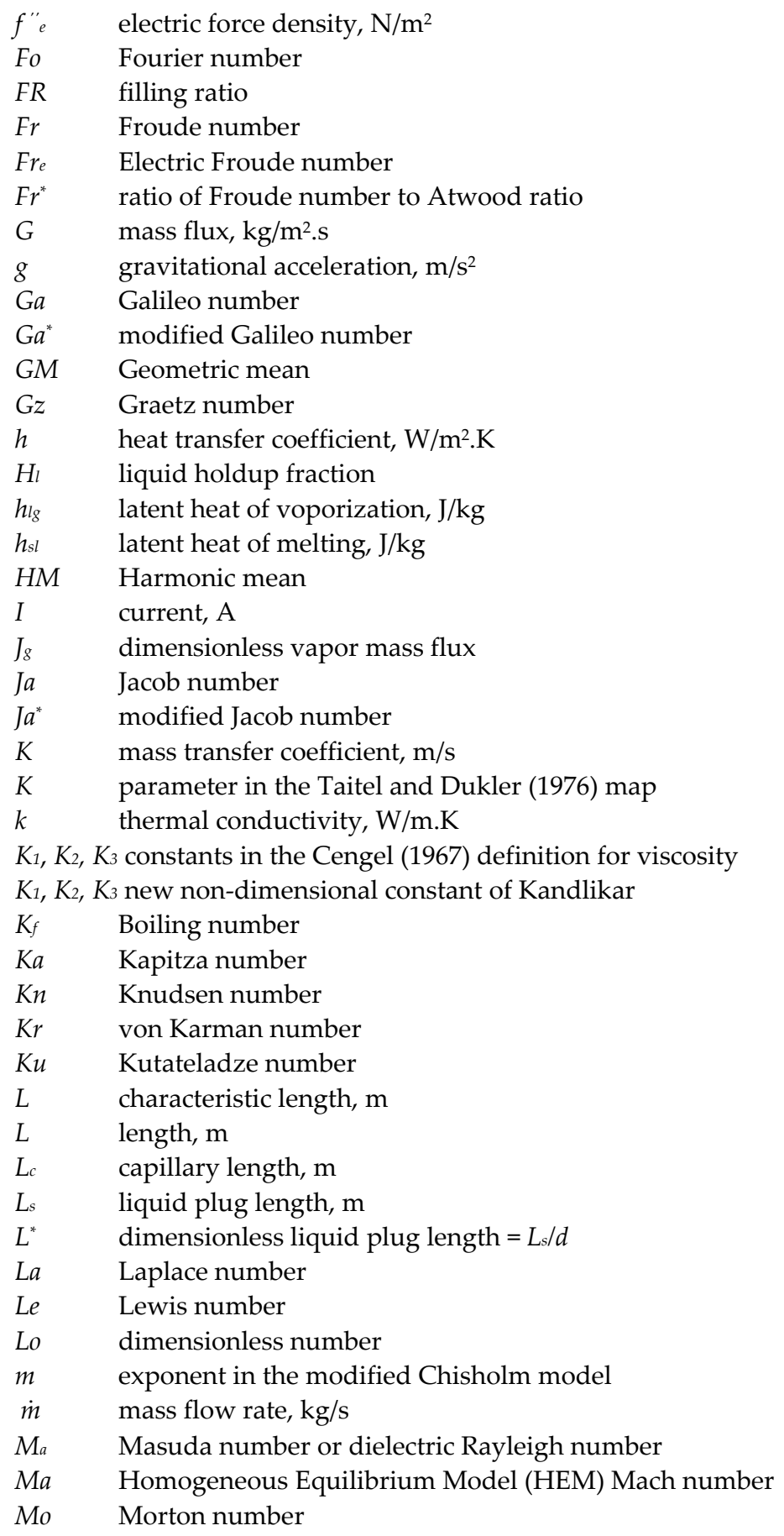


$n \quad$ Blasius index

$n$ exponent

$N_{f} \quad$ inverse viscosity number

$\mathrm{Nu} \quad$ Nusselt number

Oh Ohnesorge number

$p \quad$ fitting parameter

$d p / d z \quad$ pressure gradient, $\mathrm{Pa} / \mathrm{m}$

$\Delta p \quad$ pressure drop, $\mathrm{Pa}$

$\Delta p_{f}^{*} \quad$ dimensionless frictional pressure drop, $\mathrm{Pa}$

$\mathrm{Pe} \quad$ Peclet number

$\mathrm{Ph}$ phase change number

Po Poiseuille constant

$\mathrm{Pr} \quad$ Prandtl number

$Q \quad$ heat transfer rate, $\mathrm{W}$

$\dot{Q} \quad$ volumetric flow rate, $\mathrm{m}^{3} / \mathrm{s}$

$q$ heat flux, $\mathrm{W} / \mathrm{m}^{2}$

$R \quad$ pipe radius, $\mathrm{m}$

Re Reynolds number

$\operatorname{Ref}_{f} \quad$ film Reynolds number

$R_{p} \quad$ particle Reynolds number

$R e^{*} \quad$ laminar equivalent Reynolds number

$R i \quad$ Richardson number

$S \quad$ slip ratio

Sc Schmidt number

Sh Sherwood number

St Stanton number

Stk Stokes number

Str Strouhal number

Su Suratman number

T parameter in the Taitel and Dukler (1976) map

$T$ temperature, $\mathrm{K}$

$\Delta T$ temperature difference, $\mathrm{K}$

$U$ superficial velocity, $\mathrm{m} / \mathrm{s}$

$u_{g j} \quad$ mean drift velocity, $\mathrm{m} / \mathrm{s}$

$v \quad$ specific volume, $\mathrm{m}^{3} / \mathrm{kg}$

$X \quad$ Lockhart-Martinelli parameter

$x \quad$ distance in $\mathrm{x}$-direction, $\mathrm{m}$

$x \quad$ mass quality

$X^{*} \quad$ modified Lockhart-Martinelli parameter

Greek

$\alpha \quad$ concentration

$\alpha \quad$ thermal diffusivity, $\mathrm{m} / \mathrm{s}$ 


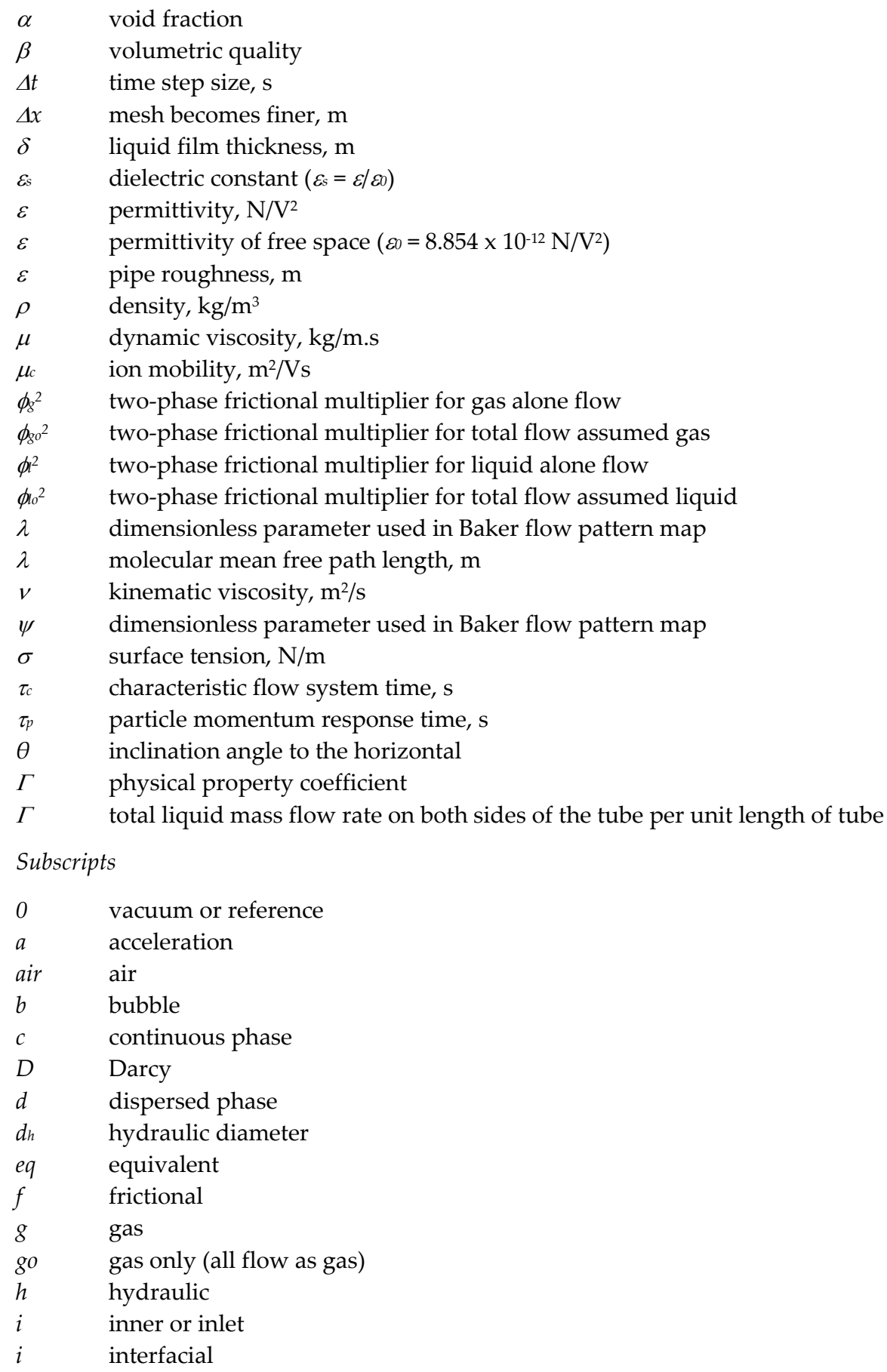




$\begin{array}{ll}l & \text { liquid } \\ l e & \text { laminar equivalent } \\ l l & \text { laminar liquid-laminar gas flow type } \\ l o & \text { liquid only (all flow as liquid) } \\ l t & \text { laminar liquid- turbulent gas flow type } \\ m & \text { homogeneous mixture } \\ m & \text { mean } \\ \text { max } & \text { maximum } \\ \text { min } & \text { minimum } \\ o & \text { outer or outlet } \\ o & \text { oil } \\ p & \text { particle } \\ p & \text { plug } \\ \text { Poise } & \text { Poiseuille flow } \\ r & \text { refrigerant } \\ s & \text { saturation } \\ s & \text { sound } \\ \text { slug } & \text { slug } \\ t l & \text { turbulent liquid-laminar gas flow type } \\ t p & \text { two-phase } \\ t t & \text { turbulent liquid-turbulent gas flow type } \\ w & \text { wall } \\ w a t e r & \text { water }\end{array}$

\section{References}

Agrawal, N., Bhattacharyya, S., and Nanda, P., 2011, Flow Characteristics of Capillary Tube with $\mathrm{CO}_{2}$ Transcritical Refrigerant Using New Viscosity Models for Homogeneous Two-Phase Flow, International Journal of Low-Carbon Technologies, 6 (4), pp. 243-248.

Akbar, M. K., Plummer, D. A., and Ghiaasiaan, S. M., 2003, On Gas-Liquid Two-Phase Flow Regimes in Microchannels, International Journal of Multiphase Flow, 29 (5) pp. 855-865. Akers, W. W., Deans, H. A., and Crosser, O. K., 1959, Condensation Heat Transfer within Horizontal Tubes, Chemical Engineering Progress Symposium Series, 55 (29), pp. 171176.

Al-Sarkhi, A., Sarica, C., and Magrini, K., 2012, Inclination Effects on Wave Characteristics in Annular Gas-Liquid Flows, AIChE Journal, 58 (4), pp. 1018-1029.

Angeli, P., and Gavriilidis, A., 2008, Hydrodynamics of Taylor Flow in Small Channels: A Review, Proceedings of the Institution of Mechanical Engineers, Part C: Journal of Mechanical Engineering Science, 222 (5), pp. 737-751.

Arrhenius, S., 1887, On the Internal Friction of Solutions in Water, Zeitschrift für Physikalische Chemie (Leipzig), 1, pp. 285-298.

ASHRAE, 1993, Handbook of Fundamentals, ASHRAE, Atlanta, GA, Chap. 4. 
Aussillous, P., and Quere, D., 2000, Quick Deposition of a Fluid on the Wall of a Tube, Physics of Fluids, 12 (10), pp. 2367-2371.

Awad, M. M., 2007a, Two-Phase Flow Modeling in Circular Pipes, Ph.D. Thesis, Memorial University of Newfoundland, St. John's, NL, Canada.

Awad, M. M., 2007b, Comments on Condensation and evaporation heat transfer of R410A inside internally grooved horizontal tubes by M. Goto, N. Inoue and N. Ishiwatari, International Journal of Refrigeration, 30 (8), pp. 1466.

Awad, M. M., 2010a, Comments on Experimental Investigation and Correlation of TwoPhase Frictional Pressure Drop of R410A-Oil Mixture Flow Boiling in a $5 \mathrm{~mm}$ Microfin Tube Int. J. Refrigeration 32/1 (2009) 150-161, by Ding, G., Hu, H., Huang, X., Deng, B., and Gao, Y., International Journal of Refrigeration, 33 (1), pp. 205-206.

Awad, M. M., 2010b, Comments on Measurement and Correlation of Frictional Two-Phase Pressure Drop of R410A/POE Oil Mixture Flow Boiling in a $7 \mathrm{~mm}$ Straight Micro-Fin Tube by H.-t. Hu, G.-l. Ding, and K.-j. Wang, Applied Thermal Engineering, 30 (2-3), pp. 260-261.

Awad, M. M., 2011, Comments on "Pressure drop during horizontal flow boiling of R410A/oil mixture in $5 \mathrm{~mm}$ and $3 \mathrm{~mm}$ smooth tubes" by H-t Hu, G-1 Ding, X-c Huang, B. Deng, and Y-f Gao, Applied Thermal Engineering, 31 (16), pp. 3629-3630.

Awad, M. M., 2012a, Discussion: Heat Transfer Mechanisms During Flow Boiling in Microchannels (Kandlikar, S. G., 2004, ASME Journal of Heat Transfer, 126 (2), pp. 8-16), ASME Journal of Heat Transfer, 134 (1), Article No. (015501).

Awad, M. M., 2012b, Comments on "Two-phase flow and boiling heat transfer in two vertical narrow annuli", Nuclear Engineering and Design, 245, pp. 241-242.

Awad, M. M., and Butt, S. D., 2009a, A Robust Asymptotically Based Modeling Approach for Two-Phase Liquid-Liquid Flow in Pipes, ASME 28 $8^{\text {th }}$ International Conference on Offshore Mechanics and Arctic Engineering (OMAE2009), Session: Petroleum Technology, OMAE2009-79072, Honolulu, Hawaii, USA, May 31-June 5, 2009.

Awad, M. M., and Butt, S. D., 2009b, A Robust Asymptotically Based Modeling Approach for Two-Phase Gas-Liquid Flow in Fractures, $12^{\text {th }}$ International Conference on Fracture (ICF12), Session: Oil and Gas Production and Distribution, ICF2009-646, Ottawa, Canada, July 12-17, 2009.

Awad, M. M., and Butt, S. D., 2009c, A Robust Asymptotically Based Modeling Approach for Two-Phase Flow in Porous Media, ASME Journal of Heat Transfer, 131 (10), Article (101014) (The Special Issue of JHT on Recent Advances in Porous Media Transport), Also presented at ASME 27 ${ }^{\text {th }}$ International Conference on Offshore Mechanics and Arctic Engineering (OMAE2008), Session: Offshore Technology, Petroleum Technology II, OMAE2008-57792, Estoril, Portugal, June 15-20, 2008.

Awad, M. M., and Muzychka, Y. S., 2004a, A Simple Two-Phase Frictional Multiplier Calculation Method, Proceedings of IPC2004, International Pipeline Conference, Track: 3. Design \& Construction, Session: System Design/Hydraulics, IPC04-0721, Vol. 1, pp. 475-483, Calgary, Alberta, October 4-8, 2004. 
Awad, M. M., and Muzychka, Y. S., 2004b, A Simple Asymptotic Compact Model for TwoPhase Frictional Pressure Gradient in Horizontal Pipes, Proceedings of IMECE 2004, Session: FE-8 A Gen. Pap.: Multiphase Flows - Experiments and Theory, IMECE200461410, Anaheim, California, November 13-19, 2004.

Awad, M. M., and Muzychka, Y. S., 2005a, Bounds on Two-Phase Flow. Part I. Frictional Pressure Gradient in Circular Pipes, Proceedings of IMECE 2005, Session: FED-11 B Numerical Simulations and Theoretical Developments for Multiphase Flows-I, IMECE2005-81493, Orlando, Florida, November 5-11, 2005.

Awad, M. M., and Muzychka, Y. S., 2005b, Bounds on Two-Phase Flow. Part II. Void Fraction in Circular Pipes, Proceedings of IMECE 2005, Session: FED-11 B Numerical Simulations and Theoretical Developments for Multiphase Flows-I, IMECE2005-81543, Orlando, Florida, November 5-11, 2005.

Awad, M. M. and Muzychka, Y. S., 2007, Bounds on Two-Phase Frictional Pressure Gradient in Minichannels and Microchannels, Heat Transfer Engineering, 28 (8-9), pp. 720-729. Also presented at The $4^{\text {th }}$ International Conference on Nanochannels, Microchannels and Minichannels (ICNMM 2006), Session: Two-Phase Flow, Numerical and Analytical Modeling, ICNMM2006-96174, Stokes Research Institute, University of Limerick, Ireland, June 19-21, 2006.

Awad, M. M. and Muzychka, Y. S., 2008, Effective Property Models for Homogeneous Two Phase Flows, Experimental and Thermal Fluid Science, 33 (1), pp. 106-113.

Awad, M. M., and Muzychka, Y. S., 2010a, Review and Modeling of Two-Phase Frictional Pressure Gradient at Microgravity Conditions, ASME $20103^{\text {rd }}$ Joint US-European Fluids Engineering Summer Meeting and $8^{\text {th }}$ International Conference on Nanochannels, Microchannels, and Minichannels (FEDSM2010-ICNMM2010), Symposium 1-14 $4^{\text {th }}$ International Symposium on Flow Applications in Aerospace, FEDSM2010ICNMM2010-30876, Montreal, Canada, August 1-5, 2010.

Awad, M. M., and Muzychka, Y. S., 2010b, Two-Phase Flow Modeling in Microchannels and Minichannels, Heat Transfer Engineering, 31 (13), pp. 1023-1033. Also presented at The $6^{\text {th }}$ International Conference on Nanochannels, Microchannels and Minichannels (ICNMM2008), Session: Two-Phase Flow, Modeling and Analysis of Two-Phase Flow, ICNMM2008-62134, Technische Universitaet of Darmstadt, Darmstadt, Germany, June 23-25, 2008.

Baker, O., 1954, Simultaneous Flow of Oil and Gas, Oil and Gas Journal, 53, pp.185-195.

Balcilar, M., Dalkilic, A. S., and Wongwises, S., 2011, Artificial Neural Network Techniques for the Determination of Condensation Heat Transfer Characteristics during Downward Annular Flow of R134a inside a Vertical Smooth Tube, International Communications in Heat and Mass Transfer 38 (1), pp. 75-84.

Banasiak, K., and Hafner, A., 2011, 1D Computational Model of a Two-Phase R744 Ejector for Expansion Work Recovery, International Journal of Thermal Sciences, 50 (11), pp. 2235-2247. 
Bandel, J., 1973, Druckverlust und Wärmeübergang bei der Verdampfung siedender Kältemittel im durchströmten waagerechten Rohr, Doctoral Dissertation, Universität Karlsruhe.

Bankoff, S. G., 1960, A Variable Density Single-Fluid Model for Two-Phase Flow with Particular Reference to Steam-Water Flow, Journal of Heat Transfer, 82 (4), pp. 265-272.

Beattie, D. R. H., and Whalley, P. B., 1982, A Simple Two-Phase Frictional Pressure Drop Calculation Method, International Journal of Multiphase Flow, 8 (1), pp. 83-87.

Becher, P., 2001, Emulsions: Theory and Practice, $3^{\text {rd }}$ edition, Oxford University Press, New York, NY.

Bico, J., and Quere, D., 2000, Liquid Trains in a Tube, Europhysics Letters, 51 (5), pp. 546550.

Blasius, H., 1913, Das Ähnlichkeitsgesetz bei Reibungsvorgängen in Flüssikeiten, Forsch. Gebiete Ingenieurw., 131.

Bonfanti, F., Ceresa, I., and Lombardi, C., 1979, Two-Phase Pressure Drops in the Low Flowrate Region, Energia Nucleare, 26 (10), pp. 481-492.

Borishansky, V. M., Paleev, I. I., Agafonova, F. A., Andreevsky, A. A., Fokin, B. S., Lavrentiev, M. E., Malyus-Malitsky, K. P., Fromzel V. N., and Danilova, G. P., 1973, Some Problems of Heat Transfer and Hydraulics in Two-Phase Flows, International Journal of Heat and Mass Transfer, 16 (6), pp. 1073-1085.

Brauner, N., and Moalem-Maron, D., 1992, Identification of the Range of 'Small Diameters' Conduits, Regarding Two-Phase Flow Pattern Transitions, International Communications in Heat and Mass Transfer, 19 (1), pp. 29-39.

Breber, G., Palen, J., and Taborek, J., 1980, Prediction of Horizontal Tube-Side Condensation of Pure Components Using Flow Regime Criteria, ASME Journal of Heat Transfer, 102 (3), pp. 471-476.

Bretherton, F. P., 1961, The Motion of Long Bubbles in Tubes, Journal of Fluid Mechanics, 10 (2), pp. 166-188.

Carson, J. K., Lovatt, S. J., Tanner, D. J., and Cleland, A. C., 2005, Thermal Conductivity Bounds for Isotropic, Porous Materials, International Journal of Heat and Mass Transfer, 48 (11), pp. 2150-2158.

Catchpole, J. P., and Fulford, G. D., 1966, Dimensionless Groups, Industrial and Engineering Chemistry, 58 (3), pp. 46-60.

Cavallini, A., Censi, G., Del Col, D., Doretti, L., Longo, G. A., and Rossetto, L., 2002, Condensation of Halogenated Refrigerants inside Smooth Tubes, HVAC and R Research, 8 (4), pp. 429-451.

Celata, G. P., 2004, Heat Transfer and Fluid Flow in Microchannels, Begell House, Redding, CT.

Cengel, J., 1967, Viscosity of Liquid-Liquid Dispersions in Laminar and Turbulent Flow, PhD Dissertation Thesis, Oregon State University.

Chang, J. S., 1989, Stratified Gas-Liquid Two-Phase Electrohydrodynamics in Horizontal Pipe Flow, IEEE Transactions on Industrial Applications, 25 (2), pp. 241-247. 
Chang, J. S., 1998, Two-Phase Flow in Electrohydrodynamics, in: Castellanos, A., (Ed.), Part V, Electrohdyrodynamics, International Centre for Mechanical Sciences Courses and Lectures No. 380, Springer, New York.

Chang., J. S., and Watson, A., 1994, Electromagnetic Hydrodynamics, IEEE Transactions on Dielectrics and Electrical Insulation, 1 (5), pp. 871-895.

Changhong, P., Yun, G., Suizheng, Q., Dounan, J., and Changhua, N., 2005. Two-Phase Flow and Boiling Heat Transfer in Two Vertical Narrow Annuli, Nuclear Engineering and Design, 235 (16), pp. 1737-1747.

Charoensawan, P., and Terdtoon, P., 2007, Thermal Performance Correlation of Horizontal Closed-Loop Oscillating Heat Pipes, $9^{\text {th }}$ Electronics Packaging Technology Conference (EPTC 2007), pp. 906-909, 10-12 December 2007, Grand Copthorne Waterfront Hotel, Singapore.

Chen, Y., Kulenovic, R., and Mertz, R., 2009, Numerical Study on the Formation of Taylor Bubbles in Capillary Tubes, International Journal of Thermal Sciences, 48 (2), pp. 234242. Also presented at Proceedings of the $5^{\text {th }}$ International Conference on Nanochannels, Microchannels and Minichannels (ICNMM2007), ICNMM2007-30182, pp. 939-946, June 18-20, 2007, Puebla, Mexico.

Cherlo, S. K. R., Kariveti, S., and Pushpavanam, S., 2010, Experimental and Numerical Investigations of Two-Phase (Liquid-Liquid) Flow Behavior in Rectangular Microchannels, Industrial and Engineering Chemistry Research, 49 (2), pp. 893-899.

Chisholm, D., 1967, A Theoretical Basis for the Lockhart-Martinelli Correlation for TwoPhase Flow, International Journal of Heat and Mass Transfer, 10 (12), pp. 1767-1778.

Chisholm, D., 1973, Pressure Gradients due to Friction during the Flow of Evaporating TwoPhase Mixtures in Smooth Tubes and Channels, International Journal of Heat and Mass Transfer, 16 (2), pp. 347-358.

Chisholm, D., 1983, Two-Phase Flow in Pipelines and Heat Exchangers, George Godwin in Association with Institution of Chemical Engineers, London.

Churchill, S. W., 1977, Friction Factor Equation Spans all Fluid Flow Regimes, Chemical Engineering, 84 (24), pp. 91-92.

Churchill, S. W. and Usagi, R., 1972, A General Expression for the Correlation of Rates of Transfer and Other Phenomena, American Institute of Chemical Engineers Journal, 18 (6), pp. 1121-1128.

Cicchitti, A., Lombaradi, C., Silversti, M., Soldaini, G., and Zavattarlli, R., 1960, Two-Phase Cooling Experiments- Pressure Drop, Heat Transfer, and Burnout Measurements, Energia Nucleare, 7 (6), pp. 407-425.

Cioncolini, A., Thome, J. R., and Lombardi, C., 2009, Unified Macro-to-Microscale Method to Predict Two-Phase Frictional Pressure Drops of Annular Flows, International Journal of Multiphase Flow, 35 (12), pp. 1138-1148.

Colebrook, C. F., 1939, Turbulent Flow in Pipes, with Particular Reference to the Transition between the Smooth and Rough Pipe Laws, J. Inst. Civ. Eng. Lond., 11, pp. 133-156.

Collier, J. G. and Thome, J. R., 1994, Convective Boiling and Condensation ( $3^{\text {rd }}$ Edn), Claredon Press, Oxford. 
Cotton, J., Robinson, A. J., Shoukri, M., and Chang, J. S., 2005, A Two-Phase Flow Pattern Map for Annular Channels under a DC Applied Voltage and the Application to Electrohydrodynamic Convective Boiling Analysis, International Journal of Heat and Mass Transfer, 48 (25-26), pp. 5563-5579.

Cotton, J. S., Shoukri, M., Chang, J. S., and Smith-Pollard, T., 2000, Electrohydrodynamic (EHD) Flow and Convective Boiling Augmentation in Single-Component Horizontal Annular Channels, 2000 International Mechanical Engineering Congress and Exposition, HTD-366-4, pp. 177-184.

Crowe, C. T., 2006, Multiphase Flow Handbook, CRC: Taylor \& Francis, Boca Raton, FL.

Cui, X., and Chen, J. J. J., 2010, A Re-Examination of the Data of Lockhart-Martinelli, International Journal of Multiphase Flow, 36 (10), pp. 836-846.

Davidson, W. F., Hardie, P. H., Humphreys, C. G. R., Markson, A. A., Mumford, A. R., and Ravese, T., 1943, Studies of Heat Transmission Through Boiler Tubing at Pressures from 500-3300 Lbs, Trans. ASME, 65 (6), pp. 553-591.

Ding, G., Hu, H., Huang, X., Deng, B., and Gao, Y., 2009, Experimental Investigation and Correlation of Two-Phase Frictional Pressure Drop of R410A-Oil Mixture Flow Boiling in a $5 \mathrm{~mm}$ Microfin Tube, International Journal of Refrigeration, 32 (1), pp. 150-161.

Drew, T. B., Koo, E. C., and McAdams, W. H., 1932, The Friction Factor for Clean Round Pipe, Trans. AIChE, 28, pp. 56.

Duda, J. L., and Vrentas, J. S., 1971, Heat Transfer in a Cylindrical Cavity, Journal of Fluid Mechanics, 45, pp. 261-279.

Dukler, A. E., Moye Wicks and Cleveland, R. G., 1964, Frictional Pressure Drop in TwoPhase Flow. Part A: A Comparison of Existing Correlations for Pressure Loss and Holdup, and Part B: An Approach through Similarity Analysis AIChE Journal, 10 (1), pp. 38-51.

Einstein, A., 1906, Eine neue Bestimmung der Moleküldimensionen (A New Determination of Molecular Dimensions), Annalen der Physik (ser. 4), 19, pp. 289-306.

Einstein, A., 1911, Berichtigung zu meiner Arbeit: Eine neue Bestimmung der Moleküldimensionen (Correction to My Paper: A New Determination of Molecular Dimensions), Annalen der Physik (ser. 4), 34, pp. 591-592.

English, N. J., and Kandlikar, S. G., 2006, An Experimental Investigation into the Effect of Surfactants on Air-Water Two-Phase Flow in Minichannels, Heat Transfer Engineering, 27 (4), pp. 99-109. Also presented at The $3^{\text {rd }}$ International Conference on Microchannels and Minichannels (ICMM2005), ICMM2005-75110, Toronto, Ontario, Canada, June 1315, 2005.

Fairbrother, F., and Stubbs, A. E., 1935, Studies in Electro-Endosmosis. Part VI. The BubbleTube Method of Measurement, Journal of the Chemical Society (Resumed), pp. 527-529.

Fang, X., Xu, Y., and Zhou, Z., 2011, New Correlations of Single-Phase Friction Factor for Turbulent Pipe Flow and Evaluation of Existing Single-Phase Friction Factor Correlations, Nuclear Engineering and Design, 241 (3), pp. 897-902. 
Fourar, M. and Bories, S., 1995, Experimental Study of Air-Water Two-Phase Flow Through a Fracture (Narrow Channel), International Journal of Multiphase Flow, 21 (4), pp. 621637.

Friedel, L., 1979, Dimensionless Relationship for The Friction Pressure Drop in Pipes during Two-Phase Flow of Water and of R 12, Verfahrenstechnik, 13 (4), pp. 241-246.

Fulford, G. D., and Catchpole, J. P., 1968, Dimensionless Groups, Industrial and Engineering Chemistry, 60 (3), pp. 71-78.

García, F., García, R., Padrino, J. C., Mata, C., Trallero J. L., and Joseph, D. D., 2003, Power Law and Composite Power Law Friction Factor Correlations for Laminar and Turbulent Gas-Liquid Flow in Horizontal Pipelines, International Journal of Multiphase Flow, 29 (10), pp. 1605-1624.

García, F., García, J. M., García, R., and Joseph, D. D., 2007, Friction Factor Improved Correlations for Laminar and Turbulent Gas-Liquid Flow in Horizontal Pipelines, International Journal of Multiphase Flow, 33 (12), pp. 1320-1336.

Ghiaasiaan, S. M., 2008, Two-Phase Flow, Boiling and Condensation in Conventional and Miniature Systems, Cambridge University Press, New York.

Glielinski, V., 1976, New Equations for Heat and Mass Transfer in Turbulent Pipe and Channel Flow, International Chemical Engineering, 16 (2), pp. 359-367.

Gnielinski, V., 1999, Single-Phase Convective Heat Transfer: Forced Convection in Ducts, Heat Exchanger Design Updates, Heat Exchanger Design Handbook, Begell House, New York, NY, Chapter 5.

Goto, M., Inoue, N., and Ishiwatari, N., 2001, Condensation and Evaporation Heat Transfer of R410A inside Internally Grooved Horizontal Tubes, International Journal of Refrigeration, 24 (7), pp. 628-638.

Graham, D. M., Kopke, H. P., Wilson, M. J., Yashar, D. A., Chato, J. C. and Newell, T. A., 1999, An Investigation of Void Fraction in the Stratified/Annular Flow Regions in Smooth Horizontal Tubes, ACRC TR-144, Air Conditioning and Refrigeration Center, University of Illinois at Urbana-Champaign.

Grimes, R., King, C., and Walsh, E., 2007, Film Thickness for Two Phase Flow in a Microchannel, Advances and Applications in Fluid Mechanics, 2 (1), pp. 59-70.

Gunther, A., and Jensen, K. F., 2006, Multiphase Microfluidics: From Flow Characteristics to Chemical and Materials Synthesis, Lab on a Chip, 6 (12), pp. 1487-1503.

Gupta, R., Fletcher, D. F., and Haynes, B. S., 2009, On the CFD Modelling of Taylor Flow in Microchannels, Chemical Engineering Science, 64 (12), pp. 2941-2950.

Han, Y., and Shikazono, N., 2009a, Measurement of the Liquid Film Thickness in Micro Tube Slug Flow, International Journal of Heat and Fluid Flow, 30 (5), pp. 842-853.

Han, Y., and Shikazono, N., 2009b, Measurement of the Liquid Film Thickness in Micro Square Channel, International Journal of Multiphase Flow, 35 (10), pp. 896-903.

Haraguchi, H., Koyama, S., and Fujii, T., 1994, Condensation of Refrigerants HCF C 22, HFC 134a and HCFC 123 in a Horizontal Smooth Tube (2nd Report, Proposals of Empirical Expressions for the Local Heat Transfer Coefficient), Transactions of the JSME, Part B, 60 (574), pp. 2117-2124. 
Hayashi, K., Kurimoto, R., and Tomiyama, A., 2010, Dimensional Analysis of Terminal Velocity of Taylor Bubble in a Vertical Pipe, Multiphase Science and Technology, 22 (3), pp. 197-210.

Hayashi, K., Kurimoto, R., and Tomiyama, A., 2011, Terminal Velocity of a Taylor Drop in a Vertical Pipe, International Journal of Multiphase Flow, 37 (3), pp. 241-251.

He, Q., Hasegawa, Y., and Kasagi, N., 2010, Heat Transfer Modelling of Gas-Liquid Slug Flow without Phase Change in a Micro Tube, International Journal of Heat and Fluid Flow, 31 (1), pp. 126-136.

Hemeida, A., and Sumait, F., 1988, Improving the Lockhart and Martinelli Two-Phase Flow Correlation by SAS, Journal of Engineering Sciences, King Saud University, 14 (2), pp. 423-435.

Hewitt, G. F., and Roberts, D. N., 1969, Studies of Two-Phase Flow Patterns by Simultaneous Flash and X-Ray Photography, AERE-M2159.

Hoogendoorn, C. J., 1959, Gas-Liquid Flow in Horizontal Pipes, Chemical Engineering Science, 9, pp. 205-217.

Howard, J. A., Walsh, P. A., and Walsh, E. J., 2011, Prandtl and Capillary Effects on Heat Transfer Performance within Laminar Liquid-Gas Slug Flows, International Journal of Heat and Mass Transfer, 54 (21-22), pp. 4752-4761.

Hu, H. -t., Ding, G. -1., and Wang, K. -j., 2008, Measurement and Correlation of Frictional Twophase Pressure Drop of R410A/POE Oil Mixture Flow Boiling in a $7 \mathrm{~mm}$ Straight Micro-Fin Tube, Applied Thermal Engineering, 28 (11-12), pp. 1272-1283.

Hu, H. -t., Ding, G. -1., Huang, X. -c., Deng, B., and Gao, Y. -f., 2009, Pressure Drop During Horizontal Flow Boiling of R410A/Oil Mixture in $5 \mathrm{~mm}$ and $3 \mathrm{~mm}$ Smooth Tubes, Applied Thermal Engineering, 29 (16), pp. 3353-3365.

$\mathrm{Hu}$, X., and Jacobi, A. M., 1996, The Intertube Falling Film: Part 1-Flow Characteristics, Mode Transitions, and Hysteresis, ASME Journal of Heat Transfer, 118 (3), pp. 616-625.

Hulburt, E. T. and Newell, T. A., 1997, Modeling of the Evaporation and Condensation of Zeotropic Refrigerants Mixtures in Horizontal Annular Flow, ACRC TR-129, Air Conditioning and Refrigeration Center, University of Illinois at Urbana-Champaign.

Irandoust, S., and Andersson, B., 1989, Liquid Film in Taylor Flow through a Capillary, Industrial \& Engineering Chemistry Research, 28 (11), pp. 1684-1688.

Ishii, M., 1987, Two-Fluid Model for Two Phase Flow, Multiphase Science and Technology, 5 (1), pp. 1-63.

Jayawardena, S. S., Balakotaiah, V., and Witte, L., 1997, Pattern Transition Maps for Microgravity Two-Phase Flow, AIChE Journal, 43 (6), pp. 1637-1640.

Kandlikar, S. G., 1990, A General Correlation for Saturated Two-Phase Flow Boiling Heat Transfer inside Horizontal and Vertical Tubes, ASME Journal of Heat Transfer 112, (1) pp. 219-228.

Kandlikar, S. G., 2001, A Theoretical Model to Predict Pool Boiling CHF Incorporating Effects of Contact Angle and Orientation, ASME Journal of Heat Transfer, 123 (12), pp. 1071-1079. 
Kandlikar, S. G., 2004, Heat Transfer Mechanisms During Flow Boiling in Microchannels, ASME Journal of Heat Transfer, 126 (2), pp. 8-16.

Kandlikar, S. G., 2010a, Scale Effects on Flow Boiling Heat Transfer in Microchannels: A Fundamental Perspective, International Journal of Thermal Sciences, 49 (7), pp. 10731085.

Kandlikar, S. G., 2010b, A Scale Analysis Based Theoretical Force Balance Model for Critical Heat Flux (CHF) During Saturated Flow Boiling in Microchannels and Minichannels, ASME Journal of Heat Transfer, 132 (8), Article No. (081501).

Kandlikar, S. G., 2012, Closure to Discussion of 'Heat Transfer Mechanisms During Flow Boiling in Microchannels (2012, ASME J. Heat Transfer, 134, p. 015501), ASME Journal of Heat Transfer, 134 (1), Article No. (015502).

Kandlikar, S. G., Garimella, S., Li, D., Colin, S., and King, M. R., 2006, Heat Transfer and Fluid Flow in Minichannels and Microchannels, Elsevier, Oxford, UK.

Kawahara, A., Sadatomi, M., Nei, K., and Matsuo, H., $\quad$ 2011, Characteristics of TwoPhase Flows in a Rectangular Microchannel with a T-Junction Type Gas-Liquid Mixer, Heat Transfer Engineering, 32 (7-8), pp. 585-594.

Keilin, V. E., Klimenko, E. Yu., and Kovalev, I. A., 1969, Device for Measuring Pressure Drop and Heat Transfer in Two-Phase Helium Flow, Cryogenics, 9 (2), pp. 36-38.

Kew, P., and Cornwell, K., 1997, Correlations for the Prediction of Boiling Heat Transfer in Small-Diameter Channels, Applied Thermal Engineering, 17 (8-10), pp. 705-715.

Kleinstreuer, C., 2003, Two-Phase Flow: Theory and Applications, Taylor \& Francis, New York, NY.

Kreutzer, M. T., 2003. Hydrodynamics of Taylor Flow in Capillaries and Monoliths Channels, Doctoral dissertation. Delft University of Technology, Delft, The Netherlands.

Kreutzer, M. T., Kapteijn, F., Moulijin, J. A., and Heiszwolf, J. J., 2005a, Multiphase Monolith Reactors: Chemical Reaction Engineering of Segmented Flow in Microchannels, Chemical Engineering Science, 60 (22), pp. 5895-5916.

Kreutzer, M. T., Kapteijn, F., Moulijin, J. A., Kleijn, C. R., and Heiszwolf, J. J., 2005b, Inertial and Interfacial Effects on Pressure Drop of Taylor Flow in Capillaries, AIChE Journal, 51 (9), pp. 2428-2440.

Kutateladze, 1948, On the Transition to Film Boiling under Natural Convection, Kotloturbostroenie, 3, pp. 10-12.

Kutateladze, S. S., 1972, Elements of Hydrodynamics of Gas-Liquid Systems, Fluid Mechanics - Soviet Research, 1, pp. 29-50.

Lazarek, G. M., and Black, S. H., 1982, Evaporative Heat Transfer, Pressure Drop and Critical Heat Flux in a Small Vertical Tube with R-113, International Journal of Heat and Mass Transfer, 25 (7), pp. 945-960.

Lefebvre, A. H., 1989,. Atomization and Sprays. Hemisphere Publishing Corp., New York and Washington, D. C. 
Li, W., and $\mathrm{Wu}, \mathrm{Z} ., 2010$, A General Correlation for Adiabatic Two Phase Flow Pressure Drop in Micro/Mini-Channels, International Journal of Heat and Mass Transfer, 53 (1314), pp. 2732-2739.

Li, W., and Wu, Z., 2011, Generalized Adiabatic Pressure Drop Correlations in Evaporative Micro/Mini-Channels, Experimental Thermal and Fluid Science, 35 (6,) pp. 866-872.

Lin, S., Kwok, C. C. K., Li, R. Y., Chen, Z. H., and Chen, Z. Y., 1991, Local Frictional Pressure Drop during Vaporization for R-12 through Capillary Tubes, International Journal of Multiphase Flow, 17 (1), pp. 95-102.

Liu, Y., Cui, J., and Li, W. Z., 2011, A Two-Phase, Two-Component Model for Vertical Upward Gas-Liquid Annular Flow, International Journal of Heat and Fluid Flow, 32 (4), pp. 796-804.

Lockhart, R. W., and Martinelli, R. C., 1949, Proposed Correlation of Data for Isothermal Two-Phase, Two-Component Flow in Pipes, Chemical Engineering Progress Symposium Series, 45 (1), pp. 39-48.

Lombardi, C., and Ceresa, I., 1978, A Generalized Pressure Drop Correlation in Two-Phase Flow, Energia Nucleare, 25 (4), pp. 181-198.

Lombardi, C., and Carsana, C. G., 1992, Dimensionless Pressure Drop Correlation for TwoPhase Mixtures Flowing Upflow in Vertical Ducts Covering Wide Parameter Ranges, Heat and Technology, 10 (1-2), pp. 125-141.

Lun, I., Calay, R. K., and Holdo, A. E., 1996, Modelling Two-Phase Flows Using CFD, Applied Energy, 53 (3), pp. 299-314.

Ma, X., Briggs, A., and Rose, J. W., 2004, Heat Transfer and Pressure Drop Characteristics for Condensation of R113 in a Vertical Micro-Finned Tube with Wire Insert, International Communications in Heat and Mass Transfer, 31, pp. 619-627.

Mandhane, J. M., Gregory, G. A., and Aziz, K., 1974, A Flow Pattern Map of Gas-Liquid Flow in Horizontal Pipes, International Journal of Multiphase Flow, 1 (4), pp. 537-553.

Marchessault, R. N., and Mason, S. G., 1960, Flow of Entrapped Bubbles through a Capillary, Industrial \& Engineering Chemistry, 52 (1), pp. 79-84.

Martinelli, R. C., and Nelson, D. B., 1948, Prediction of Pressure Drop during ForcedCirculation Boiling of Water, Trans. ASME, 70 (6), pp. 695-702.

McAdams, W. H., Woods, W. K. and Heroman, L. C., 1942, Vaporization inside Horizontal Tubes. II -Benzene-Oil Mixtures, Trans. ASME, 64 (3), pp. 193-200.

Mishima, K., and Hibiki, T., 1996, Some Characteristics of Air-Water Two-Phase Flow in Small Diameter Vertical Tubes, International Journal of Multiphase Flow, 22 (4), pp. 703-712.

Moody, L. F., 1944, Friction Factors for Pipe Flow, Trans. ASME, 66 (8), pp. 671-677.

Mudawwar, I. A., and El-Masri, M. A., 1986, Momentum and Heat Transfer across FreelyFalling Turbulent Liquid Films, International Journal of Multiphase Flow 12 (5), pp. 771-790. 
Muradoglu, M., Gunther, A., and Stone, H. A., 2007, A Computational Study of Axial Dispersion in Segmented Gas-Liquid Flow, Physics of Fluids, 19 (7), Article No. (072109).

Muzychka, Y. S., Walsh, E., Walsh, P., and Egan, V., 2011, Non-boiling Two Phase Flow in Microchannels, in Microfluidics and Nanofluidics Handbook: Chemistry, Physics, and Life Science Principles, Editors: Mitra, S. K., and Chakraborty, S., CRC Press Taylor \& Francis Group, Boca Raton, FL.

Ohnesorge, W., 1936, Formation of Drops by Nozzles and the Breakup of Liquid Jets, Zeitschrift für Angewandte Mathematik und Mechanik (ZAMM) (Applied Mathematics and Mechanics) 16, pp. 355-358.

Oliemans, R., 1976, Two Phase Flow in Gas-Transmission Pipelines, ASME paper 76-Pet-25, presented at Petroleum Division ASME meeting, Mexico, September 19-24, 1976.

Ong, C. L., and Thome, J. R., 2011, Experimental Adiabatic Two-Phase Pressure Drops of R134a, R236fa and R245fa in Small Horizontal Circular Channels, Proceedings of the ASME/JSME $20118^{\text {th }}$ Thermal Engineering Joint Conference (AJTEC2011), AJTEC201144010, March 13-17, 2011, Honolulu, Hawaii, USA.

Osman, E. A., 2004, Artificial Neural Network Models for Identifying Flow Regimes and Predicting Liquid Holdup in Horizontal Multiphase Flow, SPE Production and Facilities, 19 (1), pp. 33-40.

Osman, E. A., and Aggour, M. A., 2002, Artificial Neural Network Model for Accurate Prediction of Pressure Drop in Horizontal and Near-Horizontal-Multiphase Flow, Petroleum Science and Technology, 20 (1-2), pp. 1-15.

Ouyang, L., 1998, Single Phase and Multiphase Fluid Flow in Horizontal Wells, PhD Dissertation Thesis, Department of Petroleum Engineering, School of Earth Sciences, Stanford University, CA.

Owens, W. L., 1961, Two-Phase Pressure Gradient, ASME International Developments in Heat Transfer, Part II, pp. 363-368.

Petukhov, B. S., 1970, Heat Transfer and Friction in Turbulent Pipe Flow with Variable Physical Properties, Advances in Heat Transfer, 6, pp. 503-564.

Phan, H. T., Caney, N., Marty, P., Colasson, S., and Gavillet, J., 2011, Flow Boiling of Water in a Minichannel: The Effects of Surface Wettability on Two-Phase Pressure Drop, Applied Thermal Engineering, 31 (11-12), pp. 1894-1905.

Phillips, R. J., 1987, Forced Convection, Liquid Cooled, Microchannel Heat Sinks, Master's Thesis, Department of Mechanical Engineering, Massachusetts Institute of Technology, Cambridge, MA.

Pigford, R. L., 1941, Counter-Diffusion in a Wetted Wall Column, Ph. D. Dissertation, The University of Illinois/Urbana, IL.

Quan, S. P., 2011, Co-Current Flow Effects on a Rising Taylor Bubble, International Journal of Multiphase Flow, 37 (8), pp. 888-897.

Quiben, J. M., and Thome, J. R., 2007, Flow Pattern Based Two-Phase Frictional Pressure Drop Model for Horizontal Tubes. Part II: New Phenomenological Model, International Journal of Heat and Fluid Flow, 28 (5), pp. 1060-1072. 
Renardy, M., Renardy, Y., and Li, J., 2001, Numerical Simulation of Moving Contact Line Problems Using a Volume-of-Fluid Method, Journal of Computational Physics, 171 (1), pp. 243-263.

Revellin, R., and Haberschill, P., 2009, Prediction of Frictional Pressure Drop During Flow Boiling of Refrigerants in Horizontal Tubes: Comparison to an Experimental Database, International Journal of Refrigeration, 32 (3) pp. 487-497.

Rezkallah, K. S., 1995, Recent Progress in the Studies of Two-Phase Flow at Microgravity Conditions, Journal of Advances in Space Research, 16, pp. 123-132.

Rezkallah, K. S., 1996, Weber Number Based Flow-Pattern Maps for Liquid-Gas Flows at Microgravity, International Journal of Multiphase Flow, 22 (6), pp. 1265-1270.

Rouhani S. Z., and Axelsson, E., 1970, Calculation of Volume Void Fraction in the Subcooled and Quality Region, International Journal of Heat and Mass Transfer, 13 (2), pp. 383393.

Sabharwall, P., Utgikar, V., and Gunnerson, F., 2009, Dimensionless Numbers in PhaseChange Thermosyphon and Heat-Pipe Heat Exchangers, Nuclear Technology, 167 (2), pp. 325-332.

Saisorn, S., and Wongwises, S., 2008, Flow Pattern, Void Fraction and Pressure Drop of TwoPhase Air-Water Flow in a Horizontal Circular Micro-Channel, Experimental Thermal and Fluid Science, 32 (3), pp. 748-760.

Saisorn, S., and Wongwises, S., 2009, An Experimental Investigation of Two-Phase AirWater Flow Through a Horizontal Circular Micro-Channel, Experimental Thermal and Fluid Science, 33 (2), pp. 306-315.

Saisorn, S., and Wongwises, S., 2010, The Effects of Channel Diameter on Flow Pattern, Void Fraction and Pressure Drop of Two-Phase Air-Water Flow in Circular Micro-Channels, Experimental Thermal and Fluid Science, 34 (4), pp. 454-462.

Salman, W., Gavriilidis, A., and Angeli, P., 2004, A Model for Predicting Axial Mixing During Gas-Liquid Taylor Flow in Microchannels at Low Bodenstein Numbers, Chemical Engineering Journal, 101 (1-3), pp. 391-396.

Sardesai, R. G., Owen, R. G., and Pulling, D. J., 1981, Flow Regimes for Condensation of a Vapour Inside a Horizontal Tube, Chemical Engineering Science, 36 (7), pp. 1173-1180.

Scott, D. S., 1964, Properties of Co-Current Gas- Liquid Flow, Advances in Chemical Engineering, 4, pp. 199-277.

Selli, M. F., and Seleghim, P., Jr., 2007, Online Identification of Horizontal Two-Phase Flow Regimes Through Gabor Transform and Neural Network Processing, Heat Transfer Engineering, 28 (6), pp. 541-548.

Shah, M. M., 1982, Chart Correlation for Saturated Boiling Heat Transfer: Equations and Further Study, ASHRAE Trans., 88, Part I, pp. 185-196.

Shannak, B., 2009, Dimensionless Numbers for Two-Phase and multiphase flow. In: International Conference on Applications and Design in Mechanical Engineering (ICADME), Penang, Malaysia, 11-13 October, 2009.

Sherwood, T. K., Pigford, R. L., and Wilke, C. R., 1975, Mass Transfer, Mc-Graw Hill, New York, NY, USA. 
Shippen, M. E., and Scott, S. L., 2004, A Neural Network Model for Prediction of Liquid Holdup in Two-Phase Horizontal Flow, SPE Production and Facilities, 19 (2), pp 67-76.

Sobieszuk, P., Cygański, P., and Pohorecki, R., 2010, Bubble Lengths in the Gas-Liquid Taylor Flow in Microchannels, Chemical Engineering Research and Design, 88 (3), pp. 263-269.

Spelt, P. D. M., 2005, A Level-Set Approach for Simulations of Flows with Multiple Moving Contact Lines with Hysteresis, Journal of Computational Physics, 207 (2), pp. 389-404.

Stephan, K., and Abdelsalam, M., 1980, Heat Transfer Correlation for Natural Convection Boiling, International Journal of Heat and Mass Transfer, 23 (1), pp. $73-87$.

Suo, M., and Griffith, P., 1964, Two Phase Flow in Capillary Tubes, ASME Journal of Basic Engineering, 86 (3), pp. 576-582.

Swamee, P. K., and Jain, A. K., 1976, Explicit Equations for Pipe Flow Problems, Journal of the Hydraulics Divsion - ASCE, 102 (5), pp. 657-664.

Taha, T., and Cui, Z. F., 2006a, CFD Modelling of Slug Flow inside Square Capillaries, Chemical Engineering Science 61 (2), pp. 665-675.

Taha, T., and Cui, Z. F., 2006b, CFD Modelling of Slug Flow in Vertical Tubes, Chemical Engineering Science, 61 (2), pp. 676-687.

Taitel, Y., 1990, Flow Pattern Transition in Two-Phase Flow, Proceedings of $9^{\text {th }}$ International Heat Transfer Conference (IHTC9), Jerusalem, Vol. 1, pp. 237-254.

Taitel, Y., and Dukler, A. E., 1976, A Model for Predicting Flow Regime Transitions in Horizontal and Near Horizontal Gas-Liquid Flow, AIChE Journal, 22 (1), pp. 47-55.

Talimi, V., Muzychka, Y. S., and Kocabiyik, S., 2012, A Review on Numerical Studies of Slug Flow Hydrodynamics and Heat Transfer in Microtubes and Microchannels, International Journal of Multiphase Flow, 39, pp. 88-104.

Tandon, T. N., Varma, H. K., and Gupta. C. P., 1982, A New Flow Regime Map for Condensation Inside Horizontal Tubes, ASME Journal of Heat Transfer, 104 (4), pp. 763 768.

Tandon, T. N., Varma, H. K., and Gupta. C. P., 1985, Prediction of Flow Patterns During Condensation of Binary Mixtures in a Horizontal Tube, ASME Journal of Heat Transfer, 107 (2), pp. 424-430.

Taylor, G. I., 1932, The Viscosity of a Fluid Containing Small Drops of Another Fluid, Proceedings of the Royal Society of London, Series A, 138 (834), pp. 41-48.

Taylor, G. I., 1961, Deposition of a Viscous Fluid on the Wall of a Tube, Journal of Fluid Mechanics, 10 (2), pp. 161-165.

Thome, J. R., 2003, On Recent Advances in Modeling of Two-Phase Flow and Heat Transfer, Heat Transfer Engineering, 24 (6), pp. 46-59.

Tran, T. N., Wambsganss, M. W., and France, D. M., 1996, Small Circular- and RectangularChannel Boiling with Two Refrigerants, International Journal of Multiphase Flow, 22 (3), pp. 485-498.

Tribbe, C., and Müller-Steinhagen, H. M., 2000, An Evaluation of the Performance of Phenomenological Models for Predicting Pressure Gradient during Gas-Liquid Flow 
in Horizontal Pipelines, International Journal of Multiphase Flow, 26 (6), pp. 10191036.

Triplett, K. A., Ghiaasiaan, S. M., Abdel-Khalik, S. I., and Sadowski, D. L., 1999, Gas-Liquid Two-Phase Flow in Micro-Channels, Part 1: Two-Phase Flow Pattern, International Journal of Multiphase Flow 25 (3), pp. 377-394.

Turner, J. M., 1966, Annular Two-Phase Flow, Ph.D. Thesis, Dartmouth College, Hanover, $\mathrm{NH}$, USA.

Ullmann, A., and Brauner, N., 2007, The Prediction of Flow Pattern Maps in Mini Channels, Multiphase Science and Technology, 19 (1), pp. 49-73.

van Baten, J. M., and Krishna, R., 2004, CFD Simulations of Mass Transfer from Taylor Bubbles Rising in Circular Capillaries, Chemical Engineering Science, 59 (12), pp. 25352545.

Vandervort, C. L., Bergles, A. E., and Jensen, M. K., 1994, An Experimental Study of Critical Heat Flux in very High Heat Flux Subcooled Boiling, International Journal of Heat and Mass Transfer, 37 (Supplement 1), pp. 161-173.

Venkatesan, M., Das, Sarit K., and Balakrishnan, A. R., 2011, Effect of Diameter on TwoPhase Pressure Drop in Narrow Tubes, Experimental Thermal and Fluid Science, 35 (3), pp. 531-541.

Wallis, G. B., 1969, One-Dimensional Two-Phase Flow, McGraw-Hill Book Company, New York.

Walsh, E. J., Muzychka, Y. S., Walsh, P. A., Egan, V., and Punch, J., 2009, Pressure Drop in Two Phase Slug/Bubble Flows in Mini Scale Capillaries, International Journal of Multiphase Flows, 35 (10), pp. 879-884.

Wang X. -Q., and Mujumdar A. S., 2008a, A Review on Nanofluids - Part I: Theoretical and Numerical Investigations, Brazilian Journal of Chemical Engineering, 25 (4), pp. 613630.

Wang X. -Q., and Mujumdar A. S., 2008b, A Review on Nanofluids - Part II: Experiments and Applications, Brazilian Journal of Chemical Engineering, 25 (4), pp. 631-648.

Wei, W., Ding, G., Hu, H., and Wang, K., 2007, Influence of Lubricant Oil on Heat Transfer Performance of Refrigerant Flow Boiling inside Small Diameter Tubes. Part I: Experimental Study, Experimental Thermal and Fluid Science, 32 (1), pp. 67-76.

Weisman, J., Duncan, D., Gibson, J., and Crawford, T., 1979, Effects of Fluid Properties and Pipe Diameter on Two-Phase Flow Patterns in Horizontal Lines, International Journal of Multiphase Flow 5 (6), pp. 437-462.

Whalley, P. B., 1987, Boiling, Condensation, and Gas-Liquid Flow, Clarendon Press, Oxford.

Whalley, P. B., 1996, Two-Phase Flow and Heat Transfer, Oxford University Press, UK.

White, F. M., 2005, Viscous Fluid Flow, $3^{\text {rd }}$ edition, McGraw-Hill Book Co, USA.

Wilson, M. J., Newell, T. A., Chato, J. C., and Infante Ferreira, C. A., 2003, Refrigerant Charge, Pressure Drop and Condensation Heat Transfer in Flattened Tubes, International Journal of Refrigeration, 26 (4), pp. 442-451. 
Yan, Y.-Y., and Lin, T.-F., 1998, Evaporation Heat Transfer and Pressure Drop of Refrigerant R134a in a Small Pipe, International Journal of Heat and Mass Transfer, 41 (24). pp. 4183-4193.

Yang, C., Wu, Y., Yuan, X., and Ma, C., 2000, Study on Bubble Dynamics for Pool Nucleate, International Journal of Heat and Mass Transfer, 43 (18), pp. 203-208.

Yarin, L. P., Mosyak, A., and Hetsroni, G., 2009, Fluid Flow, Heat Transfer and Boiling in Micro-Channels, Springer, Berlin.

Yun, J., Lei, Q., Zhang, S., Shen, S., and Yao, K., 2010, Slug Flow Characteristics of GasMiscible Liquids in a Rectangular Microchannel with Cross and T-Shaped Junctions, Chemical Engineering Science, 65 (18), pp. 5256-5263.

Zhang, W., Hibiki, T., and Mishima, K., 2010, Correlations of Two-Phase Frictional Pressure Drop and Void Fraction in Mini-Channel, International Journal of Heat and Mass Transfer, 53 (1-3), pp. 453-465.

Zhao, L., and Rezkallah, K. S., 1993, Gas-Liquid Flow Patterns at Microgravity Conditions, International Journal of Multiphase Flow, 19 (5), pp. 751-763.

Zivi, S. M., 1964, Estimation of Steady-State Void Fraction by Means of the Principle of Minimum Energy Production, ASME Journal of Heat Transfer, 86 (2), pp. 247-252. 